\title{
A Theoretical and Empirical Investigation of Slotting and \\ Promotional Allowances in the Grocery Industry
}

\section{Adam David Rennhoff}

B.A., Bucknell University, 1998

M.A., University of Virginia, 2000

A Dissertation Presented to the Graduate Faculty of the University of Virginia in Candidacy for the Degree of Doctor of Philosophy

\section{Department of Economics}

\section{University of Virginia} January 2006 .
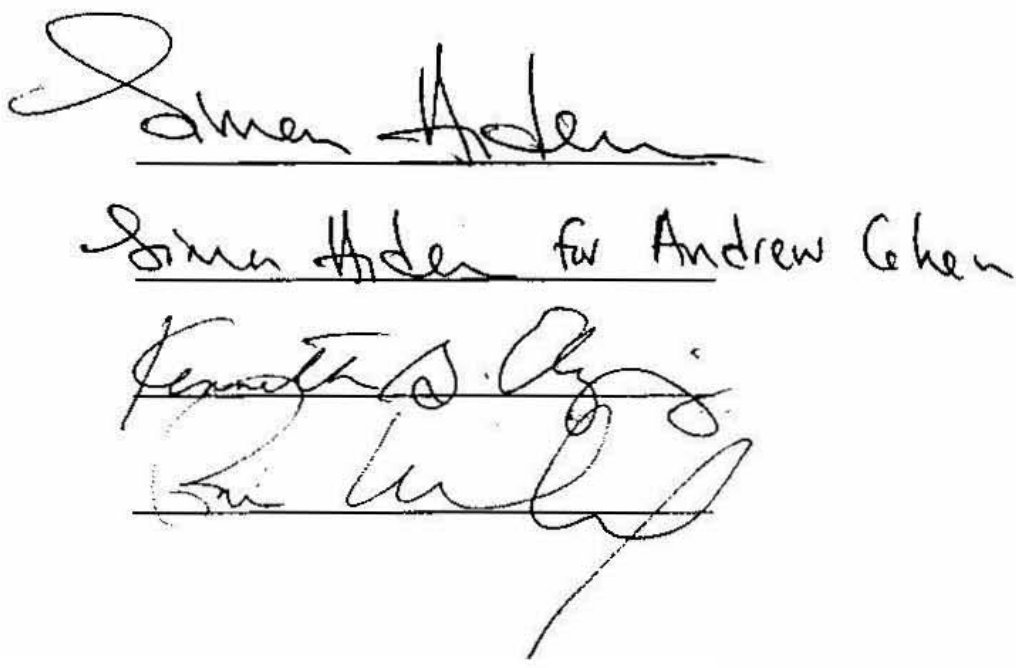


\begin{abstract}
This dissertation examines the behavior of manufacturers and retailers in the presence of slotting allowances. Slotting allowances are fees manufacturers pay retailers to encourage them to allocate certain in-store promotional activities to the manufacturer's brand. These promotional activities include such things as an end-of-aisle display or premium shelf space. According to estimates, retailers collect billions of dollars in these allowance payments annually. Public and private sector interest in determining the impact of slotting allowances has lead to an increase in academic research on the topic. Unfortunately, the theoretical work has been unable to reach a consensus regarding whether slotting allowances are welfare-enhancing or reducing. This dissertation attempts to address that question by offering the first empirical model on slotting allowances.
\end{abstract}

Using scanner data on ketchup sales, I construct an interactive model of behavior in which manufacturers compete for premium shelf space at retail outlets. The structural model is based on models of vertical competition and traditional discrete-choice models of differentiated products. Formally modeling firm and consumer behavior allows me to examine the decisions being made: the retailer's shelf space allocation, the wholesale and retail pricing strategies, and the consumer's choice of which product to purchase.

In addition to estimating the demand parameters associated with consumer tastes and preferences, the model allows for estimates of manufacturer wholesale prices and slotting allowances. My estimates indicate that Heinz, the market share leader, makes the 
largest slotting allowance payments. They do not make them as frequently, however, as the firm with the second largest market share (Hunts). Using the parameter estimates, I conduct a policy simulation to determine how wholesale prices, retail prices, and, ultimately, consumer surplus respond to an alternative state where slotting allowances are illegal of forbidden.

I find that the presence of slotting allowances raises total welfare. Using a consumer surplus measure, I find that, on average, each consumer/household experiences a welfare gain of $\$ 0.0006$ annually. This figure aggregates to a national total of roughly $\$ 80,000$ for the ketchup industry. Retail profit is also higher because of slotting allowances, contributing to the net increase in total welfare. 
To my wife and family 


\section{Contents}

List of Figures $\quad$ vii

List of Tables viii

1 Introduction 1

2 Literature Review $\quad 8$

2.1 Theoretical Models . . . . . . . . . . . . . . . . . . 8

2.2 Marketing and Advertising Literature . . . . . . . . . . . . . . . . . 14

2.3 Discrete-Choice Structural Models . . . . . . . . . . . . . . . . . 17

3 A Brief History of Allowances $\quad 19$

4 Using Accounting Statements to Learn About Promotional Payments 22

4.1 Introduction \& Background . . . . . . . . . . . . . . . . . 22

4.2 Expectations \& Hypotheses . . . . . . . . . . . . . . . . . . 24

4.3 Data . . . . . . . . . . . . . . . . . . 26

4.4 The Empirical Models . . . . . . . . . . . . . . . . . . . . . . 30

4.4.1 Binomial Choice Model . . . . . . . . . . . . . . 30

4.4.2 Censored Regression (Tobit) Model . . . . . . . . . . . . . . . 31

4.5 Results . . . . . . . . . . . . . . . . . . 33

4.6 Conclusions . . . . . . . . . . . . . . . . . . 35

5 The Model $\quad 38$

5.1 The Game . . . . . . . . . . . . . . . . . . . . . 38

5.2 Theoretical Model of Behavior . . . . . . . . . . . . . . . . . . 39

5.2.1 Equilibrium Values and Brand Quality . . . . . . . . . . . . . 43

5.2.2 The Relationship between Mark-ups and Quality . . . . . . . . . . 44

5.2 .3 Perfect Information . . . . . . . . . . . . . . . . . . . . 45

5.2 .4 Behavior with Private Information . . . . . . . . . . . . . 47 
6 The Empirical Model $\quad 50$

6.1 Utility and Demand . . . . . . . . . . . . . . . . . . . 50

6.2 Behavior of the Firms . . . . . . . . . . . . . . 55

6.2.1 The Retailer's Problem . . . . . . . . . . . . . . . 55

6.2 .2 The Manufacturer's Problem . . . . . . . . . . . . 58

7 The Market for Ketchup $\quad 62$

8 Data $\quad 64$

8.1 Sales Data . . . . . . . . . . . . . . . . . . 64

8.2 Demographic Data . . . . . . . . . . . . . . 66

9 Preliminary Data Analysis $\quad 68$

10 Estimation $\quad 71$

11 Results $\quad \mathbf{7 4}$

11.1 Parameter Estimates . . . . . . . . . . . . . . . . . . . . 74

11.2 Perception Maps . . . . . . . . . . . . . . . . . . . 77

11.3 Comparing Accounting Regression Results with Structural Model Estimates 79

11.3.1 Market Share and the Probability of Offering Allowances . . . . . . 80

11.3.2 Gross Margin and Allowance Payment Values . . . . . . . . . . . . . 80

11.3.3 Market Share and Allowance Payment Values . . . . . . . . . . . . . 81

11.3.4 Herfindahl Indices and the Probability of Offering Allowances . . . . 81

11.3.5 Contradictory or Ambiguous Results . . . . . . . . . . . . . 82

12 Testing and Counterfactual Experiment $\quad 83$

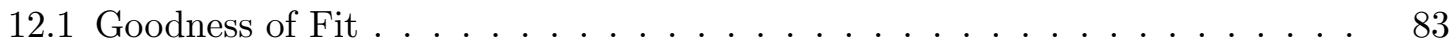

12.1.1 Chi-square Tests . . . . . . . . . . . . . . . . . 83

12.1.2 Predicting Mark-Ups . . . . . . . . . . . . . . . 84

12.2 Counterfactual and Welfare Analysis . . . . . . . . . . . . . 85

12.2.1 Second Counterfactual Specification . . . . . . . . . . . 91

13 Conclusions and Extensions $\quad 92$

$\begin{array}{ll}\text { A Theoretical Appendix } & 96\end{array}$

A.1 Mark-Ups and Brand Quality . . . . . . . . . . . . . . . . . 96

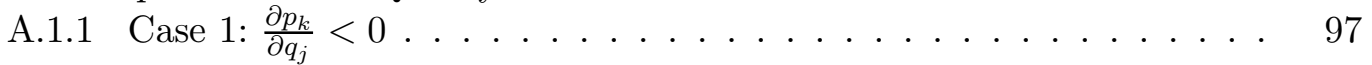

A.1.2 Case $2: \frac{\partial p_{k}}{\partial q_{j}}>0 \ldots \ldots \ldots \ldots \ldots \ldots \ldots \ldots$

A.2 Calculating Optimal Allowance Offers . . . . . . . . . . . . . . . 99

B Data Appendix 102

B.1 Simulating Individuals . . . . . . . . . . . . . . . . . . 102 
$\begin{array}{lr}C \text { Figures and Tables } & 104\end{array}$

C.1 Figures and tables of Chapter 4 . . . . . . . . . . . . . . . . 104

C.2 Figures and tables of Chapter $5 \ldots \ldots \ldots \ldots \ldots$

C.3 Figures and tables of Chapter $7 \ldots \ldots \ldots \ldots \ldots 11$

C.4 Figures and tables of Chapter $8 \ldots \ldots \ldots \ldots \ldots$

C.5 Figures and tables of Chapter $9 \ldots \ldots \ldots \ldots \ldots$

C.6 Figures and tables of Chapter $11 \ldots \ldots \ldots \ldots \ldots$

C.7 Figures and tables of Chapter $12 \ldots \ldots \ldots \ldots \ldots$

$\begin{array}{ll}\text { Bibliography } & 139\end{array}$ 


\section{List of Figures}

C.1 Sample 10-K Reports . . . . . . . . . . . . . . . . . . . . . . . 109

C.2 Basic Game Structure . . . . . . . . . . . . . . . . . . . . . 110

C.3 Ketchup Unit Sales . . . . . . . . . . . . . . . . . . . . . . . 111

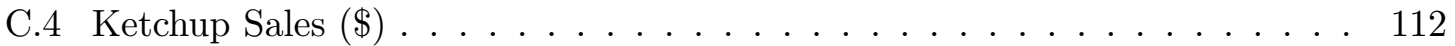

C.5 Demand Curves for Heinz Ketchup . . . . . . . . . . . . . . . . 125

C.6 Frequency Distribution of Price Coefficient . . . . . . . . . . . . . . 126

C.7 Perception Map \#1 . . . . . . . . . . . . . . . . . . . . . . . . . . . . . 127

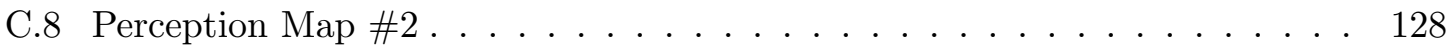

C.9 Perception Map \#3. . . . . . . . . . . . . . . . . . . . . . . 129

C.10 Expected Profit . . . . . . . . . . . . . . . . . 138 


\section{List of Tables}

C.1 Summary Statistics . . . . . . . . . . . . . . . . . . . . 104

C.2 Regressor Variables . . . . . . . . . . . . . . . . . . . 105

C.3 Logit Marginal Effects . . . . . . . . . . . . . . . . . . . . . 106

C.4 Logit, Probit, and Linear Probability Models . . . . . . . . . . . . . 107

C.5 Tobit Consideration Regressions _. . . . . . . . . . . . . . . . 108

C.6 Metropolitan Markets . . . . . . . . . . . . . . . . . . . . . 113

C.7 Market Share by Region (all years) . . . . . . . . . . . . . . . . . . 114

C.8 Summary Statistics . . . . . . . . . . . . . . . . . . 115

C.9 Product Characteristics . . . . . . . . . . . . . . . 116

C.10 Preliminary Logit Estimates . . . . . . . . . . . . . . . . . . 117

C.11 Parameter Estimates . . . . . . . . . . . . . . . . . . . 118

C.12 Demographic Characteristics . . . . . . . . . . . . . . . . . . . 119

C.13 Own- and Cross-Price Elasticities . . . . . . . . . . . . . . . . . 120

C.14 Wholesale Prices . . . . . . . . . . . . . . . . . . . . . . 121

C.15 Conditional Wholesale Prices . . . . . . . . . . . . . . . . . . 122

C.16 Display Probabilities . . . . . . . . . . . . . . . . . . . . 123

C.17 Slotting Allowance Payments (\% Retail Profits) . . . . . . . . . . . . . 124

C.18 Counterfactual Experiment \#1: Two Wholesale Prices . . . . . . . . . . . . 130

C.19 Expected Wholesale Prices . . . . . . . . . . . . . . . . . . . 131

C.20 Display Probabilities without Slotting Allowances . . . . . . . . . . . . . . 132

C.21 Counterfactual \#1 Welfare Analysis . . . . . . . . . . . . . . . . 133

C.22 Counterfactual Experiment \#2: One Wholesale Price . . . . . . . . . . . . 134

C.23 Expected Wholesale Prices _. . . . . . . . . . . . . . . 135

C.24 Display Probabilities without Slotting Allowances (Counterfactual \#2) . . 136

C.25 Counterfactual \#2 Welfare Analysis . . . . . . . . . . . . . . . . . . 137 


\section{Acknowledgements}

I could not have written this dissertation without the help of my advisors at the University of Virginia. Simon Anderson, Andrew Cohen, and Kenneth Elzinga generously offered their guidance and help throughout the dissertation process. I have benefited enormously from my frequent discussions with each of them. It is difficult to summarize, in words, the unique contribution that each of my advisors has had on this dissertation and my growth as an economist. I would also like to thank Ron Wilcox for agreeing to serve as a reader on my dissertation committee and Ronald W. Cotterill at the Food Marketing Policy Center for making the ketchup scanner data available to me.

This dissertation is dedicated to my wife, Christina, and my family. Without their support and encouragement, I would not have been able to successfully make it through the challenges of graduate school. I thank you with all my heart. I would also like to thank my uncle, Chris Neely, for inspiring me to become an economist.

Finally, I would like to thank my roommates from Charlottesville, Andre Kurmann, Greg Hite, and Scott Tobler. 


\section{Chapter 1}

\section{Introduction}

The term slotting allowance refers to a fee that manufacturers pay retailers to encourage them to carry a new product or allocate premium shelf space to a product. Slotting allowances are one component of a contract between the manufacturer and the retailer, which typically involves the transaction or invoice price, the magnitude of the slotting allowance, and any other conditions involved in the transaction. ${ }^{1}$ The terms of the contract would also include a quantity component. While often discussed in the context of the grocery industry, slotting allowances are becoming increasingly prevalent in industries such as computer software, tobacco products, and over-the-counter drugs, where shelf space has become a precious commodity. This competition over space has even emerged on the internet, where online search engines like Google and Yahoo are increasingly relying on "pay-for-performance" in search results.

Since they first appeared in the mid-1980s, slotting allowances have become a

\footnotetext{
${ }^{1}$ Examples might include: requirements about the location of the product on the shelf or if the product will receive any special display or promotion.
} 
source of controversy and disagreement. ${ }^{2}$ Some of the disagreement can be attributed to the ambiguous legal status of slotting allowances. Currently, slotting allowances remain legal and unregulated. This may eventually change. On April 14, 2000, the Independent Bakers Association, the Tortilla Industry Association, and the National Association of Chewing Gum Manufacturers, all associations who claim that slotting allowances have hurt the competitive viability of their members, filed a formal petition asking the Federal Trade Commission (FTC) to establish and enforce clear guidelines about the fair use of slotting allowances. While the FTC has declined to develop formal guidelines at this time, Congress has earmarked a portion of the FTC's budget for investigating possible slotting allowance abuses and implementing new accounting standards to require greater disclosure of manufacturer allowances.

The growing interest in slotting allowances is largely attributable to the amount of money devoted to the practice. A 1990 study found that slotting allowance payments account for up to $\$ 9$ billion in annual grocery industry expenditures (Deloitte \& Touche 1990). The same study also reported that slotting allowance payments account for approximately 16 percent of all costs associated with introducing a new product to the market. ${ }^{3}$ More recent reports put the current amount spent on slotting fees at $\$ 16$ billion per year (Desiraju 2001). In 1999, the tobacco industry, an industry not counted in the Deloitte \& Touche figures, spent roughly $\$ 3.5$ billion on allowances to retailers (FTC 2001b). Recent inquiries into the Great Atlantic \& Pacific Tea Company (A\&P Supermarkets), K-Mart,

\footnotetext{
${ }^{2}$ The subject was addressed in a spring 2000 Federal Trade Commission (FTC) workshop. The workshop allowed various participants in the grocery industry to voice their opinions on slotting allowances. A summary of these opinions and conclusions appears in a February 2001 FTC staff report.

${ }^{3}$ In comparison, the Deloitte \& Touche study estimates that research and development and market analysis account for about 18 percent of new product introduction costs.
} 
and Royal Ahold's handling of "vendor allowances" has attracted even more attention to the practice. ${ }^{4}$

In February 2003, the Dutch company Royal Ahold announced that it had improperly overstated earnings for its U.S. Foodservice division by $\$ 500$ million for 1999 and 2000. A more thorough inspection revealed that the actual overstatement was closer to $\$ 880$ million. The overstatement has been attributed to improper accounting of promotional allowances that the U.S. Foodservice division, which supplies food to hotels and restaurants, received from their suppliers. Such large dollar amounts make slotting allowances a major source of revenue for retailers and, conversely, a major financial consideration for manufacturers.

In this dissertation, I construct an interactive model of behavior in which manufacturers compete for premium shelf space at retail outlets. Predictions from a theoretical model are then tested empirically using a structural model based on models of vertical competition and traditional discrete-choice models of differentiated products. Formally modeling firm and consumer behavior allows us to examine some of the decisions being made: the retailer's shelf space allocation, the wholesale and retail pricing strategies, and, ultimately, the consumer's choice of which product to purchase.

While there is a growing literature on slotting allowances, no empirical studies have emerged to complement the work that has been started in the theoretical papers. In the FTC staff report on slotting allowances, it was noted that "The few studies that have been undertaken reflect opinion...rather than empirical research," (FTC 2001a). Having

\footnotetext{
${ }^{4}$ Details regarding the accounting treatment of slotting allowances and recent changes to the accounting rules appear in Chapter 4.
} 
a clear understanding of the effects of slotting allowances becomes more important as the FTC considers policy options. The lack of rigorous empirical analysis is the largest gap in the slotting literature. This research represents a step towards filling the gap.

The structural model allows for estimates of manufacturer wholesale prices and slotting allowances. Using the parameter estimates, I conduct policy simulations to determine how wholesale prices, retail prices, and, ultimately, consumer surplus respond to various policy scenarios. The primary counterfactual involves examining how firms and consumers respond to an alternative state were slotting allowances are illegal.

I find that the presence of slotting allowances increases total welfare. Using a measure of consumer surplus, I find that, on average, each consumer/household experiences a slight welfare gain. The individual gain aggregates to a national total of roughly $\$ 80,000$. Total firm profit is higher because of slotting allowances, yielding a net increase in total welfare due to slotting allowances.

The remainder of the dissertation is organized as follows: In the next chapter, I review the relevant literature on slotting allowances and in-store product marketing. Because the research on slotting allowances is hard to categorize, I present literature from a number of different categories. First, I discuss the theoretical models that have emerged in order to explain the various ways in which slotting allowances may be used. These papers focus on the use of slotting allowances as a signal of product quality or as a means of risk-sharing. Marketing and advertising research are also addressed. The literature in this vein specifically address the importance of the retailer optimizing his shelf space allocation and the effect a brand's shelf space has on sales. I conclude the chapter by highlighting a 
number of the recent empirical papers on discrete-choice models, which serve as the basis for my empirical model.

Chapter 3 presents a brief history of slotting allowances. While the popular consensus dates the appearance of slotting allowances to the mid-1980's, retail trade promotions, as a strategic element in the vertical channel, were being used earlier. In this chapter, I also discuss some of explanations usually given for the growth and proliferation of slotting allowances. Among these explanations are the availability of precise sales data and a trend towards greater concentration in the retail grocery market.

In Chapter 4, I use accounting data made available due to new accounting regulations to examine the prevalence of merchandising allowances in various industries. While the structural model presented in this dissertation focuses on behavior in the grocery industry, merchandising (and slotting) allowances are becoming commonplace in industries ranging from computer software to pharmaceutical products. Using financial data on the allowance payments made to retailers, along with firm- and industry-specific variables, I estimate two reduced form models to determine (a) which type of firms are most likely to make allowance payments and (b) what firm and industry characteristics impact the magnitude of these allowance payments. The results from these regressions will be compared with the results from the full structural model in Chapter 11.

In Chapter 5, I describe the precise timing or stages of the model. In addition, I present a simplified theoretical model of two manufacturers competing for shelf space at a monopolist's retail store. This theoretical model allows me to form expectations regarding firm behavior. The model also generates some predictions, such as which manufacturer is 
likely to offer the largest slotting allowance and which type of manufacturer the retailer prefers to have in the premium shelf space, which can be tested using the empirical model.

The formal structural model is introduced in Chapter 6. In the model, there are three segments: consumers, retailers, and manufacturers. Consumer behavior is modeled using a traditional discrete-choice framework, wherein all consumers choose whether to purchase 0 or 1 units of the good. In order to avoid the independence of irrelevant alternatives (IIA) problem, I employ a random coefficients framework in which tastes and preferences are allowed to vary across individuals. ${ }^{5}$ Retailer and manufacturer interaction is explicitly modeled as a four-stage game, using a structural model similar to those proposed by Besanko, Gupta, and Jain (1998).

To estimate the empirical model presented in Chapter 6, I use data on ketchup sales in forty markets across the U.S. For background purposes, Chapter 7 presents a brief history of the ketchup industry and a summary of the major industry participants. Competition in the market for ketchup is restricted to only four major brands, each producing a nearly homogeneous product. Chapter 8 contains information regarding the data used in this study. The data come from two sources: scanner data collected by Information Resources, Inc. (IRI) and demographic data available through the Census Bureau's annual Current Population Survey.

Preliminary data analysis is done in Chapter 9. A series of logit regressions are run in order to identify relationships present within the data. This preliminary work highlights the need for a more thorough model, in order to estimate measures of interest, such as wholesale prices and slotting allowance payments.

\footnotetext{
${ }^{5}$ More detail on the IIA problem will be presented in Chapter 5 .
} 
The ten-step estimation procedure is detailed in Chapter 10. I employ a method of moments (MoM) estimation technique, wherein I minimize the difference between my model's predictions and the actual observed data. Specifically, the model will generate predictions regarding each brand's expected price, market share, and the percent of units a brand sells with merchandising. The purpose of the estimation algorithm is to find the parameter values that minimize the distance between the model's predictions and the observed data.

Chapter 11 contains estimation results and analysis and Chapter 12 contains goodness of fit tests and counterfactual analysis. The estimates, beyond simply helping us better understand consumer tastes and preferences for ketchup, allow me to calculate each brand's predicted wholesale price, the dollar value of any slotting allowance payments, and each brand's probability of receiving the premium shelf space. I also present several perception maps, which help to illustrate the benefits of premium shelf space. Perception maps, which are widely used in the marketing literature, are 2-dimensional depictions of the correlation between products. Finally, using the parameter estimates, I also conduct a counterfactual experiment to examine what might happen to average retail prices if slotting allowances were prohibited.

The final chapter provides some concluding remarks regarding this dissertation research and outlines extensions and possible areas for future research on this topic. 


\section{Chapter 2}

\section{Literature Review}

Research on slotting allowances overlaps the boundaries of several academic disciplines, therefore, a number of relevant literature sources need to be addressed. These are economics, advertising, marketing, and literature on structural discrete-choice models.

\subsection{Theoretical Models}

Within economics, there is a small but expanding base of literature. The first papers on slotting allowances were published in the early 1990s. Economists focused on examining the different roles slotting allowances play in the vertical channel. With these differing models have come conflicting welfare predictions.

Shaffer (1991) compares slotting allowances, resale price maintenance, and standard Nash equilibrium pricing in an effort to determine which practice is more profitable for retailers. To determine which of these pricing strategies yields the highest profits, Shaffer sets up a three stage pricing game. In the first stage, manufacturers announce the terms of accepting their product (i.e. a wholesale price, the slotting allowance, and/or the specified maintained retail price). In the second stage, retailers decide which of the manufacturers to purchase from. Finally, the retailers compete in the downstream market by setting the 
retail price. In Shaffer's model, there are two homogeneous manufacturers upstream and two retailers downstream. The retailers are differentiated to consumers, even though the product they sell is homogeneous. Shaffer shows that, compared to an environment with no slotting allowances, the retailers earn more profit and consumers pay higher retail prices when a lump sum slotting allowance is used.

These results should not be surprising, however, given Shaffer's assumptions. In the baseline case with no slotting allowances or resale price maintenance, intuition makes it easy to see that the two homogeneous manufacturers will charge wholesale prices equal to their marginal cost. ${ }^{1}$ The manufacturers, then, earn zero profit while the downstream retailers charge $P_{i}^{*}>c$ and earn positive profit. In the case with slotting allowances, however, Shaffer states that the retailer will purchase from the manufacturer who has chosen a wholesale price-slotting allowance pair that maximizes retail profit, subject to a nonnegativity constraint on manufacturer profit. Using the upstream and downstream firms' first order conditions, Shaffer shows that the equilibrium wholesale price must be greater than marginal cost. While this leads to lower retail sales profit, the loss in sales is more than offset by the slotting allowance payment the retailer receives. Once again, manufacturers earn zero profit, while retailers earn positive profit. Because the wholesale price is now above marginal cost, the resulting retail price must be higher than in the baseline (no allowance) case. Shaffer concludes, then, that slotting allowances result in higher retail prices for consumers.

Another avenue of research has examined the role slotting allowances may play in signaling the quality of a manufacturer's brand to a retailer. Given the several thousand

\footnotetext{
${ }^{1}$ Both manufacturers are assumed have a constant marginal cost of production $(c)$.
} 
new grocery products developed each year, all vying for limited shelf space or limited promotion efforts, manufacturers can use a slotting fee to signal (to the retailer) their belief about the quality of their product. Most practitioners (including the studies below) assume manufacturers, because of market research and analysis, have better knowledge than the retailer about consumer demand for their product. They often further assume that all new products can be grouped into one of two categories: a high quality product $(\mathrm{H})$ or a low quality (L) product. The retailer would, ideally, prefer to choose the high quality brand because it is assumed that demand for the high quality product is greater than demand for the low quality product.

Chu (1992) examines two different games: one in which manufacturers signal their quality through advertising expenditures and another in which the retailer screens the manufacturers' quality (to eliminate low quality goods) by requiring slotting allowance payments. While the first case results in higher prices, Chu shows that retail prices will not increase when the retailer uses slotting allowances to screen for manufacturer-type. In Chu's equilibrium, only high-quality goods are willing to pay the allowance, so lower-quality goods disappear from the market and total welfare increases.

Lariviere and Padmanabhan (1997), while also examining the role allowances can play in signaling quality, alter the timing of the game presented in Chu by allowing manufacturers to offer slotting allowances to the retailer. These allowance offers are intended to signal product quality as well as reimburse the retailer for a portion of the cost associated with stocking the product. Lariviere and Padmanabhan, in specifying a separating equilibrium, show that the optimal behavior for a high demand manufacturer is to offer a positive 
slotting allowance and a lower wholesale price.

While most papers on slotting allowances examine the role slotting allowances play in the vertical channel and its effect on profits and retail prices, Desiraju (2001) is one of the few papers to focus on comparing the strategies retailers may use to set the magnitude of slotting allowance payments. Desiraju compares two different methods a retailer might plausibly use to set slotting allowances: one in which allowances are determined "brand-bybrand" (i.e. each manufacturer pays a different slotting allowance) and another in which all products pay a uniform allowance. Desiraju, following the convention used in Chu and Lariviere and Padmanabhan, classifies new products as being a product for which consumers have either a high or low attraction. Desiraju solves for the optimal retailer-manufacturer contract under a number of different scenarios (ex. asymmetric information regarding the market attractiveness of the new product, exogenous wholesale prices) and finds that brandby-brand allowances are preferable regardless of whether there is symmetric or asymmetric information about a product's attractiveness, but actual slotting allowance payments are larger in magnitude in the uniform allowance case. Desiraju's model also makes a prediction about retail margins that my empirical model can address. Desiraju predictions that retail margins and slotting allowances should be negatively correlated. The brand observed to have the highest margin should be the firm paying the lowest amount in slotting allowances. I will address this in greater detail in Chapter 10.

At the heart of these models is the notion that the retailer takes on risk when agreeing to carry a manufacturer's brand. Retailers incur several costs when agreeing to accept a new product: e.g. stocking costs, computer costs, opportunity cost. Some products 
will ultimately fail or sell below expectations and an allowance can be thought of as a means of transferring some costs back to the manufacturer. Sullivan (1997) models the use of slotting allowances in the context of product failure and concludes that allowances may be affective tools in risk-sharing and are consistent with a situation wherein the supply of goods far outpaces sales growth. To accomplish this, Sullivan develops a supply and demand framework. In Sullivan's model, retailers stock multiple products to attract consumers, who attempt to minimize their search cost by visiting the retailer with the largest number of products. The price a consumer is willing to pay depends upon the number of products the retailer carries; with the consumer willing to pay more to decrease their search cost. The consumer's search behavior translates into a downstream demand for grocery products. Sullivan imposes a market equilibrium condition that the number of products demanded by retailers equals the number of products supplied by the manufacturers. The equilibrium condition allows Sullivan to illustrate how the optimal slotting allowance may help the market clear by equating supply and demand.

In addition to the theoretical model presented, Sullivan offers historical data on the number of products introduced by manufacturers, retail prices, margins, and retail profit to anecdotally contradict Shaffer's claims that slotting allowances have negative welfare implications. Sullivan shows that in 1970 , there were roughly 1,800 new products introduced. By 1990 this number had grown to around 16,000 products annually. According to the logic presented in the theoretical model, if new product introductions have increased substantially (i.e. if the supply of products has increased), then slotting allowances may, in fact, be an efficiency enhancing mechanism that both decreases the tendency of manufacturers 
to develop new products and increases the number of products a retailer would be willing to carry. Sullivan shows that in 1970 , there were roughly 1,800 new products introduced. By 1990 this number had grown to around 16,000 products annually.

Shaffer's model implies that retail prices are higher because of slotting allowances. To contradict these claims, Sullivan examines data from the Consumer Price Index (CPI), Food Index, and Food-at-Home Index (FAH), which measures the price changes of food sold in non-restaurant establishments. The data shows that the FAH index has increased over time, but not as much as the CPI or the overall food index. Normalized to 1975 dollars, in 1994 the CPI was 275.4, the overall food index was 241.3, and the FAH index was 233.3. This seems to be a contradiction to the implication that grocery prices have increased due to slotting allowances. ${ }^{2}$

While there has been greater understanding of the roles allowances play, the studies above illustrate that there is no clear consensus with regard to welfare implications. ${ }^{3}$ Are allowances an efficiency-enhancing mechanism, as Sullivan might argue, or are they synonymous with retail power, as Shaffer might argue? In an effort to answer this question, Bloom, Gundlach, and Cannon (2000) conduct a survey of participants in the grocery industry (both manufacturers and retailers). ${ }^{4}$ The respondents were asked about their level of agreement or disagreement with a number of statements regarding slotting allowances, such as "Retailer product assortments are often based on slotting fees" or "Slotting fees have come about as a result of greater retailer influence." The respondents were also asked

\footnotetext{
${ }^{2}$ According to the June 2003 CPI, the FAH index is still lower than both the overall food index and the overall CPI.

${ }^{3}$ Azzam (2001) addresses this by proposing an empirical model which can be used to test the effect slotting allowances have on price-cost margins.

${ }^{4}$ Bloom, Gundlach, and Cannon also provide a thorough summary of the numerous pro- and anticompetitve arguments on slotting allowances.
} 
a set of questions regarding the effect slotting allowances have had on the industry, such as "What effect have slotting fees had on the prices charged by retailers?" Not surprisingly, Bloom, Gundlach, and Cannon find mixed reviews: manufacturers tend to see slotting allowances as symptomatic of retail-power, while retailers tend to view slotting allowances as fair or efficient. ${ }^{5}$ For example, manufacturers were much more likely to "strongly agree" with the statement regarding whether retailer product assortments are based on slotting fees and manufacturers were also more likely to say that slotting fees have lead to a "large increase" in retail prices.

\subsection{Marketing and Advertising Literature}

Relevant literature in the marketing and advertising fields focuses primarily on two specific areas: how retailers allocate shelf space and the impact that shelf space has on retail sales. ${ }^{6}$

The work devoted to examining how retailers determine shelf space allocation typically involves developing a mathematical algorithm in which a retailer compares his expected profits under all possible shelving combinations. Whether these models are static (Borin, Farris, and Freeland 1994) or dynamic (Corstjens and Doyle 1983), the main idea is that the retailer has limited space to store goods and must, then, determine which mix of products earns him the greatest profit.

One example of this type of research is the work of Borin, Farris, and Freeland.

\footnotetext{
${ }^{5}$ Smaller manufacturers are particularly upset about slotting allowances. As MacAvoy (1987) shows, large manufacturers may actually wish to use slotting allowances to raise the price of shelf space in order to foreclose rivals from the market.

${ }^{6}$ Naming this section "Marketing and Advertising Literature" is a bit of a misnomer in that it would be hard to categorize any of the literature on slotting allowances as belonging, exclusively, to a particular academic area.
} 
They develop a shelf-management model upon the assumption that there are four potential sources of demand. These four demand factors are: unmodified demand (the preference a consumer has before entering the store), modified demand (how unmodified demand is altered upon seeing the in-store merchandising support each brand receives), acquired demand (consumers that may switch products if their preferred brand is no longer in stock), and stockout demand (the loss in sales if the demand exceeds the shelf inventory given to the product). Given this set-up, retailers maximize their profit by choosing the number of facings each brand receives, subject to the constraint that the total number of facings does not exceed the available shelf space for the category.

Chen et al. (1999) take a slightly different approach to a similar allocation problem. In Chen et al., the retailer optimizes his shelf space allocation (across all product categories) in order to attract the most consumers, by increasing the probability that a consumer will be able to find his or her preferred brands. The assumption is that the more shelf space (as measured in linear feet) category $j$ has at retailer $i$, the more likely it is that the consumer will be able to find his or her preferred brand (in category $j$ ) at $i$ 's store.

These models overlook some important decision variables, however. The most glaring omission is their failure to incorporate slotting allowances or other types of incentives. In addition, a number of the important decisions, such as the retail margins or mark-ups, are exogenous to the retailer. Another shortcoming of the models in this particular vein of the marketing literature is that they ignore the decision of where the chosen products should be placed on the shelf. ${ }^{7}$ It makes no difference whether a product is displayed on the top, bottom, or middle shelf; at the checkout counter or in the store's back corner.

\footnotetext{
${ }^{7}$ Instead, the focus is on choosing the optimal number of facings for each brand.
} 
Since shelf space allocation models do not address the importance of positioning, the natural question to ask is whether shelf space location actually matters to sales. According to the literature, the answer is yes. Several studies have used reduced form models to estimate the impact of shelf space on price elasticity (often referred to as "space elasticity"). Curhan (1972) defines space elasticity as the ratio of the relative change in unit sales to the relative change in shelf space: $E=\frac{\left(U_{t_{1}}-U_{t_{0}}\right) / U_{t_{0}}}{\left(S_{t_{1}}-S_{t_{0}}\right) / S_{t_{0}}}$, where $U_{t_{i}}$ and $S_{t_{i}}$ are the unit sales and shelf space, respectively, at time $i$. These studies conclude that shelf space does matter, but its magnitude may not be that large compared to other variables, such as price (Frank and Massy 1970, Curhan 1972, and Bommer and Walters 1996)). A cross-category study by Chiang and Wilcox (1997) also finds a strong correlation between dollar sales and the shelf space allocation.

Drèze, Hoch, and Purk (1994) is one of the few papers that draws a clear distinction between shelf space, measured as the number of facings or store-keeping units (SKUs), and the position of the product on the shelf. After conducting a series of field experiments at sixty Dominick's Finer Foods stores in the Chicago area, they conclude that the position on the shelf is far more important, in determining sales, than the number of facings. ${ }^{8}$ While this result is promising, the majority of work has largely overlooked the role that positioning can play in retail sales. Areni, Duhan, and Kiecker (1999) use field and laboratory experiments to test whether point-of-purchase displays increase sales of the featured brand. Their paper does not attempt to model consumer behavior explicitly, however, so it is difficult to generalize from their findings.

\footnotetext{
${ }^{8}$ Drèze, Hoch, and Purk, in fact, state that "A couple of facings at eye level did more for a product than five facings on the bottom shelf."
} 


\subsection{Discrete-Choice Structural Models}

The modeling technique used in this dissertation is based on discrete-choice structural models of differentiated products. The majority of recent papers in this research area, such as Chintagunta, Dube, and Singh (2003), Manuszak (2000), and Nevo (2001), can trace their roots to Berry (1994) and Berry, Levinsohn, Pakes (1995, henceforth BLP). The modeling technique pioneered by Berry and BLP has changed demand estimation for two principle reasons: the random coefficients approach adopted to model consumer heterogeneity alleviates the independence of irrelevant alternatives (IIA) problem that has plagued logit models and provides a solution to the problem of endogenous prices. ${ }^{9}$ As a result, models in the likeness of Berry and BLP produce more accurate price elasticities and unbiased coefficient estimates.

The majority of these empirical discrete-choice models fail to differentiate between manufacturer and retailer behavior, however. Retailers are included only to the extent that they place a fixed mark-up on the wholesale price. For example, BLP focuses on pricesetting behavior at the manufacturer level in their paper on automobile prices. Similarly, Nevo models the manufacturers of ready-to-eat cereal, but does not model the supermarkets. Given the nature of slotting allowances, it is essential to model the behavior of both manufacturers and retailers, separately, for they both make decisions critical to understanding the role slotting allowances play. A few papers, however, such as Besanko, Gupta, and Jain (1998), Besanko, Dube, and Gupta (2000), and Chintagunta, Dube, and Singh (2003) have formally modeled both the upstream and downstream firms in the vertical channel. In

\footnotetext{
${ }^{9}$ Chapter 5 contains a more thorough discussion of the IIA problem and endogenous prices.
} 
these models, manufacturers set a wholesale price for the product and retailers, taking the wholesale price as given, set the retail price as some mark-up over the wholesale price. 


\section{Chapter 3}

\section{A Brief History of Allowances}

By all accounts, slotting allowances were "born" in the mid-1980s. Sullivan (1997), citing an industry trade publication, asserts that the practice dates to 1984, although other authors have been less inclined to pinpoint an exact starting date. For example, Fortune magazine published an article on retail trade promotions "careening out of control" in their July 1983 issue. The article estimates that expenditures on retail trade promotion, which includes slotting allowances, were roughly $\$ 8$ billion in 1983. In addition, an inter-office correspondence, dated April 24, 1981, I obtained from the manufacturer of a well-known grocery product, describes how the manufacturer's brand lost shelf space during 1980 to brands which were more willing to offer allowances: "The effect on (brand name) is obvious; this high level of support (for the rivals) had resulted in greater price differentials between (brand name) and any other brand...as well as reallocation of shelf space based on support rather than dollar sale or share levels. Trade support is holding shelf space for some brands which do not deserve it. As dollar sales clearly indicate, (brand name) deserves far more space than it is allotted." 1

\footnotetext{
${ }^{1}$ The brand and manufacturer names have been omitted for confidentiality reasons. "Support" refers to payments made by rival manufacturers.
} 
Just as when allowances began is unclear, so are the precise reasons for the growth of the practice, although several factors are often cited. The first factor commonly acknowledged is the availability of scanner data. Manufacturers were able to purchase scanner data from one of several market research firms, including AC Nielsen and IRI, beginning in 1981. Retailers and manufacturers now had detailed information about which products, brands, or categories were selling (and which were not). Selling-Area Markets, Inc. (SAMI), however, had been providing more aggregated sales information since 1966. Rather than counting sales when a product was "scanned" at a checkout counter, SAMI tracked product sales primarily through warehouse-withdrawal. While SAMI's figures are not as accurate as data collected through scanners, it still provided a useful measure of product performance. Before SAMI went out of business in 1991, they had expanded to cover 483 product categories. $^{2}$

A second commonly cited factor is the sheer growth of new products offered to retailers. The number of new products introduced by manufacturers has grown substantially since the early 1980s. As Sullivan's data shows, from 1980 to 1990, the number of new products introduced annually grew by about 640 percent from approximately 2,500 new product introductions in 1980 to approximately 16,000 new product introductions in 1990. This growth is often attributed to the use of scanner data, which may decrease the cost of introducing new products by allowing the manufacturer to have greater certainty about which variations or spin-offs are most likely to sell. The number of total products available from manufacturers, in the grocery industry and a number of others, exceeds the amount

\footnotetext{
${ }^{2}$ The Department of Agricultural Economics at Purdue University maintains an archive of SAMI reports. My thanks to Professor John Connor for providing me with the information.
} 
of shelf space available at retail stores. This overabundance has resulted in competition for scare shelf space and promotional efforts.

A third factor is the increase in retail concentration, due to both mergers and acquisitions and economies of scale, that has occurred since the 1970s. Consider the market share of the top five supermarkets in 1980 versus their share in 1999. In 1980, the top five supermarkets had a combined market share around 20 percent. By 1999, however, this share had almost doubled to 37 percent (Turcsik 2000). As evidenced by Bloom, Gundlach, and Cannon's survey responses, some believe that this increased retail concentration has placed significantly more power in the hands of the supermarket. On a scale from 1 (strongly disagree) to 5 (strongly agree), the average response by a manufacturer to the statement "Slotting fees have come about as a result of greater retailer influence" was 4.11. The supermarket, it is argued, may use its market power in order to extract allowance payments from manufacturers. 


\section{Chapter 4}

\section{Using Accounting Statements to Learn About Promotional Payments}

\subsection{Introduction \& Background}

Until recently, the details of payments made to retailers were well-guarded secrets. Agreements were often off-invoice and accounting practices varied from firm to firm. The overall post-Enron emphasis on greater corporate responsibility and disclosure, as well as more targeted government and public inquisitions into the practices of the grocery industry (such as the use of slotting allowance payments), has resulted in the passage of several new accounting regulations, aimed at making these payments more transparent to the general public.

In November 2001, the Financial Accounting Standards Board's (FASB) Emerging Issues Task Force (EITF) introduced EITF Issue No. 01-9, "Accounting for Consideration Given by a Vendor to a Customer or a Reseller of the Vendor's Products." Issue 019 consolidated and codified two previous EITF issues: Issue No. 00-25, "Accounting for Consideration from a Vendor to a Retailer in Connection with the Purchase or Promotion 
of the Vendor's Products," and Issue No. 00-14, "Accounting for Certain Sales Incentives." EITF Issue No. 00-25 addressed the accounting treatment and classification of various types of "consideration" given by manufacturers, such as buy-downs and slotting fees. Issue No. 00-14 provided guidance on the accounting treatment of sales incentives aimed at consumers, such as manufacturer coupons.

These new accounting regulations have fundamentally changed the way companies account for promotional payments. For manufacturers, the main change is that promotional incentives are no longer considered an expense or a cost of doing business for the firm offering the incentive. Rather, they are to be taken as a reduction in net revenues. The theory is that paying an up-front fee for premium shelf space, for example, really reduces the amount of revenue generated by the resulting sales. While these payments may lead to a reduction in revenue, there is generally no net impact on the manufacturer's financial position or overall profit, as the reduction in revenue is off-set by a similar decrease in reported expenses. ${ }^{1}$

As press reports have noted, the retailers and distributors that receive the payments face more difficulties coming into compliance with the new accounting standards. Prior to EITF Issues No. 00-25 and 00-14, retailers accounted for sales incentives and promotional allowances in a variety of ways. As a simple illustration, suppose that manufacturer $M$ agrees to pay retailer $R$ a lump sum amount if sales of $M$ 's product eclipse an agreed upon target level at $R$ 's stores within a five year period. Should retailer $R$ record this payment as income when the contract is signed? Or, instead, should retailer $R$ only record the revenue from the lump sum payment once the target has been reached? Or should the

\footnotetext{
${ }^{1}$ The majority of firms I have examined previously classified the sales incentives under "selling, general, and administrative expenses."
} 
full value of the lump sum payment be spread out evenly over the length of the contract? Without explicit guidance, firms have employed all three of these strategies. Another series of complications arise when one takes into account the possibility that retailer $R$ might fail to meet the sales target and refunds a portion (or all) of the payment to the manufacturer. Retailers would, then, have to go back and restate earnings from previous years. In fact, many of the firms under investigation from the Securities and Exchange Commission (SEC) are suspected of either exploiting the timing of payments to inflate earnings or failing to accurately restate earnings when appropriate.

Given this context, the purpose of this chapter is to use accounting data, recently made available because of EITF Issue 01-09, to look for trends and information regarding such questions as: which types of manufacturers are more likely to pay promotional allowances? and what factors influence the dollar amounts of the promotional consideration paid by manufacturers?

\section{$4.2 \quad$ Expectations \& Hypotheses}

As I stated above, the main purposes of this chapter are to examine differences across manufacturers to determine which firms are most likely to rely on promotional allowances and also to try and ascertain which types of firms pay the largest amounts in promotional allowances.

Sullivan (1997) is one of the only academics to make predictions about where promotional allowance payments might be found. ${ }^{2}$ Sullivan hypothesizes that allowances are likely to occur in nondurable consumer goods markets where the growth of new products

\footnotetext{
${ }^{2}$ For a thorough summary of academic studies on allowances, please see Bloom, Gundlach, and Cannon (2000).
} 
outpaces the growth in sales per store. Sullivan compares historical data on sales and new product introductions for several different types of retail stores (grocery, drugstores, bookstores, toy stores, and hardware stores) to explain why grocery stores and drugstores are the only ones receiving allowances. It should be noted, however, that Sullivan was explicitly discussing the use of slotting allowances. Promotional allowances, which includes slotting allowances, encompass a wider variety of payments. Sullivan's intuition, however, still seems relevant here. One would expect to find allowance payments in industries where the growth of new products is relatively high. In addition, one might also expect to find promotional allowance payments to be prevalent (a) in industries with a number of competing brands that are close substitutes or (b) in industries with increased retail concentration/power.

To illustrate this, consider Microsoft Corp. and Pepsico. Microsoft produces a set of products for which there is really no close alternative. In addition, software can be sold easily in a number of different retail stores. For example, a brief search shows that Microsoft's newest personal computer operating system, Microsoft XP, can be found in software stores, office supply stores, mail-order catalogs, and through Microsoft's own website. This diminishes the power or importance of any specific retailer, thereby making it less likely Microsoft would be willing to engage in costly in-store promotion. Consider Pepsi's situation on the other hand. Pepsi has a number of close substitutes (Coke and many other beverages) competing for sales. Additionally, soft drinks are primarily sold in grocery stores and convenience stores. ${ }^{3} \quad$ Pepsi's reliance on obtaining favorable in-store promotion would seem to be quite large.

Characterizing which firms pay the most in promotional allowances is a subject

\footnotetext{
${ }^{3}$ Pepsi's website sells merchandise on their website. They do not, however, sell any Pepsi beverages.
} 
that has not been directly addressed. Three potential hypotheses to test are:

1. Larger firms and firms with considerable market share may be willing to pay promotional allowances in order to either maintain their current position or fend off competitors. $^{4}$

2. Smaller firms and firms with low market share may find it necessary to engage in in-store promotional spending in order to remain competitive with their larger (more popular) rivals.

3. Firms in industries that are likely to have promotional allowances might also be the firms that pay the most in these allowances. The rationale behind this is that the "price" of in-store promotion (or shelf space) might be bid up due to the fact that more firms will be competing for advantage at the retail outlet.

\subsection{Data}

The data on promotional allowances used in this study come from corporate annual reports (Form 10-K) for 2001. Careful consideration was given to selecting the firms used in this study. I began by compiling an extensive list of manufacturing firms using lists, such as those compiled by the Fortune 1000 and the Grocery Manufacturers of America. The dataset includes only those manufacturers that produce pre-packaged consumer goods, sold through retailers that carry brands from multiple manufacturers. This qualification is established to eliminate vertically integrated firms, such as the Gap, as well as direct-to-

\footnotetext{
${ }^{4}$ Nike just signed a $\$ 90$ million shoe contract with high school basketball phenomena LeBron James. A number of sports marketing experts believe that Nike was prompted to out-bid other companies for James' endorsement in order to protect their market share from rivals Reebok and Addidas (Associated Press).
} 
consumer sellers, such as Dell Computers. Firms were grouped, using the SEC's Standard Industrial Classifications as a guideline, into one of the following broad categories:

1. Grocery products (food and beverage)

2. Computer Software

3. Home products (hardware, tools, furniture)

\section{Electronics}

5. Media (newspapers and magazines)

6. Pharmaceutical products (including over-the-counter drugs)

7. Personal care products (make-up, deodorants, health and beauty)

\section{Clothing}

A number of firms, initially selected, were, ultimately, excluded from the study due to one of the following three common reasons: (1) ambiguously worded annual reports that made it difficult to ascertain whether payments were made, (2) firms that had not yet adopted the accounting standards requiring disclosure of retailer payments, and (3) foreignowned firms that adhere to different accounting standards. In total, the final sample consists of 171 firms, 100 firms that have been identified as making promotional payments and 71 that do not. Summary statistics appear in Table C.1. ${ }^{5}$

For each of the firms in the sample, information regarding the amount of "consideration" a manufacturer paid can be found in the Footnotes section of the firm's 10-K

\footnotetext{
${ }^{5}$ The included variables are defined below and in Table C.2.
} 
filing. There is great variation, however, in the level of detail each firm presents. Figure C.1 contains excerpts from two sample reports (Pepsico and the Monterey Pasta Company) and illustrates the differences in how thoroughly firms disclose the required information. Monterey Pasta breaks down their spending on Issue 01-09 related consideration, into three distinct categories (coupons, slotting fees, and promotions), while Pepsi reports only the total amount. While detailed spending information is, obviously, preferable, to maintain consistency across the varied reporting techniques, only the total amounts reclassified (due to EITF Issue 01-09) are included in the data.

In addition to classifying firms into industry groups and recording the amount of consideration paid (if any), I also collect data on several variables, which will help to examine the firm or industry characteristics that influence the decision to pay consideration to retailers. The variables included are: market share, sales, sales-to-inventory ratio, gross margin, market capitalization, each industry's Herfindahl Index.

Data is collected on gross margin under the assumption that this variable might give some indication about the firm's relative strength or performance (measured in revenue). There has been some discussion (see Bloom, Gundlach, and Cannon) about whether retailers exert their market power by demanding promotional payments or whether "stronger" manufacturers may offer allowances in order to exclude their rivals. In this context, inclusion of these variables will help determine whether profitable or high-margin firms are more likely to pay allowances than less profitable or low-margin firms.

The sales-to-inventory ratio is included to help address how well each manufacturer's product "moves." A firm's sales-to-inventory ratio is defined as their total revenue 
divided by their current inventory (in dollars). A high ratio indicates one of two things: either the brand has very high sales or the firm's sales are achieved without having too much excess inventory on hand. A low ratio, on the other hand, implies the opposite: the firm's sales are low or they hold a large amount of inventory, relative to their sales. One hypothesis is that firms with high sales-to-inventory ratios are more efficient or stronger sellers, thereby making them less risky to the retailer. A priori, we might expect these brands to be less likely to need to make large payments to retailers.

A firm's market share is included to examine the hypotheses about whether it is the market leader or the secondary brands which pay allowances. I include two different specifications for market share (SH1 and SH2). Unfortunately, I do not have sales information on a brand-by-brand basis, so it is difficult to construct an accurate measure of a manufacturer's total market share. SH1 represents each manufacturer's share of industry sales. So, for example, the value of SH1 for Kellogg's represents Kellogg's share of the total sales in the grocery industry. Clearly this will understate Kellogg's true market share as they are not actually competing against condiment manufacturers, such as H.J. Heinz. To provide for a more accurate market share value, I also include $\mathrm{SH} 2$, which measures Kellogg's sales relative only to the total sales in the cereal category. ${ }^{6}$

The measures of market share, along with the industry classifications, are used to calculate Herfindahl Indices of market power. Each firm within a category will have the same Herfindahl, but the values will vary across categories. The Herfindahls are included to test whether a relationship exists between the likelihood of offering promotional allowances

\footnotetext{
${ }^{6}$ Obviously, even $S h 2$ will be slightly inaccurate, as a number of manufacturers produce goods in multiple categories. Even with this flaw, however, I believe that $S h 2$ provides a useful measure the relative shares of manufacturers within a given category.
} 
and the degree of concentration in that firm's market. This will allow me to compare the differences between industries with many small firms and industries with a few larger firms.

\subsection{The Empirical Models}

I will be presenting two models in this section. The first model is a binomial choice model in which firms decide whether to make promotional payments or not. The second model presented is a reduced form censored regression model (Tobit) that examines the relationship between firm-specific factors and the firm's level of spending on promotional allowances.

\subsubsection{Binomial Choice Model}

To examine manufacturer $i$ 's decision whether to pay promotional allowances, consider the following equation:

$$
y_{i}^{*}=\beta^{\prime} x_{i}+\varepsilon_{i}
$$

where $y_{i}^{*}$ is a latent variable, which is unobservable to the econometrician, $x_{i}$ is a vector of observable firm characteristics, and $\varepsilon_{i}$ is a mean-zero idiosyncratic error term, distributed type II extreme value. Rather than observing $y_{i}^{*}$, we observe an indicator variable informing us whether or not a firm pays promotional allowances. By definition, then:

$$
\begin{aligned}
& y_{i}=1 \text { if } y_{i}^{*}>0 \\
& y_{i}=0 \text { if } y_{i}^{*} \leq 0
\end{aligned}
$$


Following the standard technique, I derive the probability that firm $i$ pays promotional allowances. That is, the probability that $y_{i}=1$ :

$$
\begin{aligned}
\operatorname{Pr}\left(y_{i}\right. & =1)=\operatorname{Pr}\left(y_{i}^{*}>0\right) \\
& =F\left(\beta^{\prime} x_{i}\right)
\end{aligned}
$$

where $F()$ is the cumulative distribution function (cdf) of $\varepsilon$. By the same principle, the probability that a firm $i$ does not pay promotional allowances can be expressed as:

$$
\operatorname{Pr}\left(y_{i}=0\right)=1-F\left(\beta^{\prime} x_{i}\right)
$$

Since this binomial choice framework has only two mutually-exclusive states (payment or no payment), the model can be estimated using the simple likelihood function:

$$
L=\prod_{i=1}^{N}\left[1-F\left(\beta^{\prime} x_{i}\right)\right]^{1-y_{i}}\left[F\left(\beta^{\prime} x_{i}\right)\right]^{y_{i}}
$$

where $N$ is the total number of firms in the sample. The $x$ 's included in the model consist of the firm-specific and industry-specific variables described in the data section, as well as a constant. In total, the logit model was estimated using four separate specifications.

\subsubsection{Censored Regression (Tobit) Model}

In addition to examining whether or not a manufacturer pays promotional allowances, it is also useful to look at the factors that impact the dollar amount of the payments. The total dollar amount manufacturer $i$ spends on the allowances is represented 
by $y_{i}$. However, a number of manufacturers offer no allowances, so the value of $y_{i}$ is constrained to be greater than or equal to zero. To account for the censoring, I define a new value $y_{i}^{*}$, such that:

$$
y_{i}^{*}=\beta^{\prime} x_{i}+\varepsilon_{i}
$$

and

$$
\begin{aligned}
& y_{i}=y_{i}^{*} \text { if } y_{i}^{*}>0 \\
& y_{i}=0 \text { if } y_{i}^{*} \leq 0
\end{aligned}
$$

where (again) $x_{i}$ is a vector of observable characteristics of manufacturer $i$, and $\varepsilon_{i}$

is an idiosyncratic error term. ${ }^{7}$ The observable characteristics included here are the same characteristics that were described in the preceding section.

The results from estimating this model will expand upon the previous section's findings by determining which type of firm pays the highest amount in promotional allowances. The inclusion of firm size and profitability variables may also help shed some light on the debate about whether it is the larger or smaller firms paying most of these allowances.

\footnotetext{
${ }^{7}$ To allow for comparison, I will estimate the Tobit model both under the assumption that the $\varepsilon$ 's are distributed Normal and under the assumption that they are distributed Logistic. The general results do not depend on the assumption.
} 


\subsection{Results}

It is well-known that logit parameter estimates, on their own, have virtually no useful interpretation. ${ }^{8}$ Therefore, in order to determine how a variable affects the probability of a firm paying promotional consideration to retailers, it is necessary to calculate each variable's marginal effect. Table C.3 presents the estimated marginal effects from seven different logit specifications. The final column in the table summarizes the relationships by showing the estimated sign for each variable. Across the specifications, several of the coefficients are statistically significant at the 10 percent level or better, including GROCERY $(+)$, SOFTWARE (-), ELECTRONICS (-), PERSONAL $(+)$, MARGIN $(+)$, and SHARE1

(-). Examining the magnitude of the marginal effects, it appears that GROCERY and MARGIN have the largest positive impacts. Implying that firms in the grocery industry and firms with a high gross margin are more likely to pay promotional allowances. The largest negative marginal effects belong to SOFTWARE and SHARE1. Possibly because of the flexibility in distribution channels, the results indicate that software manufacturers are far less likely to pay promotional allowances. Interestingly, a firm's market share is inversely related to the probability of paying promotional allowances. ${ }^{9}$

According to the results, electronics firms are less likely to pay promotional allowances, while personal care product manufacturers are more likely to pay allowances. This finding is confirmed by anecdotal evidence suggesting that grocery and drug stores, two main avenues for the sale of personal care products, are most often associated with the

\footnotetext{
${ }^{8}$ This is due to the fact that, unlike the linear probability model, $\frac{\partial L\left(x_{i}^{\prime} \beta\right)}{\partial x_{i}} \neq \beta$.

${ }^{9}$ While not statistically significant, the negative sign on the SHARE2 variable confirms these findings. Because SHARE1 is a "wider" measure of market share, it would tend to understate a firm's market share (relative to SHARE2). It is not suprising, therefore, that the coefficients on SHARE1 are larger than the coefficients on SHARE2.
} 
use of promotional allowances, such as slotting allowances.

The main financial variable included to proxy for firm profitability, MARKETCAP, is close to zero and statistically insignificant in six of the seven specifications. After controlling for industry, which is not done in specification I, the marginal effect of a firm's market capitalization is reduced to zero. The final firm-strength variable included in the regressions, INV, is not statistically significant, although it is positive in all specifications. This shows that firms with higher sales-to-inventory ratios are more likely to pay promotional allowances. From the firm's perspective, a high sales-to-inventory ratio might be considered "good," in that it implies either strong sales or low inventory on hand (or some combination of the two). So, firms with slow sales or excess inventory are actually less likely to pay promotional allowances. This finding seems contradictory to the argument that retailers request allowances, in part, to either safeguard against poor sales or cover some of the cost of storing and stocking a product. However, with marginal effects well below 0.0001 , the estimate is not statistically different from zero, and so there may not, in fact, be a correlation between inventory and promotional payments.

To test for robustness, I also ran a probit regression and two linear probability regressions. ${ }^{10}$ Table C.4 compares the parameter coefficients for the linear probability, logit, and probit models. To make the estimates directly comparable, the logit estimates have been transformed using the technique suggested by Amemiya (1981). Upon inspection, there is very little difference across specifications.

I now turn to a discussion of the censored regression model, regressing promo-

\footnotetext{
${ }^{10}$ Estimating a linear probability model using OLS results in inefficient estimates of $\beta$ because of heteroskedasticity in the error term. To correct for this problem, I also estimate the linear probability model using the weighted least squares technique described in Maddala (1999).
} 
tional payments (in $\$$ millions) on a number of independent factors. The results from seven different specifications are presented in Table C.5. Again, the final column summarizes the relationships by showing the estimated sign for each variable. Several of the so-called "firm strength" variables, MARGIN, MARKETCAP, SALES, and SHARE2, are statistically significant and positive. Taken together, these results show that stronger or more profitable firms are likely to make larger (dollar value) promotional payments. The only statistically significant industry-dummy is the coefficient on GROCERY. As we may have anticipated $a$ priori, the GROCERY coefficient is positive. We also find weak support for a positive relationship between the size of promotional payments and industry concentration, as measured through the Herfindahl Index. This implies that higher values for a firm's gross margin, market share, and total revenue lead the firm to offer larger dollar amounts of promotional allowances. Interestingly, the sign on the Herfindahl coefficients indicate that payments are higher for firms in highly concentrated industries.

\subsection{Conclusions}

While firms have, traditionally, kept their promotional payment strategies confidential, recent accounting regulation changes allow for a glimpse into the practice. In this chapter, I estimated two separate models, in order to gain a greater understanding of promotional payments, as well as to address some of the possible hypotheses regarding their use. The results of our logit regressions indicate that a firm's industry classification is, by far, the best predictor regarding whether an allowance payment is made, with grocery and personal care manufacturers most likely to pay allowances and software and electronics manufacturers the least likely. After controlling for industry differences, we find that market 
leaders (as defined by higher market share) are less likely to pay promotional allowances.

With respect to the actual dollar value of promotional payments, the findings reinforce the importance of a firm's industry classification. The measures of firm strength are all positively related to the dollar value of promotional payments. As is the measure of industry concentration.

It will be interesting to see whether manufacturers and retailers fundamentally change some of their promotion strategies because of the new accounting rules. Ghitelman (2002) conducts a survey and finds that approximately $62 \%$ of supermarkets plan to completely re-evaluate their promotional programs and strategies, while $50 \%$ of manufacturers plan a similar re-evaluation. Wellman (2002) finds that there may be other more subtle changes, such as the possible discontinuation of "end-of-quarter blow-out deals," the common promotion strategy wherein manufacturers spend significant amounts of money at the end of fiscal quarters in order to boost sales and revenues. Now that all of that promotion spending will be deducted from net revenues, most industry experts feel it is unlikely that the practice will continue.

With the trend towards greater corporate disclosure, efforts are underway to make corporate practices more visible. As this trend continues (as, hopefully, it will), the quality of research on corporate behavior will increase substantially. The list of possible research areas will grow, as well. The main roadblock to modeling and understanding firm behavior has been the lack of credible information. With more detailed (less aggregated) data, we can begin to gain a greater understanding of industry practices. As it stands, it is difficult to draw too many conclusions from currently available data. It is my hope that increased 
interest in disclosure will, ultimately, allow us to gain a better view of true firm behavior. 


\section{Chapter 5}

\section{The Model}

In this chapter, I introduce the basic model of manufacturer-retailer behavior upon which this research is based. In the next section, the timing of the model is described in four stages. The remainder of the chapter is devoted to a simplified theoretical model of manufacturer and retailer behavior.

\subsection{The Game}

Manufacturers compete with each other over premium shelf space at retail outlets.

Each manufacturer offers a slotting allowance to the retailer in exchange for an agreement to devote premium shelf space for the manufacturer's brand. Retailers are assumed to be "local monopolists" and have enough shelf space to stock each brand. ${ }^{1}$ However, each retailer can devote premium shelf space (an eye-level shelf allocation or end-of-aisle display, for example) to only one brand..$^{2}$

The interaction between manufacturers and retailers is modeled as a four-stage

\footnotetext{
${ }^{1}$ Allowing for competition downstream might produce interesting results. Downstream competition could potentially dampen the relative power of the retailer. However, Slade (1995) finds that over 90 percent of households do not engage in comparison shopping between grocery stores in order to find the lowest price. The assumption of a local monopoly does not seem inappropriate, therefore.

${ }^{2}$ The inherent idea present in this model can be easily summarized by what one marketer familiar with the grocery industry told me: "the days of supermarkets doing things, without being paid, are long gone."
} 
game. In the first stage of the game, each manufacturer $j$ makes a lump sum slotting allowance $\left(A_{j}\right)$ offer to the retailer. In the second stage, the retailer receives the allowance offers from all $J$ manufacturers, evaluates expected profit under each display configuration, and decides which brand to "feature." In the third stage, the manufacturers learn of the retailer's choice and then set wholesale prices $\left(w_{j}\right)$. Finally, conditional on the wholesale prices, the retailer sets a price $\left(p_{j}\right)$ for each of the $J$ brands. $^{3}$

Figure C.2 illustrates a simple duopoly version of this game in which two manufacturers compete for premium shelf space at a monopolist retailer.

\subsection{Theoretical Model of Behavior}

In this section, I introduce a simple theoretical model, which will help our understanding of how retailers and manufacturers might be expected to behave in the presence of slotting allowances. Consider the simple model of two manufacturers competing for premium shelf space at a monopolist retailer (shown in Figure C.2). There are two possible display configuration at this retail outlet: one in which brand $j$ receives the premium shelf space and another in which brand $k$, instead, receives the premium shelf space.

In this simple model, consumers are assumed to have utility of the form:

$$
u_{i j}=q_{j}-p_{j}+\varepsilon_{i j}
$$

where $u_{i j}$ is the utility consumer $i$ receives from consuming good $j, q_{j}$ is the "quality" of brand $j, p_{j}$ is the price of brand $j$, and $\varepsilon_{i j}$ is consumer $i$ 's idiosyncratic utility

\footnotetext{
${ }^{3}$ In some senses, slotting allowances can be thought of as a negative franchise fee. In the standard upstream-downstream model, the upstream firm receives a lump sum transfer (franchise fee) from the downstream firm. In the context of slotting allowances, the transfer flows in the opposite direction.
} 
for brand $j$ and is assumed to be distributed type II extreme value. This specification leads to familiar multinomial logit demands. This research departs from the traditional logit demand, however, by allowing quality and price to differ based on the retailer's display choice. In the utility function above, the quality parameter $(q)$ is such that, holding all else constant, a brand with a higher $q$ will face a higher demand curve.

Each brand can be thought of as having two different qualities: one when the brand is on display $\left(q_{j}^{j}\right)$ and another when it is not $\left(q_{j}^{k}\right)$. If brand $j$ is perceived as being of higher quality when it is on display, then $q_{j}^{j}>q_{j}^{k}$ and brand $j$ will receive a demand "boost" when the retailer selects $j$ for display. If there is no benefit from display, on the other hand, then we would assume that $q_{j}^{j}=q_{j}^{k} .{ }^{4}$ If the former is true and brand $j$ expects to receive a demand "boost" from the retailer's display, then this explains the manufacturer's willingness to offer a slotting allowance. The manufacturer offers an allowance in order to induce the retailer to put its brand in the premium position. With conditional quality, the market share of brand $j$, conditional upon brand $j$ being chosen for display, for example, can be expressed:

$$
S_{j}^{j}=\frac{\exp \left\{\left(q_{j}^{j}-p_{j}^{j}\right)\right\}}{1+\sum_{z} \exp \left\{\left(q_{z}^{j}-p_{z}^{j}\right)\right\}}
$$

Similarly, the market share of brand $j$, conditional upon brand $k$ being chosen for display, can be expressed:

$$
S_{j}^{k}=\frac{\exp \left\{\left(q_{j}^{k}-p_{j}^{k}\right)\right\}}{1+\sum_{z} \exp \left\{\left(q_{z}^{k}-p_{z}^{k}\right)\right\}}
$$

\footnotetext{
${ }^{4}$ Finally, if the display actually lowers demand, then one might expect $q_{j}^{j}<q_{j}^{k}$.
} 
where $q_{j}^{j}$ represents the perceived quality of brand $j$ when the premium shelf space has been given to brand $j$ and $p_{j}^{j}$ is the price of brand $j$ when brand $j$ has been given the premium space. ${ }^{5}$

For simplicity purposes, I will assume that brands $j$ and $k$ both have the same "baseline" quality (i.e. the quality when not on display), such that $q_{j}^{k}=q_{k}^{j}=\bar{q} \cdot{ }^{6}$ I further assume, without loss of generality, that brand $j$ receives a better boost from the premium shelf space, so $q_{j}^{j}>q_{k}^{k}$.

With the market size normalized to 1, the retailer's sales profit, where "sales profit" refers to the portion of profit that comes from output and pricing decisions, when brand $j$ receives the premium space (disregarding any allowance payment) is:

$$
\pi_{r \mid D=j}=\left(p_{j}^{j}-w_{j}^{j}\right) S_{j}^{j}+\left(p_{k}^{j}-w_{k}^{j}\right) S_{k}^{j}
$$

where $w_{j}^{j}\left(w_{k}^{j}\right)$ is the conditional wholesale price of brand $j(j)$ when brand $j$ is on display. While analytical solutions to the retailer's profit maximization problem are not possible, the logit formulation allows the retailer's two mark-up equations to be expressed as:

$$
\begin{aligned}
\left(p_{j}^{j^{*}}-w_{j}^{j^{*}}\right) & =\frac{1}{S_{0}^{j^{*}}} \\
\left(p_{k}^{j^{*}}-w_{k}^{j^{*}}\right) & =\frac{1}{S_{0}^{j^{*}}}
\end{aligned}
$$

where $S_{0}^{j}$ is the share of consumers that purchase neither brand $j$ nor brand $k$

\footnotetext{
${ }^{5}$ If, on the other hand, brand $k$ were chosen for display, all prices and shares would be denoted with a superscript $k$.

${ }^{6} \mathrm{I}$ will discuss other alternatives to this assumption below.
} 
when the retailer has given brand $j$ the premium shelf space. ${ }^{7}$ The retailer's equilibrium mark-up equations can be rewritten:

$$
\left(p_{j}^{j^{*}}-w_{j}^{j^{*}}\right)=\left(p_{k}^{j^{*}}-w_{k}^{j^{*}}\right)=\frac{1}{S_{0}^{j^{*}}}=1+\exp \left(q_{j}-p_{j}^{j^{*}}\right)+\exp \left(q-p_{k}^{j^{*}}\right)
$$

In order to evaluate the manufacturers' first order conditions, it is necessary to determine how wholesale prices affect retail prices (i.e. the pass-through rates $\frac{\partial p_{j}}{\partial w_{j}}$ and $\frac{\partial p_{i}}{\partial w_{j}}$ ). From the above conditions, note that $\left(p_{j}^{j^{*}}-w_{j}^{j^{*}}\right)=\left(p_{k}^{j^{*}}-w_{k}^{j^{*}}\right)$ and $\frac{\partial p_{1}}{\partial w_{1}}-1=\frac{\partial p_{2}}{\partial w_{1}}$. Using the retailer's first order condition for brands $j$ and $k$, define the following two equations:

$$
\begin{aligned}
& F_{1}=p_{j}^{j}-w_{j}^{j}-1-\exp \left(q_{j}-p_{j}^{j}\right)-\exp \left(q-p_{j}^{j}+w_{j}^{j}-w_{k}^{j}\right)=0 \\
& F_{2}=p_{k}^{j}-w_{k}^{j}-1-\exp \left(q-p_{k}^{j}+w_{k}^{j}-w_{j}^{j}\right)-\exp \left(q-p_{k}^{j}\right)=0
\end{aligned}
$$

Totally differentiating these two equations yields the following pass-through equations (suppressing superscripts):

- $\frac{\partial p_{j}}{\partial w_{j}}=S_{0}+S_{k}=1-S_{j}$

- $\frac{\partial p_{k}}{\partial w_{j}}=-S_{j}$

- $\frac{\partial p_{k}}{\partial w_{k}}=S_{0}+S_{j}=1-S_{k}$

- $\frac{\partial p_{j}}{\partial w_{k}}=-S_{k}$

The above equations imply that own brand pass-through rates are positive, while cross brand pass-through rates are negative. Finally, putting all of these parts together yields the four profit-maximizing conditions:

\footnotetext{
${ }^{7}$ More on this "outside option" will be presented in the next section.
} 
1. $p_{j}^{j^{*}}-w_{j}^{j^{*}}=\frac{1}{S_{0}^{j^{*}}}$

2. $p_{k}^{j^{*}}-w_{k}^{j^{*}}=\frac{1}{S_{0}^{j^{*}}}$

3. $w_{j}^{j^{*}}=\frac{1}{S_{0}^{j^{*}}\left(1-S_{j}^{j^{*}}\right)+S_{k}^{j^{*}}}$

4. $w_{k}^{j^{*}}=\frac{1}{S_{0}^{j^{*}}\left(1-S_{k}^{j^{*}}\right)+S_{j}^{j^{*}}}$

\subsubsection{Equilibrium Values and Brand Quality}

The equilibrium is characterized by the four equations above. How are the equilibrium values related to quality? In order to understand the role premium shelf space plays in a manufacturer's strategy, it is first necessary to understand how quality affects equilibrium price, market share, and profit. To illustrate the effect of quality on the model presented above, recall that, by definition, brand $j$ is a higher quality than brand $k .^{8}$ Superscripts have been suppressed for simplicity.

Proposition 1 In equilibrium, the brand with the higher quality will have a higher wholesale price, a higher retail price, a higher market share, and a higher profit.

Proof. Note that, from conditions (3) and (4) above, $S_{j}>S_{2} \Longleftrightarrow w_{1}>w_{2}$. In this model mark-ups are equal, so $w_{1}>w_{2} \Longleftrightarrow p_{1}>p_{2}$ and $S_{1}>S_{2} \Longleftrightarrow q_{1}-p_{1}>$ $q_{2}-p_{2}$. Because $q_{1}-p_{1}>q_{2}-p_{2}$ and $p_{1}>p_{2}$, it must also be that $q_{1}>q_{2}$. Finally, since manufacturer profit $\left(\pi^{m}\right)$ equals wholesale price multiplied by share, $S_{1}>S_{2}$ and $w_{1}>w_{2} \Longleftrightarrow \pi_{1}^{m}>\pi_{2}^{m}$. Therefore,

$$
q_{1}>q_{2} \Longleftrightarrow S_{1}>S_{2} \Longleftrightarrow w_{1}>w_{2} \Longleftrightarrow p_{1}>p_{2} \Longleftrightarrow \pi_{1}^{m}>\pi_{2}^{m}
$$

\footnotetext{
${ }^{8}$ This is due to the fact that we are referring explicitly to the situation where brand $j$ has been chosen for display.
} 
The higher quality brand, then, earns greater profit and a larger share of the market. We would expect brand $j$ (the brand with the premium shelf space) to have a higher price, higher share and earn more profit(for the retailer) than brand $k$.

\subsubsection{The Relationship between Mark-ups and Quality}

The proof shown above applies within a particular shelf space configuration, but when we consider the retailer's shelf space choice, we must compare across shelf space configurations. A crucial step in addressing this issue is to determine the relationship between equilibrium mark-ups and brand quality. In essence, the question of interest is whether mark-ups increase with quality.

This link is important because a display configuration with a higher mark-up implies greater profit. To see why consider the equation for retail profit:

$$
\begin{aligned}
\pi_{r \mid D=j}^{*} & =\left(p_{j}^{j^{*}}-w_{j}^{j^{*}}\right) S_{j}^{j^{*}}+\left(p_{k}^{j^{*}}-w_{k}^{j^{*}}\right) S_{k}^{j^{*}} \\
& =\frac{1}{S_{0}^{j^{*}}}\left(S_{j}^{j^{*}}+S_{k}^{j^{*}}\right) \\
& =\frac{1}{S_{0}^{j^{*}}}\left(1-S_{0}^{j^{*}}\right) \\
& =\frac{1}{S_{0}^{j^{*}}}-1 \\
& =\left(p_{j}^{j^{*}}-w_{j}^{j^{*}}\right)-1
\end{aligned}
$$

The final line implies that the higher the mark-up, the higher the retail profit.

So, if one understands the relationship between quality and mark-up, it should be straight forward to determine which display configuration yields the retailer the highest profit. ${ }^{9}$

\footnotetext{
${ }^{9}$ As I will show below, the level of retail profit helps us determine (a) which brand is more likely to "win" the premium shelf space and (b) how much manufacturers are willing and able to bid for the premium shelf space.
} 
Proposition 2 The higher the quality of the displayed brand, the higher the retail mark-up will be

Proof. To show this result, it must be shown that $\frac{\partial\left(p_{j}^{j}-w_{j}^{j}\right)}{\partial q_{j}}>0$

$$
\begin{aligned}
\frac{\partial\left(p_{j}^{j}-w_{j}^{j}\right)}{\partial q_{j}} & =\frac{\partial\left(\frac{1}{S_{0}^{j^{*}}}\right)}{\partial q_{j}}=\frac{\partial\left(1+\exp \left(q_{j}-p_{j}^{j^{*}}\right)+\exp \left(q-p_{k}^{j^{*}}\right)\right)}{\partial q_{j}} \\
& =\frac{\partial \exp \left(q_{j}-p_{j}^{j^{*}}\right)}{\partial q_{j}}+\frac{\partial \exp \left(q-p_{k}^{j^{*}}\right)}{\partial q_{j}} \\
& =\exp \left(q_{j}-p_{j}^{j^{*}}\right)\left(1-\frac{\partial p_{j}^{j^{*}}}{\partial q_{j}}\right)-\exp \left(q-p_{k}^{j^{*}}\right) \frac{\partial p_{k}^{j^{*}}}{\partial q_{j}}
\end{aligned}
$$

So, for $\frac{\partial\left(p_{j}^{j}-w_{j}^{j}\right)}{\partial q_{j}}>0$, it must be that $\exp \left(q_{j}-p_{j}^{j^{*}}\right)\left(1-\frac{\partial p_{j}^{j^{*}}}{\partial q_{j}}\right)>\exp \left(q-p_{k}^{j^{*}}\right) \frac{\partial p_{k}^{j^{*}}}{\partial q_{j}}$. (An outline of this proof appears in an appendix)

I expect that the retailer will earn more sales profit from the display configuration with the highest on-display quality $\left(q_{j}^{j}\right)$. With this knowledge regarding profits, I now turn to an explanation regarding how the manufacturer uses this information to determine her optimal slotting allowance offers.

\subsubsection{Perfect Information}

When manufacturers have perfect information about how a retailer will behave, the determination of slotting allowance offers resembles an English auction. To illustrate this, consider the following example: Suppose the retailer chooses brand 1 to receive the premium shelf space. As shown above, the retailer would receive sales profit of $\pi_{r \mid D=1}$ and the manufacturers would receive sales profits $\pi_{1 \mid D=1}^{m}$ and $\pi_{2 \mid D=1}^{m}$. If the retailer instead were to choose brand 2, the retailer would expect to receive a sales profit of $\pi_{r \mid D=2}$ and the manufacturers would, in turn, receive sales profits $\pi_{1 \mid D=2}^{m}$ and $\pi_{2 \mid D=2}^{m}$. Among the numerous 
questions one might be interested in examining, two of the most fundamental are: What slotting allowance values would manufacturers offer in the first stage of the game? and which brand would the retailer, ultimately, select for the premium shelf space?

The answer to both questions relies on comparing what may be called differential profits. Under perfect information, both manufacturers correctly anticipate how much variable profit $(\pi)$ the retailer expects to earn in the game's final stage, under each possible display choice (disregarding any slotting allowance payments). In the absence of slotting allowances, the retailer would select whichever display configuration earns the retailer the most variable profit. Given this knowledge, the manufacturer must determine whether it would be profitable to offer a slotting allowance in order to induce the retailer to deviate from its initial bias towards displaying the brand yielding the most sales profit.

The manufacturer would only be willing to offer an allowance if the additional profit that the manufacturer would receive with the premium shelf space $\left(\pi_{j \mid D=j}^{m}-\pi_{j \mid D=k}^{m}\right)$ was at least as great as the allowance payment $\left(A_{j}\right)$. As stated above, the process of determining the optimal slotting allowance offer resembles a traditional ascending auction. ${ }^{10}$ In this case, however, manufacturers increase allowance offers such that the winner offers a slotting allowance that yields the retailer some tiny amount of profit $(\varepsilon)$ greater than what the retailer would earn with the second best offer. In other words, the winner's optimal slotting offer would be $A_{j}^{*}=\pi_{r \mid D=k}-\pi_{r \mid D=j}+A_{k}+\varepsilon$, as long as $\pi_{j \mid D=j}^{m}-A_{j}^{*} \geq \pi_{j \mid D=k}^{m}$. If price differentials are different across manufacturers, optimal behavior will result in one brand emerging as the winner (i.e. if the brands receive different profit "boosts" from the premium

\footnotetext{
${ }^{10}$ Another analogy might be to think of this process as the opposite of the price undercutting that occurs in homogeneous product Bertrand pricing.
} 
shelf space). While this optimization has been described as an auction, the timing of the model requires the manufacturers to make their best response calculations "mentally" and make their offers simultaneously.

\subsubsection{Behavior with Private Information}

Instead of assuming that manufacturers have perfect information about the retailer's profit and behavior, consider a more plausible situation where the retailer has some private information that manufacturers are unable to observe. Specifically, suppose that the retailer incurs a fixed cost which depends upon which brand receives the retailer's premium shelf space. The manufacturer, a priori, is uncertain what these fixed costs are, but knows the distribution of these costs. This creates a situation requiring different behavior than in a perfect information case. In the remainder of the section, I will discuss how the logit model described above can be applied in the private information case. The model will be used to derive comparative static predictions which can later be tested with evidence from the empirical structural model.

When there exists private information about the retailer's display-specific fixed cost, the manufacturer chooses the optimal slotting allowance by maximizing expected profit. ${ }^{11}$ The dollar value of the allowance offer impacts a manufacturer's expected profit in an interesting way: the larger the value of an allowance, the higher the probability that the retailer chooses the manufacturer's brand, but the lower the payoff (i.e. profit) to the manufacturer expects to receive if chosen for the premium shelf space. A step-by-step example of expected manufacturer profit maximization is outlined in greater detail in an appendix.

\footnotetext{
${ }^{11} \mathrm{~A}$ more thoroughly discussion of this problem will be presented in Chapter 6 .
} 
Relying on the assumptions presented in the appendix, it is possible to obtain a closed form solution for manufacturer $j$ 's optimal slotting allowance offer $\left(A_{j}^{*}\right)$. The solution reflects many of the relationships that might be anticipated, a priori: Namely that (i) the more a manufacturer earns as the displayed brand, the more they are willing to bid, (ii) the more sales profit the retailer earns from displaying a brand, the less the manufacturer would offer, (iii) the more a manufacturer earns without the premium space, the less they are willing to offer for the premium space, and (iv) the more the retailer earns from displaying your rival, the more a manufacturer would want to offer.

While the effect of quality changes on some measures is relatively straightforward, such as the equilibrium mark-up level, the impact of quality changes on optimal slotting allowances, is ambiguous. This presents an opportunity for the empirical model to provide information that the theoretical model cannot. The intuition behind the ambiguity is as follows: if the displayed brand's quality goes up, then the manufacturer expects to earn more profit as the displayed brand. Because of this belief, the manufacturer would optimally want to offer a larger slotting allowance (in order to increase the probability it receives the premium space). At the same time, however, the quality boost the manufacturer receives also makes giving that manufacturer's brand premium shelf space a more profitable option for the retailer. The increased retailer sales profit decreases the optimal slotting allowance offer. These two effects oppose each other, leading to an uncertain total effect.

The parameter estimates from the structural model, along with counterfactual experiments, will allow for comparison between anticipated theoretical outcomes and actual empirical results. With this the background in place, I now discuss the full structural 
model, beginning in the game's final stage (consumer choice) and working backwards to the manufacturer's behavior. 


\section{Chapter 6}

\section{The Empirical Model}

\subsection{Utility and Demand}

A consumer $i=1, \ldots, I$ visits a retail store in market $m=1, \ldots, M$ and chooses either to purchase one of the $J$ brands in a given product category or chooses not to purchase any of the brands. Each brand $j$ has two attributes: $\left(x_{j}, p_{j}\right)$, where $x_{j}$ is a vector of $K$ visible attributes, and $p_{j}$ is the price. The indirect utility consumer $i$ in market $m$ obtains from purchasing product $j$ is given by:

$$
u_{i j m}=x_{j} \beta_{i}-\alpha_{i} p_{j m}+\varepsilon_{i j m}
$$

The coefficients $\left(\alpha_{i}, \beta_{i}\right)$ capture consumer $i$ 's tastes for attributes $x$ and price p. The term $\varepsilon_{i j m}$ is a mean-zero stochastic term capturing consumer $i$ 's idiosyncratic utility from product $j$ and is assumed to be distributed type II extreme value, yielding the traditional multinomial logit.

As stated above, consumers also have the ability to by-pass purchasing any of the offered brands. This is referred to as purchasing the "outside good" or the "no purchase" option. For identification purposes, I normalize the indirect utility from the outside option 
to be:

$$
u_{i 0 m}=\varepsilon_{i 0 m}
$$

The multinomial logit model displays the previously-mentioned independence of irrelevant alternatives (IIA) problem. The IIA problem refers to the restrictive substitution patterns imposed by the logit model. To illustrate, suppose there are three differentiated products available in a given category $(A, B$, and $C)$. In the logit model, the ratio of $A$ 's market share $\left(S_{A}\right)$ to $B$ 's market share $\left(S_{B}\right)$ can be written:

$$
\frac{S_{A}}{S_{B}}=\frac{\frac{\exp \left(x_{A} \beta\right)}{1+\sum_{j} \exp \left(x_{j} \beta\right)}}{\frac{\exp \left(x_{B} \beta\right)}{1+\sum_{j} \exp \left(x_{j} \beta\right)}}=\frac{\exp \left(x_{A} \beta\right)}{\exp \left(x_{B} \beta\right)}
$$

Notice that the ratio of market shares does not depend on the existence of (or number of) alternative brands. If another brand $(D)$, with almost identical characteristics to brand $A$, entered the market, the logit would not predict any change in the relative market shares of $A$ and $B$, because that ratio depends solely on the characteristics of $A$ and $B$.

Another way of illustrating this problem is by examining the cross-price elasticities. Consider the cross-price elasticity of $A$ and $B$ :

$$
\eta_{A B}=\frac{\partial S_{A}}{\partial P_{B}} \frac{P_{B}}{S_{A}}=-\alpha S_{B} P_{B}
$$

The cross-price elasticity depends only on the market share (and price) of brand $B$. Notice also that the cross-price elasticity of $C$ and $B$ will be identical, implying that a change in the price of $B$ has the same effect on brands $A$ and $C$, regardless of how similar 
the products are.

Because of these unrealistic substitution patterns, several econometric techniques have emerged to correct the IIA problem, such as the nested logit model. I choose to adopt a random coefficients framework to model individual variations from mean preferences. ${ }^{1}$ More formally, I model:

$$
\left(\begin{array}{c}
\alpha_{i} \\
\beta_{i}
\end{array}\right)=\left(\begin{array}{l}
\alpha \\
\beta
\end{array}\right)+\Pi D_{i}+\nu_{i}, \nu_{i} \sim N(0,1)
$$

where $(\alpha, \beta)$ are the mean preferences for price and observable characteristics, $D_{i}$ is a $d \times 1$ vector of observed consumer characteristics, $\Pi$ is a $(K+1) \times d$ matrix of coefficients that illustrate how tastes for product characteristics vary with consumer attributes, and $\nu_{i}$ represents additional characteristics of consumer $i$ which are not captured through demographic information and are unobservable to the econometrician. Inclusion of $\nu_{i}$ accounts for the possibility that individuals with identical demographic characteristics may still have different tastes for price and observable characteristics. The $\nu_{i}$ are assumed to be independent from $D_{i}$ and are distributed i.i.d. standard normal.

The consumer is assumed to purchase one unit of the good which provides the highest expected utility from all of the goods in his choice set. In other words, consumer $i$ will purchase brand $j$ if:

$$
U\left(D_{i}, x_{j m}, p_{j m}, \varepsilon_{i j m}, \nu_{i}\right) \geq U\left(D_{i}, x_{k m}, p_{k m}, \varepsilon_{k j m}, \nu_{i}\right) \forall k \neq j
$$

This specification ignores an important component in the demand for products:

\footnotetext{
${ }^{1}$ Nevo (2000) presents a useful overview of the intricacies of the random coefficients logit model. This dissertation has benefitted greatly from Nevo's work.
} 
the shelf display space. To accurately address the question why manufacturers would be willing to pay for premium shelf space, we must try to understand how premium space affects sales. To model the way in which shelf space affects the consumer's discrete product choice decision, consider the factors that enter a consumer's decision whether to purchase or not. Clearly, if a consumer is more likely to purchase a brand when it is on display, then the consumer's perception of the brand must somehow be different (holding all else constant). To this end, we might think that consumers view a brand differently depending upon whether that brand has premium shelf space or not. Possible explanations are that a brand on display may be perceived as being more popular or of a higher quality. An alternative approach could be to allow shelf space to inform consumers about the existence of a particular product. The shelf space allocation, therefore, would determine a consumer's choice set. Goeree (2001) takes this approach in modeling the effects of advertising on the demand for personal computers. Because ketchup is the product used in this paper, however, I feel that knowledge of available options is less of an issue than it may be in other categories.

To capture consumer taste for each brand (independent of product characteristics), I use brand-specific dummy variables. As Table C.9 shows, ketchup, the product used in this research, is essentially a homogeneous good. It seems likely, then, that brand dummies will capture consumer tastes for each brand in a manner that cannot be captured through product characteristics. One problem with the use of fixed effects is that any variation in tastes across markets will be overlooked. It will not be possible, for example, to determine whether there is a difference between how Heinz is perceived in Pittsburgh and how it is perceived in Atlanta. The use of random coefficients, however, helps (partially) explain 
regional sales differences due to differing demographics.

An additional advantage of using brand dummies is that it eliminates the need to use instrumental variables to account for the endogeneity of prices. Many of the discretechoice structural models follow BLP's convention and introduce an unobserved (to the econometrician) product characteristics term $\left(\xi_{j}\right)$ into the indirect utility function. Because the retail price is likely to be correlated with these unobserved product characteristics, econometricians have been forced to employ instrumental variables estimation techniques in order to obtain unbiased estimates. Since ketchup is a homogeneous good, I argue that unobserved product characteristics are captured through the brand dummies.

To allow a consumer's tastes for each brand to vary depending on whether that brand is on display or not, two $\beta$ 's per brand are estimated: one capturing the mean taste for brand $j$ when it is on display $\left(\beta_{j}^{j}\right)$ and another capturing the mean taste for brand $j$ when another brand is featured $\left(\beta_{j}^{0}\right)$.

In order to account for this possibility, I allow each brand's observable characteristics to vary according to whether the brand is on display or not. The probability, then, that a consumer $i$ in market $m$ purchases brand $j$ when brand $j$ is featured is given by:

$$
s_{i j m \mid D=j}=\frac{\exp \left\{\beta_{i j}^{j}-\alpha_{i} p_{j m}^{j}\right\}}{1+\exp \left\{\beta_{i j}^{j}-\alpha_{i} p_{j m}^{j}\right\}+\sum_{k \neq j} \exp \left\{\beta_{i k}^{0}-\alpha_{i} p_{k m}^{j}\right\}}
$$

where $\beta_{i j}^{j}$ represents consumer $i$ 's taste for brand $j$ when brand $j$ is on display, $\beta_{i k}^{0}$ represents consumer $i$ 's taste for brand $k$ when brand $k$ is not on display, and $p_{j}^{j}\left(p_{k}^{j}\right)$ represents the retail price of brand $j(k)$, conditional upon brand $j$ being the displayed brand. $^{2}$ In a similar manner, the probability that a consumer $i$ in market $m$ purchases

\footnotetext{
${ }^{2}$ For simplification, the conditional share in the two brand case would be: $s_{i 1 m \mid D=1}=$
} 
brand $j$ when another brand $k$ is the featured brand may be expressed:

$$
s_{i j m \mid D=k}=\frac{\exp \left\{\beta_{i j}^{0}-\alpha_{i} p_{j m}^{k}\right\}}{1+\exp \left\{\beta_{i k}^{k}-\alpha_{i} p_{k m}^{k}\right\}+\sum_{g \neq k} \exp \left\{\beta_{i g}^{0}-\alpha_{i} p_{g m}^{k}\right\}}
$$

By estimating these differing taste components, we gain insight into the perceived differences between a brand with premium shelf space and that same brand in an unfeatured position (if there are, indeed, any differences). The estimated $\beta$ 's values correspond to the quality measure in the theoretical model above. In the theoretical model, it was assumed that $q_{1}^{1}>q_{1}^{2}$. Empirical results will indicate not only whether this assumption is valid, but will also help determine the magnitude of any perception "boost."

By integrating over the distribution of demographics, we can obtain conditional market shares for each brand in each market.

\subsection{Behavior of the Firms}

\subsubsection{The Retailer's Problem}

A retailer takes allowance offers from manufacturer $j$ for all $j=1, \ldots, J$ and maximizes the expected profit by comparing the expected profit earned under all possible display configurations. Retailer $r$ 's expected profit, conditional on choosing to feature manufacturer j's brand, is:

$$
\Pi_{r \mid D=j}=\pi_{j}+A_{j}+e_{j}
$$

In this manner, the retailer's expected profit can be thought of as having a variable component, a slotting allowance component, and a fixed component. The variable

$\exp \left\{\beta_{i 1}^{1}-\alpha_{i} p_{1 m}^{1}\right\}$ $\frac{\exp \left\{\beta_{i 1}^{1}-\alpha_{i} p_{1 m}^{1}\right\}}{1+\exp \left\{\beta_{i 1}^{1}-\alpha_{i} p_{1 m}^{1}\right\}+\exp \left\{\beta_{i 2}^{0}-\alpha_{i} p_{2 m}^{1}\right\}}$. 
component $\left(\pi_{j}\right)$ is the amount of profit that depends on the retailer's optimal pricing and output choices. $A_{j}$ is the slotting allowance offer from brand $j$. The retailer, by design, collects an allowance only from the chosen brand. The $\left(-e_{j}\right)$ term can be thought of as a display-specific fixed cost. ${ }^{3}$ The display and retailer-specific fixed cost might encompass such things as the fact that certain contracts may require the building of displays, certain brands may require more time to stock or unpack, employees may need to be trained for certain promotional activities, etc. at a particular retail outlet. The retailer knows the true value of the fixed cost it faces, but manufacturers only have knowledge about the distribution of these fixed costs.

We can further characterize the expected profit retailer $r$ receives when displaying brand $j$ as:

$$
\Pi_{r \mid D=j}=\left(p_{j}^{j}-w_{j}^{j}\right) Q_{j \mid D=j}+A_{j}+\sum_{k \neq j}\left(p_{k}^{j}-w_{k}^{j}\right) Q_{k \mid D=j}+e_{j}
$$

where $p_{k}^{j}$ is the retail price of brand $k$ when brand $j$ has been chosen for display, $w_{k}^{j}$ is the wholesale price of brand $k$ when brand $j$ has been chosen for display, $A_{j}$ is the lump sum allowance paid by the manufacturer of brand $j$, and $Q_{k \mid D=j}$ is the demand for brand $k$ when brand $j$ is chosen for display. The conditional demand for brand $k$ is equal to $M s_{k \mid D=j}$, where $M$ is the population and $s_{k \mid D=j}$ is the share of consumers purchasing brand $k$ when brand $j$ is on display.

The retailer determines optimal conditional prices $p_{j}^{j}$ and $p_{k}^{j}(\forall k \neq j)$ by solving the following system of first order conditions:

\footnotetext{
${ }^{3}$ This specification is similar to that used in Berry's (1992) paper on entry in the airline industry.
} 


$$
\begin{aligned}
& \frac{\partial \Pi_{r \mid D=j}}{\partial p_{j}^{j}}=Q_{j \mid D=j}+\left(p_{j}^{j}-w_{j}\right) \frac{\partial Q_{j \mid D=j}}{\partial p_{j}^{j}}+\sum_{k \neq j}\left(p_{k}^{j}-w_{k}\right) \frac{\partial Q_{k \mid D=j}}{\partial p_{j}^{j}}=0 \\
& \frac{\partial \Pi_{r \mid D=j}}{\partial p_{k}^{j}}=Q_{k \mid D=j}+\left(p_{k}^{j}-w_{k}\right) \frac{\partial Q_{k \mid D=j}}{\partial p_{k}^{j}}+\sum_{i \neq k}\left(p_{i}^{j}-w_{i}\right) \frac{\partial Q_{i \mid D=j}}{\partial p_{i}^{j}}=0
\end{aligned}
$$

For $J$ brands, the retailer will generate a system of $J \times J$ conditional prices. ${ }^{4}$ As is commonly assumed in vertical models, the manufacturer has accurately anticipated what retail price the retailer will choose for a given wholesale price. The retailer, then, when profit maximizing, is able to express wholesale prices as a function of retail price.

The specification of retail profit presented in equation (5) allows the retailer's display-selection problem to be analyzed in a familiar discrete-choice setting. This enables the probability that brand $j$ is chosen (for display or feature) by retailer $r$ to be calculated. Let $\phi_{j r}$ represent the (conditional) probability that manufacturer $j$ is chosen by retailer $r$ :

$$
\begin{aligned}
\phi_{j r} & =\operatorname{Pr}(D=j) \\
& =\operatorname{Pr}\left(\pi_{j}+A_{j}+e_{j}>\pi_{k}+A_{k}+e_{k} \forall k \neq j\right)
\end{aligned}
$$

The retailer chooses to feature the brand that yields the highest expected profit. In the two good case $(j=1,2)$, the probability that brand 1 is chosen would be given by:

$$
\begin{aligned}
\phi_{1 r} & =\operatorname{Pr}\left(\pi_{1}+A_{1}+e_{1}>\pi_{2}+A_{2}+e_{2}\right) \\
& =\operatorname{Pr}\left(e_{2}-e_{1}<\pi_{1}-\pi_{2}+A_{1}-A_{2}\right)
\end{aligned}
$$

\footnotetext{
${ }^{4}$ Each brand will have a conditional price for each possible display choice and one there will be a display choice for each brand.
} 
In the more general case with $J$ brands, the display probability can be represented:

$$
\begin{aligned}
\phi_{j} & =\int_{-\infty}^{\pi_{j}-\pi_{1}} \int_{-\infty}^{\pi_{j}-\pi_{2}} \cdots \int_{-\infty}^{\pi_{j}-\pi_{J}} f\left(e_{i}-e_{j}\right) d\left(e_{i}-e_{j}\right) \\
& =\prod_{i \neq j}^{J} \int_{-\infty}^{\pi_{j}-\pi_{i}} f\left(e_{i}-e_{j}\right) d\left(e_{i}-e_{j}\right)
\end{aligned}
$$

Making an assumption about the distribution of the $e$ 's allows for analytical computation of this probability. A more thorough discussion of this assumption and its implications appears in Chapter 8. I now turn to the manufacturer's problem.

\subsubsection{The Manufacturer's Problem}

The profit-maximizing manufacturer faces two problems: choosing a wholesale price $(w)$ and a lump sum slotting allowance $(A)$ to offer retailers. The selection of an optimal wholesale price follows from profit maximization of conditional profit functions. For example, if manufacturer $j$ knows that the retailer has selected brand $j$ for display, then manufacturer $j$ 's profit can be expressed:

$$
\begin{aligned}
\Pi_{j \mid D=j}^{m} & =\pi_{j \mid D=j}^{m}-A_{j} \\
& =w_{j}^{j} Q_{j \mid D=j}-A_{j}
\end{aligned}
$$

where $\pi_{j \mid D=j}^{m}$ represents the variable manufacturer profit that depends on pricing and output decisions. The optimal conditional wholesale price, therefore, is the solution to the following first order condition:

$$
\frac{\partial \Pi_{j \mid D=j}^{m}}{\partial w_{j}^{j}}=Q_{j \mid D=j}+w_{j}^{j} \frac{\partial Q_{j \mid D=j}}{\partial w_{j}^{j}}=0
$$


If, on the other hand, manufacturer $k$ 's brand were chosen for display, then manufacturer $j$ would expect to receive:

$$
\begin{aligned}
\Pi_{j \mid D=k}^{m} & =\pi_{j \mid D=k}^{m} \\
& =w_{j}^{k} Q_{j \mid D=k}
\end{aligned}
$$

The optimal wholesale price, in this case, would be the solution to the first order condition:

$$
\frac{\partial \Pi_{j \mid D=k}^{m}}{\partial w_{j}^{k}}=Q_{j \mid D=k}+w_{j}^{k} \frac{\partial Q_{j \mid D=k}}{\partial w_{j}^{k}}=0
$$

It is necessary to briefly discuss the calculation of the final term in the manufacturer's first order condition $\left(\frac{\partial Q_{j}}{\partial w_{j}^{j}}\right){ }^{5}$ This derivative can be simplified as:

$$
\frac{\partial Q_{j}}{\partial w_{j}^{j}}=\frac{\partial Q_{j}}{\partial p_{j}} \frac{\partial p_{j}}{\partial w_{j}}
$$

Evaluating the first term $\left(\frac{\partial Q_{j}}{\partial p_{j}}\right)$ is straightforward in the logit model. ${ }^{6}$ The second term $\left(\frac{\partial p_{j}}{\partial w_{j}}\right)$, however, requires some additional explanation. As Besanko, Dube, and Gupta (2003) point out, in the structural models of vertical competition, there has not been a consensus regarding the value of $\frac{\partial p_{j}}{\partial w_{j}}$, which they call the retailer's "pass-through" rate. For example, Besanko, Gupta, and Jain (1998) assume that the own brand pass-through ( $\left.\frac{\partial p_{j}}{\partial w_{j}}\right)$ is 1 and the cross brand pass-through $\left(\frac{\partial p_{j}}{\partial w_{k}}\right)$ is $0 .{ }^{7}$ Sudhir (2001), on the other hand,

\footnotetext{
${ }^{5}$ For simplicity, I will temporarily ignore the superscript associated with the conditional display choices.

${ }^{6}$ Recall that the logit has the well-known property that $\frac{\partial s_{i j}}{\partial p_{j}}=-\alpha s_{i j} p_{j}$ and $\frac{\partial s_{i j}}{\partial p_{k}}=\alpha s_{i j} s_{i k}$.

${ }^{7} \mathrm{~A}$ common way this assumption is justified is by saying that the retailer sets a mark-up $(m)$ over the wholesale price he receives. Therefore, $p=m+w$, so $\frac{\partial p}{\partial w}=1$.
} 
assumes that pass-through rates are between 0 and 1 (or between 0 and -1 if referring to cross brand pass-throughs) and are inversely proportional to market share.

I evaluate the pass-through rate using the implicit function theorem and the retailer's profit maximizing first-order condition. Defining the retailer's first order condition as $F=0$, the pass-through rate can be calculated:

$$
\frac{\partial p_{j}}{\partial w_{k}}=-\frac{\partial F}{\partial w_{k}} / \frac{\partial F}{\partial p_{j}}
$$

This has the property that own brand pass-through rates are between 0 and 1 , cross brand pass-through rates are between 0 and -1 , and both are inversely related to market share. I believe this pass-through rate specification most accurately represents real price-setting decisions and allows the pass-through to depend on the relative price level (rather than an absolute 1).

Recall that the manufacturer pays an allowance only when its brand has been chosen for display by the retailer. To determine the optimal slotting allowance to offer, each manufacturer maximizes its expected profit $\left(E \Pi_{j}^{m}\right)$ where:

$$
\begin{aligned}
E \Pi_{j}^{m} & =\operatorname{Pr}(D=j) * \Pi_{j \mid D=j}^{m}+\sum_{k \neq j} \operatorname{Pr}(D=k) * \Pi_{j \mid D=k}^{m} \\
& =\phi_{j}\left(w_{j}^{j} Q_{j \mid D=j}-A_{j}\right)+\sum_{k \neq j} \phi_{k} w_{j}^{k} Q_{j \mid D=k}
\end{aligned}
$$

The optimal allowance offer is the solution to the first order condition:

$$
\frac{\partial E \Pi_{j}^{m}}{\partial A_{j}}=\left(w_{j}^{j} Q_{j \mid D=j}-A_{j}\right) \frac{\partial \phi_{j}}{\partial A_{j}}-\phi_{j}+\sum_{k \neq j} w_{j}^{k} Q_{j \mid D=k} \frac{\partial \phi_{k}}{\partial A_{j}}=0
$$


Notice that the chosen slotting allowance offer not only affects manufacturer profit, conditional upon having its brand chosen for display, but also affects the probability that a given brand is chosen for display.

The vector of first order conditions generated by the retail and manufacturers characterize the equilibrium. 


\section{Chapter 7}

\section{The Market for Ketchup}

I have, thus far, kept the model general, so it might be applied to different products or industries. To conduct the empirical examination, however, it is necessary to choose a particular product or category. This paper estimates a structural model using data from the ketchup industry.

Ketchup has its origins in Indonesia and China. "Ketsiap," as it was called, was actually a salty, pickled fish sauce containing no tomatoes. ${ }^{1}$ In the 1600 s, British and Dutch seamen brought the Asian sauce back to Europe with them. Many variations evolved over the years until the late 1700s when tomatoes were added to the recipe. While there have, historically, been many smaller-scale bottlers of ketchup, the first manufacturer to make and bottle ketchup on a large scale was Henry J. Heinz. Heinz began making ketchup in Pittsburgh, Pennsylvania in 1876.

Ketchup is a fairly homogeneous product. Though there are over twenty brands of ketchup currently produced in the U.S., most brands use only slightly different formulas or ingredients. The market is dominated by three national brands: Heinz, Del Monte, and

\footnotetext{
${ }^{1}$ The historical information on ketchup was obtained from two sources: http://www.verybestbaking.com and http://www.globalgourmet.com/food/sleuth.
} 
Hunts. Heinz is the clear industry leader with approximately a 55 percent market share. The combined market share of Heinz, Hunts, and Del Monte is roughly 82 percent. $^{2}$ In 1992, the final year in my data set, ketchup sales in the U.S. were $\$ 723$ million.

There are several aspects of the ketchup market that make it attractive for this empirical study. First of all, with Heinz being a clear market leader in many markets, one would expect there to be rivalry between the remaining firms, competing for the residual consumers. It is commonly believed that powerful market leaders are often exempt from allowances and, instead, it is the second and third place brands that, ultimately, end up paying or offering the highest amounts. By estimating allowance offers, the model allows me to empirically evaluate this belief. The display probabilities will also show whether it is the market leader receiving the premium space most often or one of the rivals.

According to industry reports, annual sales in the ketchup industry are generally flat, neither growing nor decreasing noticeably from year to year. In fact, Figure C.3 shows that ketchup sales (in units) are actually declining over my sample period. As Sullivan argued, slow sales growth, in part, may contribute to the emergence of slotting allowances. This makes "business-stealing" very important for manufacturers and also makes ketchup a prime candidate to lose shelf space to a more profitable category, if a retailer decides to reallocate space.

\footnotetext{
${ }^{2}$ This figure does not include the "Private Label" brand. Chapter 8 contains more information about the combined market share of these three brands.
} 


\section{Chapter 8}

\section{Data}

To estimate the model presented in this research study, data on a number of different elements are necessary. In general, the data can be divided into several broad categories: brand unit sales in each market, brand market shares, prices for each market, the percentage of a brand's units sold through merchandising efforts in each market, brand characteristics, and demographic information. ${ }^{1}$

\subsection{Sales Data}

The variables unit sales, prices, and the percentage of units sold with merchandising (PUAM) were obtained from the Food Marketing Policy Center's IRI Infoscan Data Base. ${ }^{2}$ Founded in 1979, IRI is a sales and marketing research firm that uses supermarket checkout "scanners" to collect sales data in a national random sample of supermarkets. These supermarkets are located throughout the U.S. The IRI data used in this research ranges from the first quarter of 1988 to the fourth quarter of 1992 (20 total quarters) and includes 40 metropolitan areas. The full dataset, therefore, covers 800 markets. A list of

\footnotetext{
${ }^{1}$ I adopt the notation of Nevo (2001) and define a market as a city-quarter combination.

${ }^{2} \mathrm{My}$ thanks to Dr. Ronald Cotterill, director of the Food Marketing Center at the University of Connecticut, for making the data available.
} 
the included metropolitan areas appears in Table C.6. It is important to note that the IRI data are reported at the aggregate level for each market. This means two things: that all Heinz ketchup bottles sold, regardless of size, are recorded as one brand and that there is no distinction (in the data) between different retailers. ${ }^{3}$ Unit sales, then, refer to the number of items, for a particular brand, scanned at the grocery store checkout. Because of variation in bottle size and, therefore, price, the price reported by IRI represents an average price per unit, which is calculated as a brand's total dollar sales divided by the total unit sales. The final IRI variable, the percentage of units sold with merchandising, is necessary because information on allowance spending is closely guarded by firms. According to IRI's description, this measure represents the percentage of a brand's sales directly attributable to merchandising/display efforts at the retail level. For the purposes of this research, I assume that sales attributed to "any merchandising" can be thought of as sales resulting from being the retailer's featured brand. Therefore, the number of units sold due to any merchandising effort is assumed to equal the number of units sold while the product is the retailer's featured brand. Information about the use of this variable appears in Chapter 11. Summary statistics for the three IRI variables appear in Table C.8.

The model is estimated using the four top selling brands of ketchup: Heinz, Hunts, Del Monte, and retailers' Private Label. The first three are national brands, while the fourth typically refers to a lower-priced brand that displays the name of the supermarket on its label. Private Label brands can be thought of as vertically integrated brands in which the supermarket is not only the retailer, but also the manufacturer. ${ }^{4}$ As such, I assume

\footnotetext{
${ }^{3}$ Cohen (2001) has shown that manufacturers may use product size as a way to price discriminate between consumers, based on storage or transportation costs. The aggregate level data in this research, however, does not allow me to account for this possibility.

${ }^{4}$ Technically, the private label brand may be produced by an independent manufacturer, but strategically,
} 
that the Private Label brand pays no wholesale price or slotting allowance. The retailer, therefore, receives no slotting allowance payment if the Private Label brand is selected for display. The remaining brands of ketchup are omitted. As Table C.7 shows, Heinz, Hunts, Del Monte, and Private label, combined, have a national market share of roughly 98 percent. Looking at combined regional market shares (for Northeast, South, Midwest, and West), the four top brands have market shares between 94 percent and 99 percent.

Observable product characteristics for ketchup are readily available and have not changed in any significant way since the sample period. Observable product characteristics that we might initially be interested in are quality measures such as calories and sodium per serving. Due the high level of homogeneity in ketchup, however, there is virtually no variation in product characteristics across brands. ${ }^{5}$ This makes identification of the consumers' taste for sodium or calories, for example, impossible. As stated in Chapter 6, brand dummies will be the only product characteristics used in this study.

\subsection{Demographic Data}

Data on demographic distributions were obtained through the Census Bureau's Current Population Survey (CPS). The CPS, which comes in a short monthly version and a more extensive annual version, has been used by the Census Bureau since the late 1940's to collect data on the U.S. labor force. The CPS sample selection process is designed to ensure accurate representation across metropolitan areas and participation in the survey is completely voluntary. Survey respondents are asked to provide personal information on a number of measures, including age, educational attainment, family size, employment status,

it behaves like a subsidiary of the retailer.

${ }^{5}$ Several product characteristics are presented in Table C.9 to illustrate the homogeneity. 
housing situation, and occupation (as well as many others).

In this study, I use CPS demographic information on two variables: a household's total income and the number of children in the household under the age of $18 .^{6}$ The household income level should be an important factor in determining consumer price sensitivity. Because of the products ketchup is commonly used with "fun food" (hot dogs, hamburgers, french fries), we might imagine that a household's demand for ketchup depends, in part, on the number of children present in the household. A thorough discussion of how demographic data is used in calculating brand choice probabilities appears in an appendix.

\footnotetext{
${ }^{6}$ Ideally, I would like to include more than two demographic characteristics. Unfortunately, because of the high computation time involved in estimating my model, I restrict the number of demographic characteristics included.
} 


\section{Chapter 9}

\section{Preliminary Data Analysis}

Before estimating the structural model, I perform a number of logit regressions in order to identify relationships present within the data. To accomplish this, I begin with a simple logit model of brand choice. Using my aggregate data, I express the market share of brand $j$ in market $m, s_{j m}$, as:

$$
s_{j m}=\frac{\exp \left(x_{j} \beta\right)}{1+\sum_{k} \exp \left(x_{k} \beta\right)}
$$

where $x_{j}$ is a $1 \times K$ vector of attributes for product $j$ (including a constant term). Making an assumption about the size of the potential market allows for use of the following simplifying transformation:

$$
\ln \left(s_{j m}\right)-\ln \left(s_{0 m}\right)=\exp \left(x_{j} \beta\right)
$$

where $s_{0 m}$ represents the market share of the outside good (no purchase). The regression results for various specifications of $x$ appear in Table C.10.

The first specification uses only price as an explanatory variable. Interestingly, the coefficient on price is positive. This counter-intuitive result is likely driven by the fact 
that Heinz, the brand with the largest market share, also charges the highest average price. This leads to the illusion that demand is upward sloping.

In the second specification, I introduce brand-specific dummy variables, in addition to price. The coefficients take on the expected signs. Coefficients on the brand dummies should be interpreted relative to Del Monte. The coefficients all have the anticipated sign and magnitude, with Heinz being the "best" of the brands.

In the third specification, I include the percentage of units sold with merchandising (PUAM) variable. This measure is included to serve as a rudimentary proxy for shelf space. We might imagine that brands selling a high percentage of their goods with merchandising support are more likely to be chosen for display. The coefficient on PUAM is positive and significant.

In the final specification, I include a seasonal dummy variable (Summer) to test for the possibility that warm weather will lead to greater demand for ketchup (due to an increase in picnics and grilling). All of the estimates display the predicted sign, with the exception of the summer season variable, which is negative.

The preliminary analysis gives some insight and predictions that may be examined with the full structural model, but also illustrates the need for a more rigorous structural approach. The results indicate that brand dummies and space (as measured through PUAM) are significant explanatory variables. This seems promising. There are a number of problems, however, in addition to the IIA problem. The simple logit introduced above also does not account for the endogeneity of price. Parameter estimates may, therefore, be biased. Nor does it allow us to estimate wholesale prices or slotting allowances. Perhaps most im- 
portantly, counterfactual policy exercises are not possible without more explicitly modeling the behavior of all agents in the model. 


\section{Chapter 10}

\section{Estimation}

The parameters of the model are estimated by method of moments (MoM). For notational convenience, let me define the vector of parameters to be estimated as: $\theta=$ $\{\alpha, \beta, \Delta, \Pi\}$. The algorithm used to estimate the parameters of the model is as follows:

1. Begin by choosing initial starting values for the parameters in $\theta$.

2. For these parameter values, compute the implied market shares as a function of price for each brand and each display choice: $s_{j \mid D=k}=s_{j \mid D=k}\left(p_{j}^{k}, p_{-j}^{k}\right){ }^{1}$

3. Numerically solve both the retailer and manufacturer first order conditions to determine the profit-maximizing conditional wholesale and retail prices for each possible display choice.

4. Calculate the implied (conditional) sales for each brand under each possible display choice $\left(Q_{j \mid D=k}=M s_{j \mid D=k}^{*}\right)$.

5. Using the price-quantity pairs, calculate the variable portion of retailer profit $\left(\pi_{j}\right)$ and each manufacturer's sales revenue.

\footnotetext{
${ }^{1}$ The simulation technique employed to evaluate this integral is similar to Nevo (2001) in that I will, for each city, sample a number of individuals from the CPS. Details on this sampling technique appear in an appendix.
} 
6. Calculate the estimated slotting allowance offers $(A)$ by maximizing each manufacturer's expected profit.

7. Compute the unconditional display probabilities $(\phi)$, where computation of this $(J-1)$ dimensional integral is simplified by assuming that the $e$ 's are distributed type II extreme value, which allows for expressing the probabilities in multinomial logit form:

$$
\phi_{j r}=\frac{\exp \left\{\pi_{r \mid D=j}+A_{j}\right\}}{\sum_{k} \exp \left\{\pi_{r \mid D=k}+A_{k}\right\}}
$$

8. In this step, use the results from steps 4 and 7 to derive expected values for the expected average per unit price, the expected brand market share, and the expected percentage of units sold with merchandising (PUAM), where:

$$
\begin{aligned}
E\left(\widehat{p}_{j}\right) & =\int_{e}\left(p_{j} \mid D\right)\left(\frac{Q_{j} \mid D}{\text { Total }_{j}}\right) \operatorname{Pr}(D=d \mid e) d F(e) \\
E\left(\widehat{S}_{j}\right) & =\frac{\int_{e}\left(Q_{j} \mid D\right) \operatorname{Pr}(D=d \mid e) d F(e)}{\sum_{k} \int_{e}\left(Q_{k} \mid D\right) \operatorname{Pr}(D=d \mid e) d F(e)} \\
E\left(\widehat{P U A} M_{j}\right) & =\frac{E\left(Q_{j} \mid D=j\right)}{\int_{e}\left(Q_{j} \mid D\right) \operatorname{Pr}(D=d \mid e) d F(e)}
\end{aligned}
$$

9. Calculate the residual $\omega$, where

$$
\omega=\left[\begin{array}{c}
\widehat{p}-p_{I R I} \\
\widehat{S}-S_{I R I} \\
\widehat{P A A} M-P U A M_{I R I}
\end{array}\right]
$$


10. Search for the parameter values that minimize the objective function $\omega^{\prime} W \omega$, where $\omega$ is an $(800 \times 3 \times 4) \times 1$ vector of residuals and $W$ is an $(800 \times 3 \times 4) \times(800 \times 3 \times 4)$ weighting matrix. For the first iteration of the objective function, $W$ will be an identity matrix. For each iteration thereafter, the weighting matrix is updated using the covariance matrix. 


\section{Chapter 11}

\section{Results}

\subsection{Parameter Estimates}

Coefficients for price and the brand dummies appear in Table C.11. For each

brand $j$, the two coefficients reported represent the brand-effect when on display $\left(\beta_{j}^{j}\right)$ and the brand-effect when a rival is on display $\left(\beta_{j}^{0}\right)$. I refer to the difference between the estimated coefficients as the brand's "quality boost." These quality boosts are positive for Heinz, Hunts, and Del Monte, indicating that consumers, on average, tend to have a better perception of these brands when they appear on display. Del Monte receives the most substantial boost from premium shelf space, whereas the perception of Heinz varies little depending on Heinz's shelf space allocation. As the market leader for a considerable number of years, it may be that public awareness of Heinz is so great that Heinz receives very little benefit from improved shelf space.

Figure C.5 illustrates this fact by comparing two demand curves for Heinz ketchup. The solid line represents the demand for Heinz when it has premium shelf space, while the dashed line represents the demand for Heinz when another brand has received the premium shelf space. The latter demand curve, as we would anticipate, lies below the demand curve 
Heinz faces when receiving premium shelf space. The difference between the two, however, is small. The maximum horizontal difference between the curves (i.e. the difference in shares for a given price level) is approximately 0.02. This implies that, at most, the premium shelf space will increase Heinz's market share by 2 percent.

The coefficient on price $(\alpha)$ is statistically significant and the predicted sign. Figure C.6 shows the distribution of individual price coefficients for each of the individuals "sampled" from the CPS. ${ }^{1}$ The distribution appears to be a normal distribution. Notice that some of the coefficients are positive, indicating that the individual's utility actually increases with price. While we may be able to think of products for which this seems reasonable, it does not seem to be appropriate in the case of ketchup. Fortunately, only 3.76 percent of the individuals have positive price coefficients. ${ }^{2}$

Own- and cross-price elasticities are reported in Table C.13. Upon examining the elasticities, two things stand out. First, the own-price elasticities of Hunts, Del Monte, and Private Label are at least twice as large as the own-price elasticity of Heinz. While it is not surprising that Heinz is the least price sensitive brand of ketchup, the magnitude of the difference between Heinz and the others is larger than expected. The second noticeable result is that, in comparing cross-price elasticities, changes in the price of Heinz has the largest effect on sales of Hunts, Del Monte, and Private Label any brand. The first column in Table C.13 illustrates this point. While this result may not be surprising, the magnitude is, once again, larger than anticipated.

In Table C.14, estimated wholesale prices are presented. The reported wholesale

\footnotetext{
${ }^{1}$ In total, characteristics for 10,000 individuals were included.

${ }^{2}$ For comparison, in Nevo (1997) as much as 13 percent of the individual price coefficients are positive, while in Nevo (2001) only 0.7 percent are positive.
} 
prices are averaged over all markets and all display configurations. As the brand with the largest market share and the highest average retail price, it is not surprising to see that Heinz charges the highest wholesale price, followed by Hunts, and, finally, Del Monte. Average retail mark-ups (percentage) are also presented in Table C.14. The mark-ups for Heinz (40.2 percent) and Hunts (35.5 percent) are of similar magnitude, while the mark-up for Del Monte is considerably higher (54.3 percent). A more thorough discussion of ketchup mark-ups appears below.

Table C.15 shows average conditional wholesale prices for the sample. These prices represent the average estimated wholesale prices for each brand under each of the four possible display choices. Both Heinz and Del Monte charge their highest wholesale prices when their respective brand is in premium space. This finding provides support to the theoretical prediction that the higher a brand's quality, the larger the wholesale price charged. The exception is Hunts, which has a higher wholesale price when the Heinz brand is chosen for the premium shelf space.

Display probabilities $(\phi)$ are shown in Table C.16. Overall, Del Monte has the highest probability of being chosen for display in each of the markets. The largest average display probability is approximately 35 percent (Del Monte) and the smallest is around 7 percent (Private Label). Comparing the maximum and minimum display probabilities, Del Monte appears to receive the premium shelf space most often. While it may seem more intuitive to expect Heinz (as market leader) to receive the premium shelf space most often, the "quality boost" each brand receives may help to explain this result. Recall that Del Monte receives the largest quality boost, while Heinz receives only a small boost. All things 
being equal, it may be more attractive to place Del Monte in the premium position (over Heinz) because their perceived quality increases significantly more than Heinz's perceived quality decreases.

Slotting allowance estimates, expressed as a percentage of the retailer's conditional profit, are presented in Table C.17. According to the model, all of the brands are willing to offer slotting allowances at least a portion of the time. ${ }^{3}$ The average allowance payments are not very large, ranging from 0.6 percent (Hunts) to 1.3 percent (Heinz). ${ }^{4}$ Given that Heinz is the market leader (and has the largest estimated brand coefficients), it should not be surprising that Heinz is able to make the largest allowance payments.

The bottom row of Table C.17 shows the percentage of markets in which each brand is willing to offer a slotting allowance payment. Heinz and Del Monte each offer allowances in approximately 17 or 18 percent of retail outlets. Hunts, on the other hand, offers allowances in roughly 42 percent of the retail outlets. Based on my prior beliefs, I expected these numbers to be higher. Unfortunately, at this time, I do not have any reliable information about how often these brands pay allowances, so it is difficult to determine how accurate the model's predictions are.

\subsection{Perception Maps}

The use of perceptual maps or brand maps has become commonplace in the marketing literature. ${ }^{5}$ The basic idea behind the technique is that every brand has a number

\footnotetext{
${ }^{3}$ Recall that the Private Label brand does not pay slotting allowances. It is, therefore, omitted from the discussion.

${ }^{4}$ Even though, as a percentage, these numbers are quite small, retailer profit is quite high, making the amounts of these payments non-trivial.

${ }^{5} \mathrm{My}$ thanks to Jean-Pierre Dube for helping me understand the technique.
} 
of latent attributes for which consumers have tastes and preferences. For feasibility, it is usually assumed that each brand has two latent attributes. The perception map, then, is a two-dimensional representation of each brand's latent attributes. ${ }^{6}$ A brand's position on the perception map is independent from its price. The location of a brand depends solely on its characteristics. When each brand is plotted on the same set of axes, a brand's proximity to the other brands represents how closely consumers view these two brands. The closer two brands are plotted, the more similar these brands are perceived. The further apart, the more dissimilar these brands are perceived.

While the perception map allows one to compare how consumers view different brands, it is important to note that a brand's location in two-dimensional space cannot be used to categorize that brand as being "better" or "worse" than another brand. For example, consider the case of refrigerated orange juice. It is likely that consumers view Minute Maid orange juice with pulp as a closer substitute to Tropicana orange juice with pulp than a third brand that is pulp-free. This is what the perception map shows. It does not indicate that orange juice with pulp is more attractive or "better" than pulp-free orange juice. $^{7}$

Figure C.7 shows the perceptual map for Heinz, Hunts, Del Monte, and Private Label when none of the brands has premium shelf space. This plot represents how consumers view the four brands, disregarding any benefit for better shelf space. Del Monte and Private Label are grouped together closely in the upper right-hand corner, while Hunts and Heinz are positioned in the lower left-hand corner. Though not paired quite so closely together,

\footnotetext{
${ }^{6}$ From a technical standpoint, one recovers these latent attributes by performing a Cholesky decomposition of the covariance matrix of the brand dummies. For a more thorough description of this technique, please see Elrod (1988), Elrod and Keane (1995), or Chintagunta, Dube, and Singh (2003).

${ }^{7}$ That would depend on individual preferences.
} 
the distance between Heinz and Hunts indicates that these two brands are seen as being relatively similar. The close placement of Del Monte and the Private Label brand indicates that consumers view these two products as being very similar, as well. An implication of this is that the "premium" brands are perceived differently than the low-cost brands.

Figures C.8 and C.9 illustrate how premium shelf space may alter the consumer perceptions shown in Figure C.7. Figure C.8 plots the case where Hunts is in the premium/display position. As one can see, this "moves" Hunts closer to Heinz in the consumer's eyes. The two brands are, now, seen as being almost identical. Consider yet another case, depicted in Figure C.9. Here, Del Monte receives the premium shelf space. Once again, the more favorable shelf space allocation changes the way consumers perceive the brand. As in the previous situation, the premium shelf space allows Del Monte to "move" closer to Heinz. It appears that Heinz, Hunts, and Del Monte are now similar to each other, with the Private Label brand a considerable distance away. These graphs provide helpful intuition into the benefits of premium shelf space.

\subsection{Comparing Accounting Regression Results with Struc- tural Model Estimates}

The logit and tobit models presented in Chapter 4 generate predictions regarding (a) which firms would be willing to offer promotional allowances most often and (b) which firms would offer the largest promotional allowances payments. Using the results for Heinz and Hunts as the basis for discussion, I now compare the results from the full structural model with the results of the logit and tobit regressions. While favorable comparisons

between the two models cannot "prove" that the structural model is properly specified, 
similarities can, at the very least, provide some anecdotal support for the performance of the structural model.

\subsubsection{Market Share and the Probability of Offering Allowances}

As illustrated in Chapter 4, the logit regressions indicate that a firm's market share is inversely related to the percentage of the time the firm offers allowances. From the structural model estimates note that Heinz offers slotting allowances $18.3 \%$ of the time, while Hunts offers slotting allowance payments $41.6 \%$ of the time. Nationally, Heinz has roughly a $55 \%$ market share, while Hunts' market share is only $18 \%$. It appears that the inverse relation between market share and probability of offering allowances is supported by evidence from the structural model.

\subsubsection{Gross Margin and Allowance Payment Values}

According to the cross-industry study on how firm characteristics are related to the value of promotional payments, a firm with a higher gross margin will make higher promotional payments (holding all else constant). The results from the structural model support this finding if we link margin with mark-up. Heinz has an estimated mark-up of around 40\%, while Hunts has an estimated mark-up around 35\%. According to the structural estimates, Heinz offers an average slotting allowance payment that is $1.3 \%$ of retail profit (with a maximum of $10.2 \%$ ). In contrast, Hunts offers an average slotting allowance payment valued at $0.6 \%$ of retail profit (with a maximum of $3.7 \%$ ). Heinz has the larger mark-up and makes the larger payments, on average. 


\subsubsection{Market Share and Allowance Payment Values}

Similar to the relationship found between gross margin and allowance payments, the tobit regressions indicate a positive relation between a firm's market share (SHARE2) and the firm's promotional payments. As shown in preceding section, Heinz has a larger market share than Hunts, on average. In addition, Heinz makes larger average slotting allowance payments, according to the results implied by the structural model.

\subsubsection{Herfindahl Indices and the Probability of Offering Allowances}

Because the structural model focuses only on one industry, it is difficult to compare the results from the logit model with the results from the structural model. However, while one result may not directly prove the other, it does seem that the results are generally consistent with each other. Recall that the sign on the Herfindahl coefficient was negative in Chapter 4's logit regressions, indicating that firms in highly concentrated industries (firms

with high Herfindahl Index values) are less likely to make promotional payments. Using national average market shares, the Herfindahl for ketchup is around 3500. If you look at the percentage of the time each firm offers a slotting allowance, the range is from around $17 \%$ (for Heinz and Del Monte) to around $41 \%$ (for Hunts), which indicates that the firms in this industry do not pay slotting allowances an exorbitant amount of the time.

As I said, it is difficult to draw many strong conclusions because I only have structural estimates for one industry, but it seems that ketchup firms many not be paying allowances as often as firms in other industries (less concentrated industries, perhaps). 


\subsubsection{Contradictory or Ambiguous Results}

While the four cases presented above represent instances where it appears that the structural model estimates support the results obtained using accounting data (and vice versa), there are a number of cases where the results are more contradictory. For example, using the accounting data, the logit model predicts that the firm with the largest margin would also pay allowances more often, which does not seem to be the case for the ketchup manufacturers.

One possible explanation for the inconsistency is that the accounting data on promotional payments encompass more than just slotting allowances. The category "promotional payments" might include additional strategies or payments that make comparison more difficult.

A second possible explanation is that the ketchup category may not be a representative category for comparison. Ideally, it would be best to use data on a number of different categories and then compare the results for all of those categories with the results from the accounting regressions. It might be the case that it is not true that ketchup manufacturers with higher margins offer higher allowance payments, even though that is true for manufacturers on average.

A third, but not necessarily final, explanation is that the accounting models perform poorly, so that the models' predictions are not entirely reliable. Given that the $R^{2}$ for the accounting regressions falls below $37 \%$ for all specifications, the models' predictions may not be very strong. 


\section{Chapter 12}

\section{Testing and Counterfactual Experiment}

In this chapter, I conduct several tests aimed at evaluating the performance of the empirical model. I also perform a counterfactual experiment to determine what happens to average prices and display probabilities when slotting allowances are no longer permitted.

\subsection{Goodness of Fit}

It is useful to examine some tests which allow the performance of the structural model to be evaluated.

\subsubsection{Chi-square Tests}

First, I conduct a traditional chi-square test to see how well the model's predictions compare with what is observed in the data. I examine (separately) how well the model predicts each brand's prices and also the percentage of units sold with merchandising (PUAM) for each brand. In both cases, the null hypothesis tested is that the model's prediction equals reality. The results of these two tests, unfortunately, are mixed. With a test statistic of approximately 0.35 , I am unable to reject the hypothesis that the model's predicted 
prices are equal to the observed prices. On the other hand, the hypothesis that the model's predicted percentages of units sold with merchandising are equal to the observed values is rejected. Upon closer examination, it appears that model generally understates how many units each brand sells with merchandising (i.e. $\widehat{P U A} M<P U A M_{\text {observed }}$ ). If the benefit of premium shelf space is being undervalued, that may provide some explanation as to (a) why the estimated slotting allowance payments are not particularly high and (b) why firms may not be willing to offering slotting allowances all the time.

\subsubsection{Predicting Mark-Ups}

The second test I present is more of a qualitative test. Thanks to work by Besanko, Dube, and Gupta (2002), we have some information regarding the size of mark-ups on ketchup. Using confidential supermarket data, the authors calculate the average percentage retail mark-up on ketchup to be around 34.5 percent. This number is close to the percentage retail mark-up implied their model (39.5 percent). Recall the average predicted mark-ups presented in Table C.14. For Heinz and Hunts, the predicted mark-ups are 40.2 percent and 35.5 percent, respectively. These numbers are close to the mark-ups observed in the data, as well the mark-ups implied by Besanko, Dube, and Gupta's model. The predicted mark-up for Del Monte is higher than the average observed mark-up, however.

Recall that, according to Desiraju's model, retail mark-ups should be negatively correlated with slotting allowance payments. The empirical results above provide mixed support for this prediction. Compared to Hunts, Heinz has both a higher estimated markup and a higher average slotting allowance payment. On the other hand, Del Monte has a higher estimated mark-up than Heinz, but a lower average slotting allowance payment. 


\subsection{Counterfactual and Welfare Analysis}

Whether slotting allowances lead to higher prices is one of the most widely asked questions in the literature. To provide some insight into this question, I use the parameter estimates to conduct a counterfactual experiment. Specifically, firms will no longer be permitted to offer slotting allowances in order to obtain the shelf space. Slotting allowances are set to zero and the retailer chooses a brand for the premium shelf space based solely on the conditional sales profit. Manufacturers must strategically set their wholesale prices in order to maximize their expected profit. I assume that each manufacturer now chooses two conditional wholesale prices: one wholesale price when they receive the premium shelf space and another price for when another brand has been chosen for the premium shelf space.

The optimal wholesale prices are determined by maximizing the manufacturer's expected profit. With no allowances, manufacturer $j$ 's two first order conditions can be written:

$$
\begin{gathered}
\frac{\partial E \Pi_{j}^{m}}{\partial w_{j}^{j}}=\phi_{j}\left(Q_{j \mid D=j}+w_{j}^{j} \frac{\partial Q_{j \mid D=j}}{\partial w_{j}^{j}}\right)+\left(w_{j}^{j} Q_{j \mid D=j}\right) \frac{\partial \phi_{j}}{\partial w_{j}^{j}}+\sum_{k \neq j} w_{j}^{0} Q_{j \mid D=k} \frac{\partial \phi_{k}}{\partial w_{j}^{j}}=0 \\
\frac{\partial E \Pi_{j}^{m}}{\partial w_{j}^{0}}=\left(w_{j}^{j} Q_{j \mid D=j}\right) \frac{\partial \phi_{j}}{\partial w_{j}^{0}}+\sum_{k \neq j}\left[\phi_{k}\left(Q_{j \mid D=k}+w_{j}^{0} \frac{\partial Q_{j \mid D=k}}{\partial w_{j}^{0}}\right)+\left(w_{j}^{0} Q_{j \mid D=k}\right) \frac{\partial \phi_{k}}{\partial w_{j}^{0}}\right]=0
\end{gathered}
$$

Note that, because the retailer takes the manufacturers' wholesale prices as given when setting retail prices, the retailer's first order conditions remain the same as those presented in Section 6.2.1. Any change in the retail price, then, is driven through changes in the wholesale prices. 
Several comments should be noted here. First of all, the game (as presented in Chapter 5) has changed slightly. Under the previous specification, each manufacturer set a wholesale price that was conditional upon the identity of the manufacturer receiving the premium shelf space. In the counterfactual, however, each manufacturer sets only two prices. The main rationale behind this differentiation is that, once allowances are eliminated, the primary instrument that the manufacturers may use in order to secure the premium shelf space is price. I, therefore, allow the firms to depart from the previously-used subgame approach by having them maximize expected profit. Notice that if I continued to model the price-setting behavior using conditional wholesale prices, then the counterfactual would predict no change in either the conditional wholesale or conditional retail prices. Any differences in the average retail prices I compute, then, would be due solely to changes in the retailer's display probabilities.

The second comment is in regards to the existence of an equilibrium in wholesale prices. There is some concern that price-setting may be susceptible to an Edgeworth cycle. The logic is as follows: suppose that there are two manufacturers $(A, B)$ bidding for shelf space. If manufacturer $A$ were to decrease its price, it might be manufacturer $B$ 's best response to lower its price, as well. ${ }^{1}$ At certain wholesale prices, however, this may no longer be true. It is possible that, for a low enough wholesale price from manufacturer $A$, manufacturer $B$ 's best response would be to raise its price and forgo competing for the premium shelf space, receiving (with certainty) the non-premium space. In other words, the marginal benefit of having the premium shelf space is decreasing in a firm's wholesale

\footnotetext{
${ }^{1}$ This is because, all else constant, the retailer would prefer to select the product with the lowest wholesale price.
} 
price. Manufacturer $A$ 's best response to $B$ 's increased wholesale price would be to raise its own price, in turn. The (potential) result is a cycle of bid down prices, followed by jumps when the price falls below some threshold level.

To determine the likelihood of this problem occurring in my case, I plot a graph of Heinz's expected profit as a function of their two wholesale prices. This plot appears in Figure C.10. Notice that the expected profit function, while somewhat jagged at points, is relatively well-behaved. The expected profit surface is plotted as a function of wholesale price values between $\$ 0.00$ and $\$ 5.00$. For computation reasons, the "jump" between each possible wholesale price is set at $\$ 0.02 .^{2}$ The lesson from this graph is that when solving for the equilibrium prices in the counterfactual exercise, it is important to make steps to verify that I am not at one of the local minimums. To help give confidence in my wholesale pricing results, I solve the system of first order conditions using four separate starting values. In addition, I verify that the second derivative is the appropriate sign.

The results of the counterfactual exercise appear in Tables C.18 through C.21. As Table C.18 shows, mean expected retail prices are slightly higher for Heinz and Hunts when slotting allowances are forbidden. On the other hand, the mean expected retail prices are lower for Del Monte and Private Label when slotting allowances are no longer available. On a market-by-market basis, the average price of Heinz (Hunts) rises in roughly 63 (77) percent of the markets when allowances are prohibited. The average price of Del Monte (Private Label) falls in about 60 (56) percent of the markets. In this counterfactual it appears that the price of the more expensive brands rise and the price of the more inexpensive brands fall.

\footnotetext{
${ }^{2}$ Note that decreasing the "jump" increases the smoothness of the expected profit function. This does come with significant time drawbacks, however.
} 
The distribution of prices, then, becomes more disperse. Counterfactual wholesale prices appear in Table C.19. On average, the wholesale price for Heinz is slightly higher, while the wholesale prices for Hunts and Del Monte are lower. This result is, presumably, due to the effect that slotting allowance payments may have had on the competition for premium shelf space. Being the clear market leader, it seems likely that Heinz actually faces less competition for the premium shelf space when rival firms are prohibited from using lump sum transfer payments to bid for the space. Because Heinz is more likely to obtain the premium shelf space, we observe higher wholesale prices for their brand, on average.

The new display probabilities appear in Table C.20. Relative to the state where slotting allowances are permitted, the average display probabilities for each of the brands (except Del Monte) rise in the counterfactual experiment. This drives the results presented in Table C.18 and C.19. Without slotting allowances, it is less likely that Del Monte will obtain the premium shelf space. Since Heinz and Hunts, on average, now face higher ("ondisplay") demand curves, it makes intuitive sense that they will also, on average, collect a higher retail price. The intuition is the opposite for Del Monte. The Private Label brand, recall, has a negative "quality boost" so it is actually viewed more favorably when it is not in the premium position (i.e. $\beta_{j}^{j}<\beta_{j}^{0}$ for Private Label). Since their display probability has risen, as well, it implies that they will face their higher demand curve less often. The result is a lower predicted average price.

To help quantify the effect of eliminating slotting allowances, I calculate the change in consumer welfare associated with its elimination. To evaluate the change in consumer welfare, I rely on consumer surplus. I measure the amount of money consumers would need 
to be given (under the conditions of the counterfactual) in order to maintain their initial level of utility. Consumer $i$ 's change in welfare, therefore, can be express:

$$
C S_{i}=\sum_{k=1}^{4} \phi_{k}^{\text {noslot }}\left[\log \left(\sum_{j=0}^{J} \exp \left(V_{i j \mid D=k}^{\text {noslot }}\right)\right)\right]-\sum_{k=1}^{4} \phi_{k}^{\text {slot }}\left[\log \left(\sum_{j=0}^{J} \exp \left(V_{i j \mid D=k}^{\text {slot }}\right)\right)\right]
$$

where $\phi_{k}^{\text {noslot }}\left(\phi_{k}^{\text {slot }}\right)$ is the display probability of brand $k$ when slotting allowances are prohibited (allowed), and $V_{i j \mid D=k}^{\text {noslot }}\left(V_{i j \mid D=k}^{\text {slot }}\right)$ is consumer $i$ 's expected utility from consuming brand $j$ when brand $k$ has the premium shelf space and slotting allowances are prohibited (allowed). Using these definitions, the above equation may be interpreted as the average expected maximized utility under the counterfactual minus the average expected maximized utility with slotting allowances. This value represents, in dollars, how much better or worse off an individual consumer is because of slotting allowances. ${ }^{3}$

As Table C.21 shows, consumer surplus is improved because of slotting allowances. On average, each consumer gains approximately $\$ 0.0006$ in welfare annually, due to slotting allowances. ${ }^{4}$ This aggregates to an annual increase in welfare of approximately $\$ 80,400$ for the metropolitan areas included in this sample. In other words, nationally, consumers would be willing to pay roughly $\$ 80,000$ in exchange for an agreement not to ban slotting allowances. On an individual level, only 30 percent of consumers would be better off without slotting allowances. Most consumers prefer Heinz and Hunts and, without slotting allowances, the prices of these two brands are higher, thereby making these consumers worse off.

\footnotetext{
${ }^{3}$ By excluding income from an individual's indirect utility function, I am inherently assuming that the marginal utility of income is equal to 1 .

${ }^{4}$ Alternatively, this factors out to be roughly $\$ 0.15$ each quarter.
} 
Two comments are worth noting here. First, the figures above refer only to the ketchup industry. It is difficult to generalize on the overall impact of slotting allowances, however, because there is likely to be a great deal of variation across industries.

Secondly, the numbers above reflect only the change in consumer welfare. When thinking about total welfare, one must not overlook the role of total profit, where total profit is equal to retailer profit plus manufacturer profits. Because allowance payments are, essentially, lump sum transfers among firms, there is no change in aggregate profit due to including or excluding slotting allowances. Any potential change in total profit, then, can be attributed solely to changes in firm variable profit. Comparing the two states (slotting versus no slotting), recall, we observe two main results: (1) The average prices of Heinz and Hunts are lower when slotting allowances are permitted and (2) the average prices of Del Monte and Private Label are lower when slotting allowances are not permitted. This implies that there is greater dispersion of average prices when slotting allowances are used.

Table C.21 shows the change in profit at varying levels of aggregation. For a particular metropolitan area, retailers and manufacturers, on average, receive annual total profit that is approximately $\$ 240,000$ higher because of slotting allowances. ${ }^{5}$ Aggregated across the 40 metropolitan areas, this generates an increase in total profit of approximately $\$ 9$ million due to slotting allowances. This increase in profit is accompanied by the (much less substantial) increase in consumer welfare due to slotting allowances.

This dissertation uses data from 1988 through 1992. By all accounts, the prevalence of slotting allowances has increased since then. Given the growth in the practice, by

\footnotetext{
${ }^{5}$ Manufacturer (aggregate) profit is slightly lower with slotting allowances because although they receive a higher wholesale price (on average), this benefit is offset with the fact that allowances are sometimes paid.
} 
using data that is over a decade old, I may be underestimating the true welfare implications of slotting allowances in today's market.

\subsubsection{Second Counterfactual Specification}

As an informal specification test, I include another counterfactual simulation in which slotting allowances are again prohibited, but manufacturers are only able to choose one (unconditional) wholesale price. As in the first counterfactual, the manufacturer selects the optimal wholesale price by maximizing expected profit. The results for this alternative counterfactual exercise appear in Tables C.22 through C.25. While some of the results are slightly different (the expected retail price for the Private Label brand is now higher without

slotting allowances), the main welfare result holds; prohibiting slotting allowance payments lowers consumer surplus and total welfare. 


\section{Chapter 13}

\section{Conclusions and Extensions}

Slotting allowances remain legally ambiguous at this time. Because of increased pressure, however, governmental agencies like the Federal Trade Commission or the Department of Justice may establish guidelines regarding their use. The agencies appear hesitant, however, to move forward based on their limited knowledge of the subject. This research makes a step towards providing some insight for decision-makers.

In this dissertation I estimated a structural model of slotting allowances. The utility function was a discrete-choice, random coefficients model modified to allow space and promotion to affect the consumer's choices. To account for the way in which retail allowances affect the decisions of manufacturers and retailers, the behavior of both groups is explicitly modeled. Parameter estimates were then used to conduct a counterfactual to determine how consumers, manufacturers, and retailers might be expected to respond to changes in the current system. The results of the counterfactual imply that slotting allowances may decrease social welfare. While the practice allows firms to increase their profit, this benefit is more than offset by the dramatic decrease in consumer welfare.

One should be careful in relying too heavily on the aggregate welfare loss calcu- 
lation presented above. For all of the benefits discrete-choice models with aggregate data provide, possibly the biggest downside is the limitation placed on the quantity an individual can purchase. Closely associated with this is the independence of purchases across time. If consumer $i$ purchases a unit of brand $j$ this month, there is no effect on $i$ 's probability of purchasing in the next period. With nonperishable goods, such as ketchup, this assumption may be particularly troublesome. Ketchup is a storable good and so it seems likely that the probability of purchase at time $t$ will depend on whether a purchase was made in time $t-1$. Assuming independence over time may inflate the probability of purchase, in a given period. The welfare analysis that each consumer loses $\$ 0.62$ in welfare annually may, then, be an overestimate.

This research presents one of the first rigorous empirical examinations on slotting allowances. In this dissertation, I have attempted to add an empirical element to the theoretical work begun by Sullivan, Shaffer, Desiraju, and others. It also extends and contributes to the literature on structural models of vertical competition that follows from BLP's seminal paper. Rather than the definitive word on slotting allowances, I view this dissertation as the beginning of a new vein of research aimed at empirically examining slotting allowances. Some of the points to be considered in future research include:

- Observing Actual Shelf Space Configurations. Observing the precise shelf space configuration used in stores will greatly improve upon the accuracy of predicting which brand has made the best offer to the retailer ("best" from the retailer's perspective, of course). Aside from adding accuracy, this information should ease the high computational cost of trying to predict "the winner" through the model's structure. Welfare 
analysis regarding the use of slotting allowances is likely to be more accurate, as the introduction/deletion of products from the consumer's choice set becomes possible. ${ }^{1}$ This will allow for an even better understanding of the possible consequences of eliminating slotting allowances.

- Alternative Retailer-Manufacturer Bargaining Approaches. Having manufacturers make offers to retailers is only one possible way to model the vertical element in this model. Allowing retailers, instead, to make offers to the manufacturers might be another alternative. Or one might consider a Nash-Bargaining solution in which the upstream and downstream firms agree on $(w, A)$ pairs to split the gains from reaching an agreement. ${ }^{2}$ We might expect the choice of how to model the vertical negotiation to bias the parameter estimates. The relative power given to retailers will inherently affect their ability to extract allowances from manufacturers.

- Alternative Price-Setting Games. Instead of allowing manufacturers to choose conditional wholesale prices for each possible display configuration. It may be more consistent with the practices in the marketing literature to allow the manufacturer to set only two prices: a wholesale price if the product is accepted for display and another price if the product is not. This will also allow for a better comparison with the counterfactual results.

- Allowing for Multiple Retailers. Aggregate data, such as the IRI data used in

\footnotetext{
${ }^{1}$ For example, Petrin (2002) develops a calculation for consumer welfare that takes into account the addition (or possible deletion) of products from the consumer choice set. If slotting allowances exclude certain brands from the shelves, then any welfare analysis must take this effect into account, as well as any possible price implications.

${ }^{2}$ In the case of retailers making offers to the manufacturers, it makes more intuiative sense to think of framing the retailer's offer as, "I am willing to accept your product for a price of $\left(w^{*}, A^{*}\right)$."
} 
this research, do not allow for much accuracy in trying to evaluate what individual retailers might do. Instead, symmetry has been assumed. Utilizing data that permits the researcher to identify individual retailers could allow for incorporation of a number of interesting elements. For example, observing individual stores would capture differences in retailer size. A priori, we might expect that a retailer's ability to extract allowances (or the manufacturer's willingness to pay allowances) might depend on the relative strength of the retailer. Certainly national chains with thousands of stores would wield greater bargaining power compared to a single unit retail store.

- Alternative Error Distributions. Rather than assuming the retailer's profit error (e) is a logit error, one could estimate the model using a error distributed normal with an estimable variance. This might be attractive to test the model's sensitivity. 


\section{Appendix A}

\section{Theoretical Appendix}

\section{A.1 Mark-Ups and Brand Quality}

In order to show that mark-ups increase with quality, it is necessary to show that:

$$
\exp \left(q_{j}-p_{j}^{j^{*}}\right)\left(1-\frac{\partial p_{j}^{j^{*}}}{\partial q_{j}}\right)>\exp \left(q-p_{k}^{j^{*}}\right) \frac{\partial p_{k}^{j^{*}}}{\partial q_{j}}
$$

Unfortunately, proving this relationship relies on mathematical techniques, not on economic intuition. To make the exposition as clear as possible, I will temporarily ignore superscript notion. The condition above, then, becomes:

$$
\exp \left(q_{j}-p_{j}\right)\left(1-\frac{\partial p_{j}}{\partial q_{j}}\right)>\exp \left(q_{k}-p_{k}\right) \frac{\partial p_{k}}{\partial q_{j}}
$$

This can be rewritten:

$$
S_{j}\left(1-\frac{\partial p_{j}}{\partial q_{j}}\right)>S_{k} \frac{\partial p_{k}}{\partial q_{j}}
$$

The key to simplifying this inequality involves analytically evaluating the deriv-

atives $\frac{\partial p_{j}}{\partial q_{j}}$ and $\frac{\partial p_{k}}{\partial q_{j}}$, which can be done using the retailer's first order conditions and pass- 
through rates (both from Chapter 5). Totally differentiating the retailer's first order conditions yields the following results:

$$
\begin{aligned}
\frac{\partial p_{j}}{\partial q_{j}} & =\frac{S_{1}\left(2 S_{0}\left(1-S_{1}\right)+S_{2}\right)+\exp \left(q_{1}-p_{1}\right)\left(S_{0}\left(1-S_{1}\right)+S_{2}\right)^{2}}{S_{1}\left(2 S_{0}\left(1-S_{1}\right)+S_{2}\right)+\left(1+\exp \left(q_{1}-p_{1}\right)\right)\left(S_{0}\left(1-S_{1}\right)+S_{2}\right)^{2}} \\
\frac{\partial p_{k}}{\partial q_{j}} & =\frac{\exp \left(q_{1}-p_{1}\right)\left(S_{0}\left(1-S_{2}\right)+S_{1}\right)^{2}-S_{1} S_{2}\left(2 S_{0}+1\right)}{S_{2}\left(2 S_{0}\left(1-S_{2}\right)+S_{1}\right)+\left(1+\exp \left(q_{2}-p_{2}\right)\right)\left(S_{0}\left(1-S_{2}\right)+S_{1}\right)^{2}}
\end{aligned}
$$

Upon inspection, if the denominator is re-arranged, it is easy to see that $0<$ $\frac{\partial p_{j}}{\partial q_{j}}<1$. In words, this says that a one unit increase in quality is not totally passed on to the consumer through a higher price. The increase in own-price will not be as great as the increase in quality. The second expression, however, has an uncertain sign. Because $\frac{\partial p_{k}}{\partial q_{j}}$ can be either positive or negative, proving $\frac{\partial\left(p_{j}^{j}-w_{j}^{j}\right)}{\partial q_{j}}>0$ requires examination of two cases: (1) $\frac{\partial p_{k}}{\partial q_{j}}<0$ and (2) $\frac{\partial p_{k}}{\partial q_{j}}>0$.

\section{A.1.1 Case 1: $\frac{\partial p_{k}}{\partial q_{j}}<0$}

When the derivative of brand $k$ 's price with respect to brand $j$ 's quality is negative, it straightforward to prove that $S_{j}\left(1-\frac{\partial p_{j}}{\partial q_{j}}\right)>S_{k} \frac{\partial p_{k}}{\partial q_{j}}$. Recall that $0<\frac{\partial p_{j}}{\partial q_{j}}<1$ (strict inequality), which implies that the left-hand side is positive (because $S_{j} \geq 0$ ). The righthand side, on the other hand, will be negative as long as $\frac{\partial p_{k}}{\partial q_{j}}<0$. Therefore, under Case 1, it is true that $\frac{\partial\left(p_{j}-w_{j}\right)}{\partial q_{j}}>0$.

\section{A.1.2 Case 2: $\frac{\partial p_{k}}{\partial q_{j}}>0$}

When $\frac{\partial p_{k}}{\partial q_{j}}>0$, the proof that $S_{j}\left(1-\frac{\partial p_{j}}{\partial q_{j}}\right)>S_{k} \frac{\partial p_{k}}{\partial q_{j}}$ is more difficult. Note that $\frac{\partial p_{k}}{\partial q_{j}}>0$ implies that $\exp \left(q_{j}-p_{j}\right)\left(S_{0}\left(1-S_{k}\right)+S_{j}\right)^{2}>S_{j} S_{k}\left(2 S_{0}+1\right)$. This expression can be simplified: 


$$
S_{0}^{2}+S_{0}^{2} S_{k}^{2}+S_{j}^{2}+2 S_{0} S_{j}>3 S_{0} S_{j} S_{k}+2 S_{0}^{2} S_{k}\left(1+S_{j}\right)
$$

Clearly, evaluating this expression is not a trivial exercise. The first step is to define the following variables:

- $A=\left(S_{0}\left(1-S_{j}\right)+S_{k}\right)^{2}$

- $B=\left(S_{0}\left(1-S_{k}\right)+S_{j}\right)^{2}$

- $C=\left(2 S_{0}\left(1-S_{k}\right)+S_{j}\right)$

- $D=\left(2 S_{0}\left(1-S_{j}\right)+S_{k}\right)$

- $E=\left(2 S_{0}+1\right)$

These substitutions allow $S_{j}\left(1-\frac{\partial p_{j}}{\partial q_{j}}\right)>S_{k} \frac{\partial p_{k}}{\partial q_{j}}$ to be rewritten:

$$
\begin{aligned}
& \frac{S_{j} A}{S_{j} D+A+\exp \left(q_{j}-p_{j}\right) A}>\frac{S_{k}\left(\exp \left(q_{j}-p_{j}\right) B-S_{j} S_{k} E\right)}{S_{k} C+B+\exp \left(q_{k}-p_{k}\right) B} \\
& S_{j} A\left(S_{k} C+B+\exp \left(q_{k}-p_{k}\right) B\right) \\
& >S_{k}\left(\exp \left(q_{j}-p_{j}\right) B-S_{j} S_{k} E\right)\left(S_{j} D+A+\exp \left(q_{j}-p_{j}\right) A\right) \\
& S_{j} A\left(S_{k} C+B+\frac{S_{k}}{S_{0}} B\right)>S_{k}\left(\left(\frac{S_{j}}{S_{0}} B-S_{j} S_{k} E\right)\left(S_{j} D+A+\frac{S_{j}}{S_{0}} A\right)\right) \\
& S_{j} A\left(S_{0} S_{k} C+S_{0} B+S_{k} B\right)+S_{j} S_{k}^{2} E\left(S_{j} D+A+\frac{S_{j}}{S_{0}} A\right)>\frac{S_{j} S_{k} B}{S_{0}}\left(S_{j} D+A+\frac{S_{j}}{S_{0}} A\right)
\end{aligned}
$$

With some algebra, this expression can be simplified as:

$$
\begin{aligned}
& S_{0}^{2} A C+S_{0}^{2} S_{k} A D+2 S_{0}^{3} S_{k}^{2} A+2 S_{0}^{2} S_{j} S_{k}^{2} A+2 S_{0}^{3} S_{k}^{3}+S_{0}^{2} S_{k}^{2} A+S_{0} S_{j} S_{k}^{2} A \\
+S_{0}^{2} S_{j} S_{k}^{2} B> & S_{j} S_{k} A C+S_{0} S_{j} S_{k} B C
\end{aligned}
$$


To simplify the above term, I will eliminate one of the share equations on the right-hand side using the substitution: $S_{j}=1-S_{0}-S_{k}$. This substitution allows me to express the inequality as:

$$
\begin{aligned}
& \left(S_{0}^{2}+S_{0} S_{k}+S_{k}^{2}\right) A C+S_{0}^{2} S_{k} A D+2 S_{0}^{3} S_{k}^{2} A \\
& +2 S_{0}^{2} S_{j} S_{k}^{2} A+2 S_{0}^{3} S_{k}^{3}+S_{0}^{2} S_{k}^{2} A+S_{0} S_{j} S_{k}^{2} A \\
+\left[\left(1-S_{0}\right) S_{0} S_{k}+S_{0} S_{k}^{2}\right] B C> & 0
\end{aligned}
$$

Because each of the elements $\left(A, B, C, D, S_{0}, S_{J}\right.$, and $\left.S_{k}\right)$ are greater than or equal to zero, the left-hand side is strictly greater than zero. The conclusion, therefore, is that under Case 2, it is also true that $\frac{\partial\left(p_{j}-w_{j}\right)}{\partial q_{j}}>0$.

\section{A.2 Calculating Optimal Allowance Offers}

To calculate optimal slotting allowance offers, each manufacturer maximizes expected profit. In the two good case, expected profit has the form:

$$
E \Pi_{j}^{m}=\operatorname{Pr}(D=j) \Pi_{j \mid D=j}^{m}+\operatorname{Pr}(D=k) \Pi_{j \mid D=k}^{m}
$$

where $\operatorname{Pr}(D=j)$ is the probability that the retailer has chosen brand $j$ to receive the display/premium shelf space. Manufacturer $j$ wins the shelf space if:

$$
\pi_{r \mid D=j}+A_{j}+e_{r j} \geq \pi_{r \mid D=k}+A_{k}+e_{r k}
$$

where $e_{r j}$ represents the fixed cost the retailer incurs when agreeing to devote premium shelf space to brand $j$. Since the manufacturer only knows the distribution of the 
fixed costs, the equation above generates display probabilities, such that:

$$
\begin{aligned}
\operatorname{Pr}(D & =j)=\operatorname{Pr}\left(\pi_{r \mid D=j}+A_{j}+e_{r j} \geq \pi_{r \mid D=k}+A_{k}+e_{r k}\right) \\
& =\operatorname{Pr}\left(e_{r k}-e_{r j} \leq \pi_{r \mid D=j}+A_{j}-\pi_{r \mid D=k}-A_{k}\right) \\
& =F_{\widetilde{e}}\left(\pi_{r \mid D=j}+A_{j}-\pi_{r \mid D=k}-A_{k}\right) \\
\operatorname{Pr}(D= & k)=\operatorname{Pr}\left(\pi_{r \mid D=k}+A_{k}+e_{r k} \geq \pi_{r \mid D=j}+A_{j}+e_{r j}\right) \\
& =\operatorname{Pr}\left(e_{r j}-e_{r k} \leq \pi_{r \mid D=k}+A_{k}-\pi_{r \mid D=j}-A_{j}\right) \\
& =F_{\widetilde{e}}\left(\pi_{r \mid D=k}+A_{k}-\pi_{r \mid D=j}-A_{j}\right)
\end{aligned}
$$

where $F_{\widetilde{e}}$ is the cdf of the distribution of the difference between the two fixed costs. Substituting these specifications into the manufacturer's expected profit equation and differentiating with respect to the manufacturer's slotting allowance $\left(A_{j}\right)$ yields the following first order condition:

$$
\begin{aligned}
\frac{\partial E \Pi_{j}^{m}}{\partial A_{j}}= & f_{\widetilde{e}}\left(\pi_{r \mid D=j}+A_{j}-\pi_{r \mid D=k}-A_{k}\right)\left(\pi_{j \mid D=j}^{m}-A_{j}\right) \\
& -F_{\widetilde{e}}\left(\pi_{r \mid D=j}+A_{j}-\pi_{r \mid D=k}-A_{k}\right) \\
& -f_{\widetilde{e}}\left(\pi_{r \mid D=k}+A_{k}-\pi_{r \mid D=j}-A_{j}\right) \\
= & 0
\end{aligned}
$$

where $f_{\widetilde{e}}$ is the pdf of the distribution of the difference between the two fixed costs. The first order condition for brand $k$ is symmetric. In order to obtain a closed form solution 
for this example, assume that $\tilde{e}$ is distributed i.i.d. $\mathrm{U}[0,1]$. Note, this assumption will not be followed in the empirical section, however. Using the uniform distribution to solve the system of first order conditions allows the optimal slotting allowance to be expressed:

$$
A_{j}^{*}=\frac{1}{3}\left(2 \pi_{j \mid D=j}^{m}-2 \pi_{j \mid D=k}^{m}+\pi_{k \mid D=k}^{m}-\pi_{k \mid D=j}^{m}+\pi_{r \mid D=k}-\pi_{r \mid D=j}\right)
$$

Using implied mark-ups and the resulting profits generated by the logit demand, this optimal allowance offer can be rewritten:

$$
A_{j}^{*}=\frac{1}{3}\left(2 w_{j}^{j} S_{j}^{j}-2 w_{j}^{k} S_{j}^{k}+w_{k}^{k} S_{k}^{k}-w_{k}^{j} S_{k}^{j}+\frac{\mu}{S_{0}^{k}}\left(S_{j}^{k}+S_{k}^{k}\right)-\frac{\mu}{S_{0}^{j}}\left(S_{j}^{j}+S_{k}^{j}\right)\right)
$$

This equation may be used to conduct comparative statics. Specifically, we might be interested to examine how changes in the "boost" (quality increase) for the brand with premium shelf space impacts the optimal slotting allowance offer and retailer mark-ups. A summary of the relevant comparative statics appears in the main text. 


\section{Appendix B}

\section{Data Appendix}

This appendix contains additional information on how data was generated.

\section{B.1 Simulating Individuals}

Random coefficients models add a degree of realism to conventional logit models by allowing consumer taste parameters $(\alpha, \beta)$ to vary across individuals. This added realism comes at a computational cost, however. More specifically, the random coefficients model requires the econometrician to integrate over the distribution of demographics in order to obtain brand market shares. While there are various ways to simulate over the demographic distribution, I choose to approximate this integral by sampling a set of individuals from the Census Bureau's March Current Population Survey (CPS). This smooth simulator is preferable to the simple frequency simulator for two reasons. Firstly, the frequency simulator requires a large number of draws to ensure non-zero probabilities, whereas the smooth simulator can produce non-zero probabilities from a single draw. Also, the frequency simulator, based on an indicator function, is not smooth so the use of a gradient method in minimizing the objective function is not possible.

The simulator I employ here requires the econometrician to sample individuals 
from each metropolitan area and calculate the individual's choice probabilities for each brand. So, for each metropolitan area and year in the period, I sample 50 individuals. $^{1}$ Simultaneously, I also draw a $(K+1) \times 1$ vector of individual taste parameters from the distribution of $\nu$. Given the draws $(\nu, D)$ and the extreme value assumption on $\varepsilon$, the predicted (unconditional) market share of brand $j$ in market $m$ can be expressed as:

$$
\begin{aligned}
s_{j m} & =\frac{1}{50} \sum_{i=1}^{50} s_{i j m} \\
& =\frac{1}{50} \sum_{i=1}^{50}\left[\begin{array}{c}
\phi_{j} \frac{\exp \left\{\beta_{i j}^{j}-\alpha_{i} p_{j m}\right\}}{1+\exp \left\{\beta_{i j}^{j}-\alpha_{i} p_{j m}\right\}+\sum_{k \neq j} \exp \left\{\beta_{i k}^{0}-\alpha_{i} p_{k m}\right\}} \\
+\sum_{k \neq j} \phi_{k} \frac{\exp \left\{\beta_{i j}^{0}-\alpha_{i} p_{j m}\right\}}{1+\exp \left\{\beta_{i k}^{k}-\alpha_{i} p_{j m}\right\}+\sum_{g \neq k} \exp \left\{\beta_{i g}^{0}-\alpha_{i} p_{k m}\right\}}
\end{array}\right]
\end{aligned}
$$

In order to compute the prices and implied sales, conditional on a specific display choice, in the estimation algorithm, it is necessary to compute conditional market shares $\left(s_{j \mid D=j}, s_{j \mid D=k}\right)$. These can be expressed:

$$
\begin{aligned}
s_{j \mid D=j} & =\frac{1}{50} \sum_{i=1}^{50} s_{i j \mid D=j} \\
& =\frac{1}{50} \sum_{i=1}^{50}\left[\frac{\exp \left\{\beta_{i j}^{j}-\alpha_{i} p_{j}\right\}}{1+\exp \left\{\beta_{i j}^{j}-\alpha_{i} p_{j}\right\}+\sum_{k \neq j} \exp \left\{\beta_{i k}^{0}-\alpha_{i} p_{k}\right\}}\right] \\
s_{j \mid D=k} & =\frac{1}{50} \sum_{i=1}^{50} s_{i j \mid D=k} \\
& =\frac{1}{50} \sum_{i=1}^{50}\left[\frac{\exp \left\{\beta_{i j}^{0}-\alpha_{i} p_{j}\right\}}{1+\exp \left\{\beta_{i k}^{k}-\alpha_{i} p_{j}\right\}+\sum_{g \neq k} \exp \left\{\beta_{i g}^{0}-\alpha_{i} p_{k}\right\}}\right]
\end{aligned}
$$

\footnotetext{
${ }^{1}$ The CPS is an annual survey so I use the same sampled individuals for each quarter in the given year.
} 


\section{Appendix C}

\section{Figures and Tables}

\section{C.1 Figures and tables of Chapter 4}

Table C.1: Summary Statistics for Accounting Variables

\begin{tabular}{ccc}
\hline $\mathbf{n}$ & Firms with Payments & $\begin{array}{c}\text { Firms without } \\
\text { Payments }\end{array}$ \\
\cline { 2 - 3 } $\begin{array}{c}\text { Average Payment } \\
\text { (\$ millions) } \\
\text { Average Stock } \\
\text { Price(\$) }\end{array}$ & 100 & 71 \\
$\begin{array}{c}\text { Average Gross } \\
\text { Margin }\end{array}$ & 392.9 & N/A \\
$\begin{array}{c}\text { Average Sales to } \\
\text { Inventory Ratio }\end{array}$ & 27.11 & 37.21 \\
$\begin{array}{c}\text { Average Sales (\$) } \\
\text { Grocery (\#) }\end{array}$ & 0.40 & 0.38 \\
Software (\#) & 6679.55 & 30.02 \\
Home (\#) & 51 & 7939.22 \\
Electronics (\#) & 10 & 12 \\
Media (\#) & 7 & 9 \\
Pharm (\#) & 9 & 14 \\
Person (\#) & 5 & 9 \\
Clothes (\#) & 8 & 1 \\
\hline
\end{tabular}


Table C.2: Regressor Variables

\begin{tabular}{|c|c|}
\hline Variable & Definition \\
\hline Stock & $\begin{array}{l}\text { A firm's average common stock } \\
\text { price during fiscal year } 2001\end{array}$ \\
\hline Marg & $\begin{array}{l}\text { A firm's gross margin (total } \\
\text { revenue minus the cost of goods } \\
\text { produced) }\end{array}$ \\
\hline Inv & $\begin{array}{l}\text { A firm's sales-to-inventory ratio } \\
\text { (total revenue divided by dollar } \\
\text { value of inventory) }\end{array}$ \\
\hline Sh1 & $\begin{array}{l}\text { A firm's share of total sales within } \\
\text { their industry category }\end{array}$ \\
\hline Herf1 & $\begin{array}{l}\text { Industry Herfindahl index } \\
\text { calculated using the firm shares } \\
\text { Sh1 }\end{array}$ \\
\hline Sh2 & $\begin{array}{l}\text { A more restrictive measure of } \\
\text { firm market share calculated by } \\
\text { categorizing manufacturers into } \\
\text { groups based on the type of } \\
\text { product produced }\end{array}$ \\
\hline Herf2 & $\begin{array}{l}\text { Industry Herfindahl index } \\
\text { calculated using the firm shares } \\
\text { Sh2 }\end{array}$ \\
\hline Sales & A firm's total revenue in dollars \\
\hline
\end{tabular}


Table C.3: Logit Marginal Effects

\begin{tabular}{|c|c|c|c|c|c|c|c|c|}
\hline Variable & I & II & III & IV & V & V & VII & Est. Sign \\
\hline Grocery & & $\begin{array}{c}0.318378 \\
(0.412461)\end{array}$ & $\begin{array}{c}0.231025^{\mathrm{a}} \\
(0.115491)\end{array}$ & $\begin{array}{c}0.745690^{\star} \\
(0.280863)\end{array}$ & $\begin{array}{l}0.154779 \\
(0.122327)\end{array}$ & $\begin{array}{c}0.293879^{*} \\
(0.087133)\end{array}$ & $\begin{array}{c}0.318658^{*} \\
(0.105341)\end{array}$ & + \\
\hline Software & & $\begin{array}{c}-0.772982 \\
(0.528740)\end{array}$ & & $\begin{array}{c}-1.075337^{b} \\
(0.565816)\end{array}$ & $\begin{array}{c}-0.433343^{b} \\
(0.246395)\end{array}$ & & $\begin{array}{c}-0.108269 \\
(0.183546)\end{array}$ & - \\
\hline Home & & $\begin{array}{c}-0.070558 \\
(0.185082)\end{array}$ & & $\begin{array}{c}0.147099 \\
(0.118644)\end{array}$ & $\begin{array}{c}-0.113118 \\
(0.143448)\end{array}$ & & $\begin{array}{l}0.031019 \\
(0.130371)\end{array}$ & $-/+$ \\
\hline Media & & $\begin{array}{c}-0.124673 \\
(0.142594)\end{array}$ & & & $\begin{array}{c}-0.106094 \\
(0.149332)\end{array}$ & & & - \\
\hline Electronics & & $\begin{array}{c}-0.239737 \\
(0.219440)\end{array}$ & & & $\begin{array}{c}-0.295779^{b} \\
(0.170112)\end{array}$ & & & - \\
\hline Pharm & & & & $\begin{array}{c}-0.120789 \\
(0.270597)\end{array}$ & $\begin{array}{c}-0.043509 \\
(0.216078)\end{array}$ & & $\begin{array}{c}0.178588 \\
(0.182887)\end{array}$ & $-/+$ \\
\hline Personal & & & $\begin{array}{c}0.457869^{a} \\
(0.227623)\end{array}$ & $\begin{array}{l}0.233514 \\
(0.258500)\end{array}$ & & $\begin{array}{c}0.332816^{b} \\
(0.201567)\end{array}$ & $\begin{array}{l}0.339303 \\
(0.206470)\end{array}$ & + \\
\hline Clothes & & & $\begin{array}{c}0.114716 \\
(0.159105)\end{array}$ & $\begin{array}{c}0.162976 \\
(0.160890)\end{array}$ & & $\begin{array}{c}-0.004530 \\
(0.151647)\end{array}$ & $\begin{array}{l}0.026461 \\
(0.165185)\end{array}$ & + \\
\hline Market Cap & $\begin{array}{c}0.000001^{*} \\
(0.000006)\end{array}$ & $\begin{array}{l}0.000001 \\
(0.000006)\end{array}$ & $\begin{array}{c}-0.000001 \\
(0.000006)\end{array}$ & $\begin{array}{l}0.000001 \\
(0.000006)\end{array}$ & $\begin{array}{c}-0.000002 \\
(0.000006)\end{array}$ & $\begin{array}{c}-0.000003 \\
(0.000005)\end{array}$ & $\begin{array}{c}-0.000002 \\
(0.000005)\end{array}$ & $-/+$ \\
\hline Margin & $\begin{array}{c}0.548678 \\
(0.188961)\end{array}$ & $\begin{array}{c}0.365950^{a} \\
(0.183088)\end{array}$ & $\begin{array}{c}0.341577^{b} \\
(0.185734)\end{array}$ & $\begin{array}{r}0.330734^{b} \\
(0.184055)\end{array}$ & $\begin{array}{c}0.452183^{\mathrm{a}} \\
(0.194421)\end{array}$ & $\begin{array}{c}0.458156^{a} \\
(0.190022)\end{array}$ & $\begin{array}{r}0.445502^{a} \\
(0.191904)\end{array}$ & + \\
\hline Inventory & $\begin{array}{l}0.000042 \\
(0.000039)\end{array}$ & $\begin{array}{l}0.000039 \\
(0.000037)\end{array}$ & $\begin{array}{l}0.000037 \\
(0.000038)\end{array}$ & $\begin{array}{l}0.000038 \\
(0.000037)\end{array}$ & $\begin{array}{l}0.000048 \\
(0.000072)\end{array}$ & $\begin{array}{l}0.000040 \\
(0.000038)\end{array}$ & $\begin{array}{l}0.000042 \\
(0.000038)\end{array}$ & + \\
\hline Sales & $\begin{array}{c}-0.000004 \\
(0.000005)\end{array}$ & $\begin{array}{c}-0.000001 \\
(0.000006)\end{array}$ & $\begin{array}{c}-0.000004 \\
(0.000005)\end{array}$ & $\begin{array}{c}-0.000002 \\
(0.000006)\end{array}$ & $\begin{array}{c}-0.000003 \\
(0.000006)\end{array}$ & $\begin{array}{c}-0.000003 \\
(0.000005)\end{array}$ & $\begin{array}{c}-0.000003 \\
(0.000005)\end{array}$ & - \\
\hline Share1 & $\begin{array}{c}-0.814679 \\
(0.561455)\end{array}$ & $\begin{array}{c}-1.145001^{a} \\
(0.613053)\end{array}$ & $\begin{array}{c}-1.099563 \\
(0.701343)\end{array}$ & $\begin{array}{c}-1.295107^{b} \\
(0.680474)\end{array}$ & & & & - \\
\hline Herf1 & $\begin{array}{c}-0.000109^{*} \\
(0.000034)\end{array}$ & $\begin{array}{c}0.000147 \\
(0.000205)\end{array}$ & $\begin{array}{c}-0.000035 \\
(0.000044)\end{array}$ & $\begin{array}{c}0.000316^{b} \\
(0.000186)\end{array}$ & & & & $-/+$ \\
\hline Share2 & & & & & $\begin{array}{c}-0.376164 \\
(0.424352)\end{array}$ & $\begin{array}{c}-0.205029 \\
(0.371474)\end{array}$ & $\begin{array}{c}-0.246786 \\
(0.404411)\end{array}$ & - \\
\hline Herf2 & & & & & $\begin{array}{l}0.000019 \\
(0.000069)\end{array}$ & $\begin{array}{c}-0.000066 \\
(0.000041)\end{array}$ & $\begin{array}{c}-0.000036 \\
(0.000061)\end{array}$ & $-/+$ \\
\hline Prediction \% & 62.97 & 69.51 & 63.62 & 68.85 & 67.25 & 64.93 & 67.55 & \\
\hline
\end{tabular}


Table C.4: Logit, Probit, and Linear Probability Models

\begin{tabular}{ccccc}
\hline Variable & $\begin{array}{c}\text { Linear } \\
\text { Probability Model Probability Model }\end{array}$ & $\begin{array}{c}\text { Logit Model } \\
\text { Probit Model }\end{array}$ \\
\hline Constant & -0.28235 & -0.49471 & -0.31833 & -0.31853 \\
Grocery & 0.87644 & 0.94239 & 1.06843 & 1.06807 \\
Software & -0.3377 & -0.61009 & -0.40841 & -0.40823 \\
Home & 0.09045 & 0.19300 & 0.10189 & 0.10187 \\
Pharm & 0.53711 & 0.51546 & 0.62792 & 0.62788 \\
Person & 0.89086 & 0.83062 & 1.12381 & 1.12378 \\
Clothes & 0.06869 & 0.18139 & 0.07058 & 0.07058 \\
Market Cap & 0.00000 & 0.00000 & 0.00000 & 0.00000 \\
Margin & 1.28142 & 1.35690 & 1.55546 & 1.55533 \\
Inv & 0.00009 & 0.00007 & 0.00014 & 0.00014 \\
Sales & 0.00000 & 0.00000 & -0.00001 & -0.00001 \\
Sh2 & -0.65738 & -1.27410 & -0.84717 & -0.84712 \\
Herf2 & -0.00009 & -0.00003 & -0.00012 & -0.00012 \\
& & & & \\
$\mathbf{R}^{2}$ & 0.21426 & 0.10718 & 0.17292 & 0.17373 \\
\hline
\end{tabular}


Table C.5: Tobit Consideration Regressions

\begin{tabular}{|c|c|c|c|c|c|c|c|c|}
\hline \multicolumn{9}{|c|}{ Logistic Error Distribution } \\
\hline & $I$ & II & III & IV & V & VI & VII & \\
\hline Variable & $\begin{array}{l}\text { Estimates } \\
\text { Std. Error }\end{array}$ & $\begin{array}{l}\text { Estimates } \\
\text { Std. Error }\end{array}$ & $\begin{array}{l}\text { Estimates } \\
\text { Std. Error }\end{array}$ & $\begin{array}{l}\text { Estimates } \\
\text { Std. Error }\end{array}$ & $\begin{array}{l}\text { Estimates } \\
\text { Std. Error }\end{array}$ & $\begin{array}{l}\text { Estimates } \\
\text { Std. Error }\end{array}$ & $\begin{array}{l}\text { Estimates } \\
\text { Std. Error }\end{array}$ & Est. Sign \\
\hline Constant & $\begin{array}{c}-677.7793^{*} \\
(212.3106)\end{array}$ & $\begin{array}{c}-223.8120 \\
(146.6514)\end{array}$ & $\begin{array}{c}-788.6134^{\mathrm{a}} \\
(364.1668)\end{array}$ & $\begin{array}{c}-700.5081^{*} \\
(229.1783)\end{array}$ & $\begin{array}{c}-1356.649^{*} \\
(331.9866)\end{array}$ & $\begin{array}{c}-107.2016 \\
(402.4854)\end{array}$ & $\begin{array}{c}-1189.7610^{*} \\
(327.7688)\end{array}$ & - \\
\hline Grocery & $\begin{array}{c}510.5035^{*} \\
(119.5848)\end{array}$ & & $\begin{array}{c}530.5933^{\mathrm{a}} \\
(269.2535)\end{array}$ & $\begin{array}{c}531.1446^{*} \\
(129.9893)\end{array}$ & $\begin{array}{c}699.8940^{*} \\
(221.5644)\end{array}$ & $\begin{array}{l}-66.1483 \\
(344.6123)\end{array}$ & $\begin{array}{c}706.7533^{*} \\
(163.8551)\end{array}$ & + \\
\hline Software & & & $\begin{array}{c}-238.4000 \\
(466.7838)\end{array}$ & & $\begin{array}{c}-722.9380^{b} \\
(421.5252)\end{array}$ & $\begin{array}{l}-22.8462 \\
(437.0238)\end{array}$ & $\begin{array}{c}-479.9606 \\
(315.2490)\end{array}$ & - \\
\hline Home & & & $\begin{array}{l}280.1971 \\
(192.2620)\end{array}$ & & $\begin{array}{c}335.5640 \\
(249.8267)\end{array}$ & $\begin{array}{l}-26.0487 \\
(263.9492)\end{array}$ & $\begin{array}{c}342.9393^{\mathrm{b}} \\
(200.6610)\end{array}$ & + \\
\hline Media & & & & & $\begin{array}{l}259.9736 \\
(255.3493)\end{array}$ & $\begin{array}{l}-2.8445 \\
(269.7421)\end{array}$ & & $-/+$ \\
\hline Electronics & & & & & $\begin{array}{c}-412.8767 \\
(315.5558)\end{array}$ & $\begin{array}{c}-722.2978^{a} \\
(346.8008)\end{array}$ & & - \\
\hline Pharm & & & $\begin{array}{l}100.4149 \\
(281.3270)\end{array}$ & & $\begin{array}{l}67.8652 \\
(311.0707)\end{array}$ & $\begin{array}{c}6.4589 \\
(334.1388)\end{array}$ & $\begin{array}{l}136.9982 \\
(236.2164)\end{array}$ & + \\
\hline Personal & & & $\begin{array}{l}352.6299 \\
(267.7288)\end{array}$ & $\begin{array}{l}194.1807 \\
(226.6937)\end{array}$ & $\begin{array}{l}219.2847 \\
(289.7628)\end{array}$ & $\begin{array}{l}227.8840 \\
(312.8774)\end{array}$ & $\begin{array}{l}264.3058 \\
(236.7471)\end{array}$ & + \\
\hline Clothes & & & $\begin{array}{l}256.4866 \\
(278.8197)\end{array}$ & $\begin{array}{l}-13.4549 \\
(263.9393)\end{array}$ & & & $\begin{array}{l}192.9594 \\
(279.2452)\end{array}$ & $-/+$ \\
\hline Market Cap & $\begin{array}{l}0.0078^{\mathrm{a}} \\
(0.0127)\end{array}$ & $\begin{array}{l}0.0281^{b} \\
(0.0157)\end{array}$ & $\begin{array}{l}0.0265 \\
(0.0167)\end{array}$ & $\begin{array}{l}0.0077 \\
(0.0127)\end{array}$ & $\begin{array}{l}0.0196 \\
(0.0136)\end{array}$ & $\begin{array}{l}0.0341^{b} \\
(0.0179)\end{array}$ & $\begin{array}{l}0.0128 \\
(0.0132)\end{array}$ & + \\
\hline Margin & $\begin{array}{l}793.7756 \\
(309.0546)\end{array}$ & $\begin{array}{l}970.9711^{*} \\
(336.0809)\end{array}$ & $\begin{array}{c}886.5934^{*} \\
(339.9169)\end{array}$ & $\begin{array}{c}769.7036^{a} \\
(310.9346)\end{array}$ & $\begin{array}{c}712.3435^{a} \\
(311.5517)\end{array}$ & $\begin{array}{c}914.4433^{*} \\
(342.7741)\end{array}$ & $\begin{array}{c}804.3720^{a} \\
(321.4122)\end{array}$ & + \\
\hline Inventory & $\begin{array}{l}0.0166 \\
(0.0269)\end{array}$ & $\begin{array}{l}0.0283 \\
(0.0283)\end{array}$ & $\begin{array}{l}0.0230 \\
(0.0288)\end{array}$ & $\begin{array}{l}0.0172 \\
(0.0270)\end{array}$ & $\begin{array}{l}0.0244 \\
(0.0273)\end{array}$ & $\begin{array}{l}0.0280 \\
(0.0291)\end{array}$ & $\begin{array}{l}0.0263 \\
(0.0277)\end{array}$ & + \\
\hline Sales & $\begin{array}{l}0.0187 \\
(0.0160)\end{array}$ & $\begin{array}{c}0.0528^{*} \\
(0.0184)\end{array}$ & $\begin{array}{c}0.0556^{\star} \\
(0.0189)\end{array}$ & $\begin{array}{l}0.0193 \\
(0.0161)\end{array}$ & $\begin{array}{l}0.0341^{\mathrm{a}} \\
(0.0170)\end{array}$ & $\begin{array}{l}0.0683^{*} \\
(0.0201)\end{array}$ & $\begin{array}{l}0.0241 \\
(0.0162)\end{array}$ & + \\
\hline Share1 & & $\begin{array}{c}-2591.6110^{\mathrm{a}} \\
(1160.4020)\end{array}$ & $\begin{array}{c}-3052.3000^{\mathrm{a}} \\
(1287.0540)\end{array}$ & & & $\begin{array}{c}-3528.6750^{*} \\
(1366.7240)\end{array}$ & & - \\
\hline Herf1 & & $\begin{array}{c}-0.1525^{\star} \\
(0.0567)\end{array}$ & $\begin{array}{l}0.0367 \\
(0.1569)\end{array}$ & & & $\begin{array}{c}-0.1633 \\
(0.1500)\end{array}$ & & $-/+$ \\
\hline Share2 & $\begin{array}{c}1173.503^{\mathrm{a}} \\
(597.2777)\end{array}$ & & & $\begin{array}{c}1134.616^{\mathrm{b}} \\
(616.1482)\end{array}$ & $\begin{array}{c}413.4215 \\
(696.6983)\end{array}$ & & $\begin{array}{l}631.4342 \\
(658.4302)\end{array}$ & + \\
\hline Herf2 & $\begin{array}{c}-0.0013 \\
(0.0652)\end{array}$ & & & $\begin{array}{l}0.0032 \\
(0.0688)\end{array}$ & $\begin{array}{c}0.2565^{\mathrm{a}} \\
(0.1123)\end{array}$ & & $\begin{array}{l}0.1597 \\
(0.1006)\end{array}$ & + \\
\hline $\mathbf{R}^{2}$ & 0.3186 & 0.5024 & 0.5396 & 0.3254 & 0.5013 & 0.6107 & 0.4105 & \\
\hline
\end{tabular}

* -- Significant at the $1 \%$ level, a -- Significant at the $5 \%$ level, b -- Significant at the $10 \%$ level 


\section{Figure C.1: Sample 10-K Annual Reports}

\section{From Pepsico Incorporated's 2001 10-K Filing:}

“...During 2000 and 2001, the Financial Accounting Standards Board s (FASB) Emerging Issues Task Force (EITF) addressed various issues related to the income statement classification of certain promotional payments, including consideration from a vendor to a reseller or another party that purchases the vendor s products. EITF 01-9, Accounting for Consideration Given by a Vendor to a Customer or a Reseller of the Vendor s Products, was issued in November 2001 and codified earlier pronouncements. Primarily effective for 2002, adoption of EITF 01-9 will reduce our net sales by $\$ 3.4$ billion in 2001, $\$ 3.1$ billion in 2000 and $\$ 2.9$ billion in 1999, with selling, general and administrative expenses reduced by the same amounts."

Source: Pepsico Inc., 10-K Filing, December 29, 2001

\section{From Monterey Pasta Company's 2001 10-K Filing:}

“...The concenses reached in Issue 00-25 and Issue 00-14 (codified by Issue 01-09) are effective for fiscal quarters beginning after December 15, 2001. The Company analyzed the impact of reclassifications on its operating results for the last three fiscal years, if EITF 01-09 had been adopted with the following proforma results shown on page 18:"

\section{Proforma Retrospective impact on Income Statement of Adoption of BTF 01-09: "Accounting for Consideration Given by a Vendor to a Customer or Reseller of the Vendor's Products"}

\begin{tabular}{|c|c|c|c|c|c|c|}
\hline \multirow[b]{2}{*}{ (000's) } & \multicolumn{2}{|c|}{-1999} & \multicolumn{2}{|c|}{$-2000-$} & \multicolumn{2}{|c|}{-2001-- } \\
\hline & As Stated & Reclassified & As Stated & Redassified & As Stated & Reclassified \\
\hline Net Revenue & $\$ 36,902$ & $\$ 36,902$ & $\$ 47,962$ & $\$ 47,962$ & $\$ 59,220$ & $\$ 59,220$ \\
\hline Coupon Expense & & $\$ 153$ & & $\$ 167$ & & $\$ 66$ \\
\hline Slotting Expense & & $\$ 1,568$ & & $\$ 1,478$ & & $\$ 1,990$ \\
\hline Proms, Trade Ads & & $\$ 283$ & & $\$ 227$ & & $\$ 178$ \\
\hline Adjusted Net Revenues & $\$ 36,902$ & $\$ 34,898$ & $\$ 47,962$ & $\$ 46,090$ & $\$ 59,220$ & $\$ 56,986$ \\
\hline
\end{tabular}


C.2 Figures and tables of Chapter 5

Figure C.2: Basic Game Structure

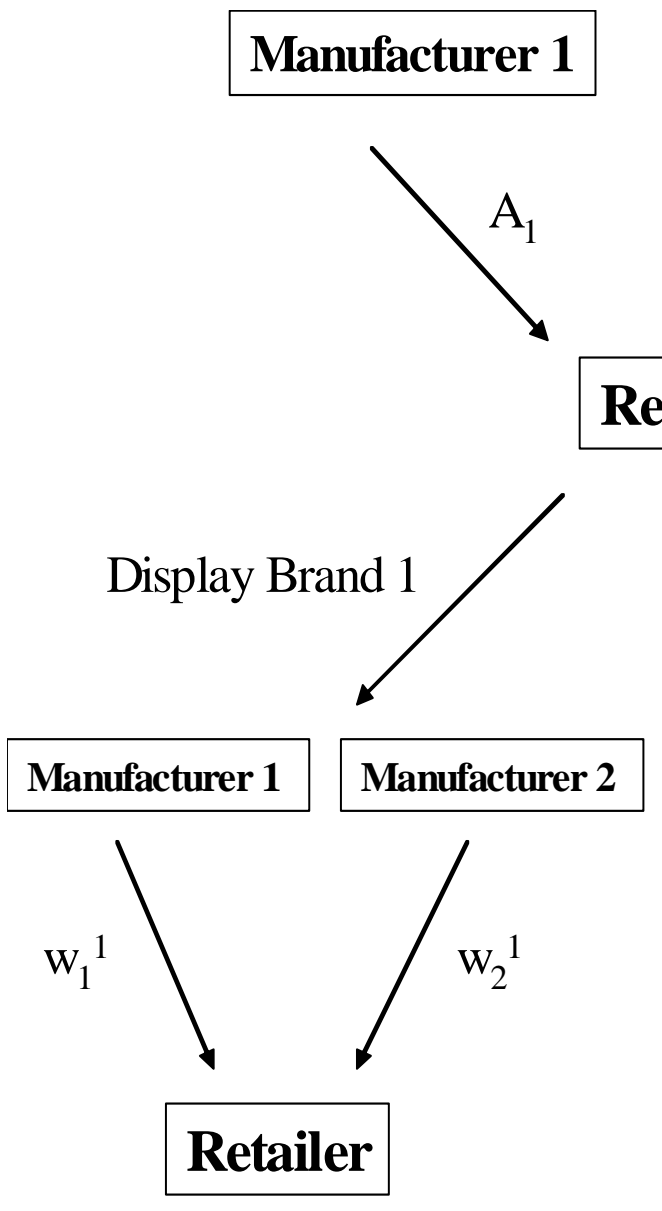

Set conditional prices $\mathrm{p}_{1}{ }^{1}, \mathrm{p}_{2}{ }^{1}$

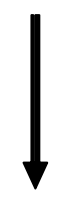

\section{Manufacturer 2}

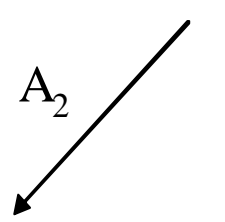

OR

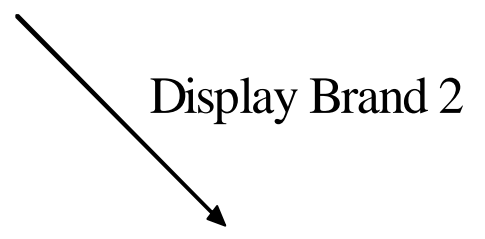

\section{Manufacturer 1 Manufacturer 2}

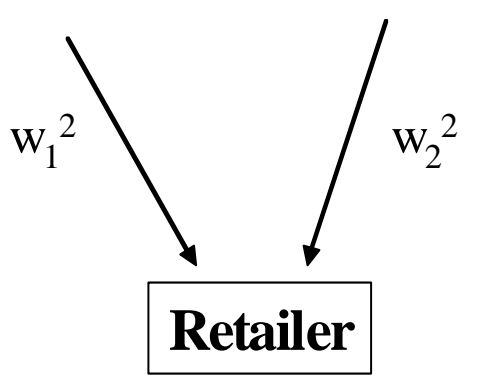

Set conditional prices $\mathrm{p}_{1}^{2}, \mathrm{p}_{2}^{2}$

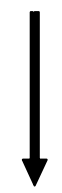




\section{C.3 Figures and tables of Chapter 7}

Figure C.3: Ketchup Unit Sales

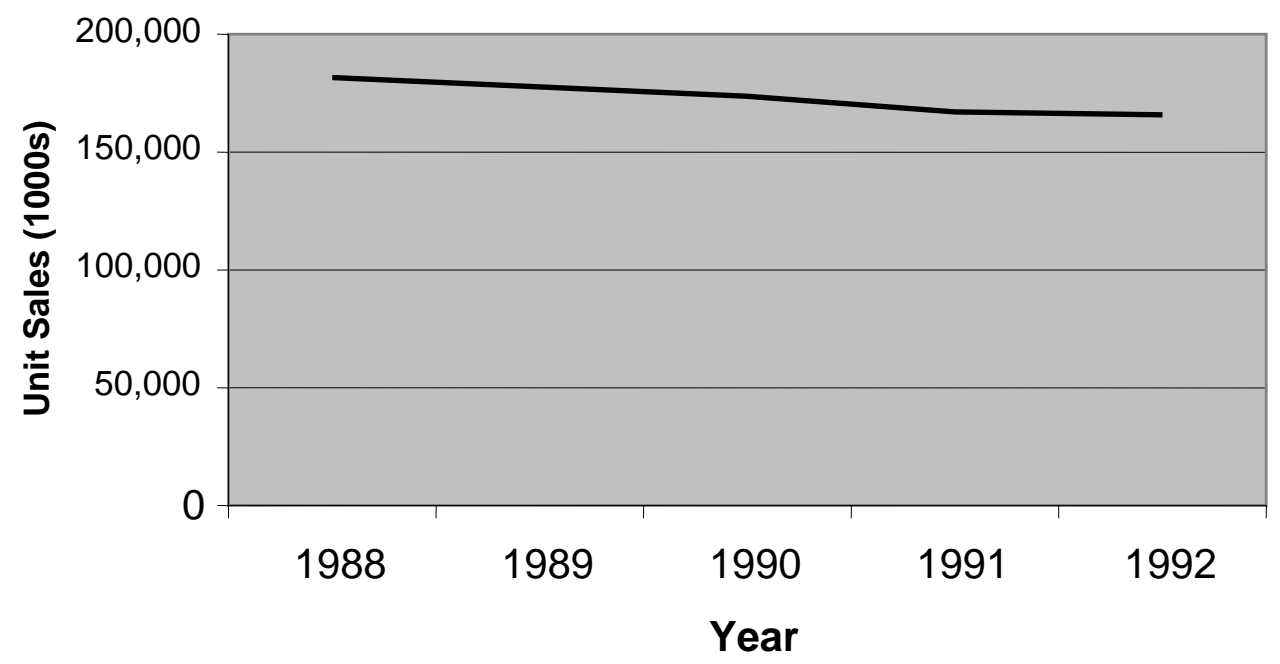


Figure C.4: Ketchup Sales (\$)

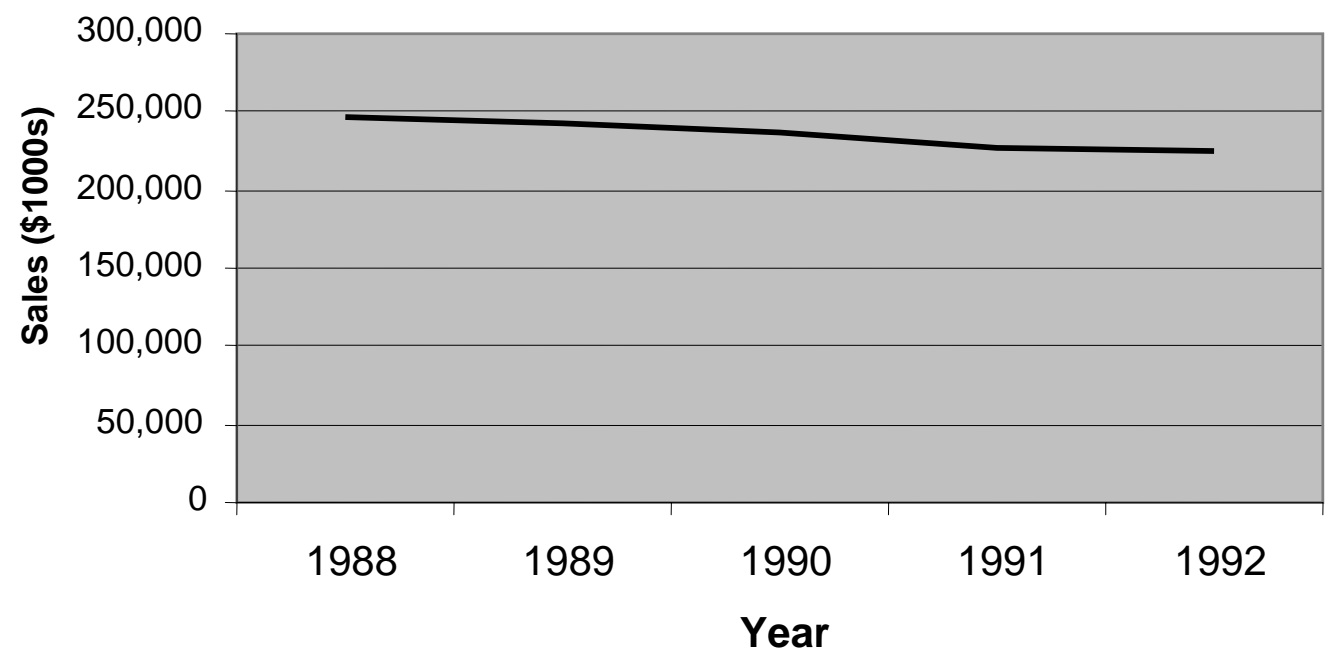




\section{C.4 Figures and tables of Chapter 8}

Table C.6: Metropolitan Markets

\begin{tabular}{cccc}
\hline Atlanta, GA & Hartford, CT & Milwaukee, WI & Raleigh, NC \\
$\begin{array}{c}\text { Balt., MD - } \\
\text { Wash., DC }\end{array}$ & Houston, TX & Nashville, TN & Sacramento, CA \\
Birmingham, AL & Indianapolis, IN & New Orleans, LA & $\begin{array}{c}\text { Salt Lake City, } \\
\text { UT }\end{array}$ \\
Chicago, IL & Jacksonville, FL & New York, NY & San Antonio, TX \\
Cincinnati, OH & Kansas City, MO & Oklahoma City, & San Diego, CA \\
Columbus, OH & Little Rock, AR & Omaha, NE & San Francisco, \\
CAA
\end{tabular}


Table C.7: Market Share by Region (all years)

\begin{tabular}{cccccc}
\hline & South & Northeast & Midwest & West & National \\
\hline Heinz & 42.81 & 66.31 & 57.49 & 45.23 & 54.36 \\
Hunts & 31.38 & 8.64 & 16.33 & 16.99 & 17.81 \\
& & & & & \\
Del Monte & 13.01 & 2.82 & 6.75 & 17.36 & 9.01 \\
$\begin{array}{c}\text { Private } \\
\text { Label }\end{array}$ & 11.87 & 21.69 & 13.55 & 19.53 & 16.84 \\
\hline $\begin{array}{c}\text { Combined } \\
\text { Haber }\end{array}$ & 99.07 & 99.46 & 94.12 & 99.11 & 98.02 \\
\hline
\end{tabular}


Table C.8: Summary Statistics

\begin{tabular}{|c|c|c|c|c|c|c|}
\hline & & 1988 & 1989 & 1990 & 1991 & 1992 \\
\hline & & $\begin{array}{c}\text { Mean } \\
\text { (Std.Dev.) }\end{array}$ & $\begin{array}{c}\text { Mean } \\
\text { (Std.Dev.) }\end{array}$ & $\begin{array}{c}\text { Mean } \\
\text { (Std.Dev.) }\end{array}$ & $\begin{array}{c}\text { Mean } \\
\text { (Std.Dev.) }\end{array}$ & $\begin{array}{c}\text { Mean } \\
\text { (Std.Dev.) }\end{array}$ \\
\hline \multicolumn{7}{|l|}{ Heinz } \\
\hline & Sales & $\begin{array}{c}569886.88 \\
(371496.67)\end{array}$ & $\begin{array}{c}393130.06 \\
(290964.30)\end{array}$ & $\begin{array}{c}869611.78 \\
(1048308.90)\end{array}$ & $\begin{array}{c}355954.19 \\
(384486.40)\end{array}$ & $\begin{array}{c}281831.34 \\
(147457.17)\end{array}$ \\
\hline & Price & $\begin{array}{c}1.53 \\
(0.149)\end{array}$ & $\begin{array}{c}1.47 \\
(0.116)\end{array}$ & $\begin{array}{c}1.46 \\
(0.112)\end{array}$ & $\begin{array}{c}1.52 \\
(0.166)\end{array}$ & $\begin{array}{c}1.54 \\
(0.153)\end{array}$ \\
\hline & PUAM & $\begin{array}{l}41.81 \% \\
(0.163)\end{array}$ & $\begin{array}{l}38.50 \% \\
(0.156)\end{array}$ & $\begin{array}{l}38.33 \% \\
(0.151)\end{array}$ & $\begin{array}{l}33.68 \% \\
(0.138)\end{array}$ & $\begin{array}{l}34.41 \% \\
(0.133)\end{array}$ \\
\hline \multicolumn{7}{|l|}{ Hunts } \\
\hline & $\begin{array}{l}\text { Unit } \\
\text { Sales }\end{array}$ & $\begin{array}{c}191043.55 \\
(95688.326)\end{array}$ & $\begin{array}{c}163587.99 \\
(143463.950)\end{array}$ & $\begin{array}{c}239684.58 \\
(173003.530)\end{array}$ & $\begin{array}{c}140308.10 \\
(95163.970)\end{array}$ & $\begin{array}{r}106470.58 \\
(48003.776)\end{array}$ \\
\hline & Price & $\begin{array}{c}1.39 \\
(0.173)\end{array}$ & $\begin{array}{c}1.29 \\
(0.128)\end{array}$ & $\begin{array}{c}1.28 \\
(0.145)\end{array}$ & $\begin{array}{c}1.33 \\
(0.201)\end{array}$ & $\begin{array}{c}1.36 \\
(0.180)\end{array}$ \\
\hline & PUAM & $\begin{array}{l}47.69 \% \\
(0.155)\end{array}$ & $\begin{array}{l}45.92 \% \\
(0.192)\end{array}$ & $\begin{array}{l}46.47 \% \\
(0.183)\end{array}$ & $\begin{array}{l}44.92 \% \\
(0.166)\end{array}$ & $\begin{array}{l}47.36 \% \\
(0.157)\end{array}$ \\
\hline \multicolumn{7}{|l|}{$\begin{array}{l}\text { Del } \\
\text { Monte }\end{array}$} \\
\hline & $\begin{array}{l}\text { Unit } \\
\text { Sales }\end{array}$ & $\begin{array}{c}113036.79 \\
(100533.190)\end{array}$ & $\begin{array}{c}52556.94 \\
(43940.310)\end{array}$ & $\begin{array}{c}130779.30 \\
(186495.130)\end{array}$ & $\begin{array}{c}72161.18 \\
(45593.842)\end{array}$ & $\begin{array}{c}87817.98 \\
(97472.999)\end{array}$ \\
\hline & Price & $\begin{array}{c}1.18 \\
(0.160)\end{array}$ & $\begin{array}{c}1.17 \\
(0.145)\end{array}$ & $\begin{array}{c}1.13 \\
(0.151)\end{array}$ & $\begin{array}{c}1.18 \\
(0.170)\end{array}$ & $\begin{array}{c}1.21 \\
(0.159)\end{array}$ \\
\hline & PUAM & $\begin{array}{l}61.89 \% \\
(0.155)\end{array}$ & $\begin{array}{l}53.13 \% \\
(0.192)\end{array}$ & $\begin{array}{l}54.79 \% \\
(0.183)\end{array}$ & $\begin{array}{l}51.89 \% \\
(0.166)\end{array}$ & $\begin{array}{l}54.34 \% \\
(0.157)\end{array}$ \\
\hline \multicolumn{7}{|l|}{$\begin{array}{l}\text { Private } \\
\text { Label }\end{array}$} \\
\hline & $\begin{array}{l}\text { Unit } \\
\text { Sales }\end{array}$ & $\begin{array}{c}175470.52 \\
(116439.870)\end{array}$ & $\begin{array}{c}112597.22 \\
(92740.320)\end{array}$ & $\begin{array}{c}236713.89 \\
(264439.690)\end{array}$ & $\begin{array}{c}123864.65 \\
(143671.110)\end{array}$ & $\begin{array}{c}117243.87 \\
(58412.583)\end{array}$ \\
\hline & Price & $\begin{array}{c}1.03 \\
(0.146)\end{array}$ & $\begin{array}{c}0.97 \\
(0.074)\end{array}$ & $\begin{array}{c}0.97 \\
(0.064)\end{array}$ & $\begin{array}{c}1.03 \\
(0.121)\end{array}$ & $\begin{array}{c}1.06 \\
(0.117)\end{array}$ \\
\hline & PUAM & $37.32 \%$ & $34.09 \%$ & $32.86 \%$ & $32.71 \%$ & $31.79 \%$ \\
\hline & & $(0.153)$ & $(0.180)$ & $(0.160)$ & $(0.152)$ & $(0.154)$ \\
\hline
\end{tabular}


Table C.9: Product Characteristics

\begin{tabular}{lccc}
\hline Per Serving Information & Heinz & Hunts & Del Monte \\
\hline Calories & 15 & 15 & 15 \\
Sodium(mg) & 190 & 190 & 190 \\
Carb.(g) & 4 & 4 & 4 \\
Sugars(g) & 4 & 4 & 4 \\
Vitamin A(\%) & 6 & 0 & 0 \\
\hline
\end{tabular}




\section{C.5 Figures and tables of Chapter 9}

Table C.10: Preliminary Logit Estimates

\begin{tabular}{lrrrrrrrr}
\hline Variable & Coefficient & Std Error & Coefficient & Std Error & Coefficient & Std Error & Coefficient & Std Error \\
\hline Constant & -3.8503 & 0.0833 & -1.5991 & 0.0831 & -1.9257 & 0.0971 & -1.9051 & 0.097 \\
Price & 1.0271 & 0.0652 & -1.5476 & 0.0687 & -1.4616 & 0.0696 & -1.478 & 0.0696 \\
Heinz & & & 2.3488 & 0.0369 & 0.4088 & 0.0639 & 0.448 & 0.0645 \\
Hunts & & & 1.1546 & 0.0309 & 2.3931 & 0.0373 & 2.4056 & 0.0374 \\
Pr. Label & & & 0.4156 & 0.031 & 1.1767 & 0.0309 & 1.1827 & 0.0309 \\
PUAM & & & & & 0.5171 & 0.0346 & 0.5229 & 0.0346 \\
Summer & & & & & & & -0.0918 & 0.0238 \\
\hline
\end{tabular}




\section{C.6 Figures and tables of Chapter 11}

Table C.11: Parameter Estimates

\begin{tabular}{ccccc}
\hline$\alpha$ & $\begin{array}{c}-9.9776^{*} \\
(4.6225)\end{array}$ & & $\begin{array}{c}\text { Number of } \\
\text { Markets }\end{array}$ & 800 \\
\hline & Heinz & Hunts & Del Monte & Private Label \\
\cline { 2 - 5 }$\beta_{\mathrm{j}}{ }^{\mathrm{N}}$ & $3.5573^{*}$ & 2.1993 & 1.0243 & $-1.1349^{\mathrm{a}}$ \\
& $(0.0598)$ & $(2.1107)$ & $(0.7160)$ & $(0.6437)$ \\
$\beta_{\mathrm{j}}{ }^{0}$ & $3.5426^{*}$ & $0.7449^{*}$ & -2.3083 & 3.6873 \\
"Quality & $(1.2731)$ & $(0.1710)$ & $(2.9900)$ & $(2.6900)$ \\
Boost" & 0.0147 & 1.4544 & 3.3326 & -4.8222 \\
& $(1.2745)$ & $(2.1176)$ & $(3.0745)$ & $(2.766)$ \\
\hline
\end{tabular}

* - Significant at $5 \%$ level

a - Significant at $10 \%$ level 
Table C.12: Demographic Characteristics

\begin{tabular}{ccc}
\cline { 2 - 3 } Price & Income $(\$$ thousands) & Children \\
\cline { 2 - 3 } Heinz & 0.8153 & 1.8333 \\
Hunts & 0.1133 & -0.1263 \\
Del Monte & 0.0018 & -0.9261 \\
Private Label & -0.0853 & 0.0703 \\
\hline
\end{tabular}


Table C.13: Own- and Cross-Price Elasticities

\begin{tabular}{|c|c|c|c|c|}
\hline & \multicolumn{4}{|c|}{ Price Change } \\
\hline & Heinz & Hunts & Del Monte & Private Label \\
\hline Heinz & -2.4273 & 0.3465 & 0.0039 & 0.5113 \\
\hline Hunts & 3.2919 & -4.8616 & 0.0180 & 0.5428 \\
\hline Del Monte & 2.8593 & 0.1401 & -4.8019 & 0.7929 \\
\hline Private Label & 2.0623 & 0.0516 & 0.0543 & -6.7479 \\
\hline \multicolumn{5}{|c|}{ Own-Price Elasticities as Displayed Brand } \\
\hline & Heinz & Hunts & Del Monte & Private Label \\
\hline & -1.9711 & -4.7221 & -4.7775 & -7.4352 \\
\hline
\end{tabular}


Table C.14: Wholesale Prices

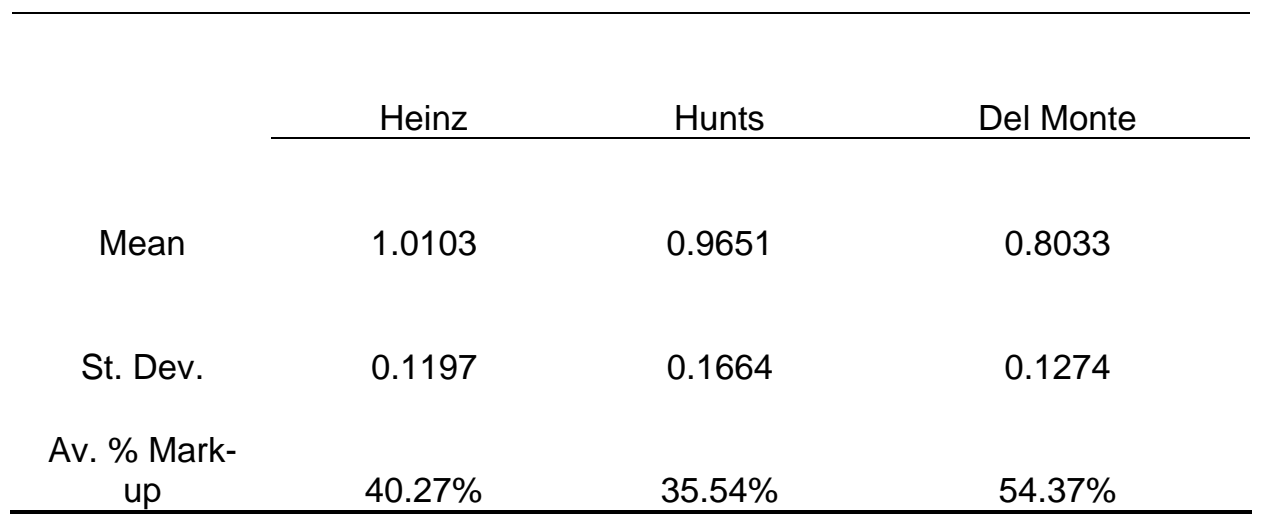


Table C.15: Conditional Wholesale Prices

\begin{tabular}{lccc}
\hline & Heinz & Hunts & Del Monte \\
\cline { 2 - 4 } $\mathrm{D}=$ Heinz & 1.3019 & 1.0340 & 0.7470 \\
$\mathrm{D}=$ Hunts & 0.9331 & 1.0259 & 0.7101 \\
$\mathrm{D}=$ Del Monte & 0.8798 & 0.8887 & 0.9237 \\
$\begin{array}{l}\mathrm{D}=\text { Private } \\
\text { Label }\end{array}$ & 1.0758 & 1.0185 & 0.8316 \\
\hline
\end{tabular}


Table C.16: Display Probabilities

\begin{tabular}{ccccc}
\hline & & & & \\
& Heinz & Hunts & Del Monte & Private Label \\
\cline { 2 - 3 } Mean & 0.2853 & 0.2853 & 0.3556 & 0.0738 \\
Max & 0.3334 & 0.3339 & 0.9997 & 0.2500 \\
Min & 0.0000 & 0.0000 & 0.2498 & 0.0000 \\
\hline
\end{tabular}


Table C.17: Slotting Allowance Payments (\% of Retail Profits)

\begin{tabular}{cccc}
\hline & Heinz & Hunts & Del Monte \\
\cline { 2 - 4 } Mean & $1.3079 \%$ & $0.6036 \%$ & $1.0918 \%$ \\
Max & $10.2161 \%$ & $3.7573 \%$ & $10.0052 \%$ \\
Min & $0.0000 \%$ & $0.0000 \%$ & $0.0000 \%$ \\
$\begin{array}{c}\text { \% of Time } \\
\text { Allowances Are } \\
\text { Offered }\end{array}$ & $18.3333 \%$ & $41.1667 \%$ & $17.0000 \%$ \\
\hline
\end{tabular}


Figure C.5: Demand Curves for Heinz Ketchup

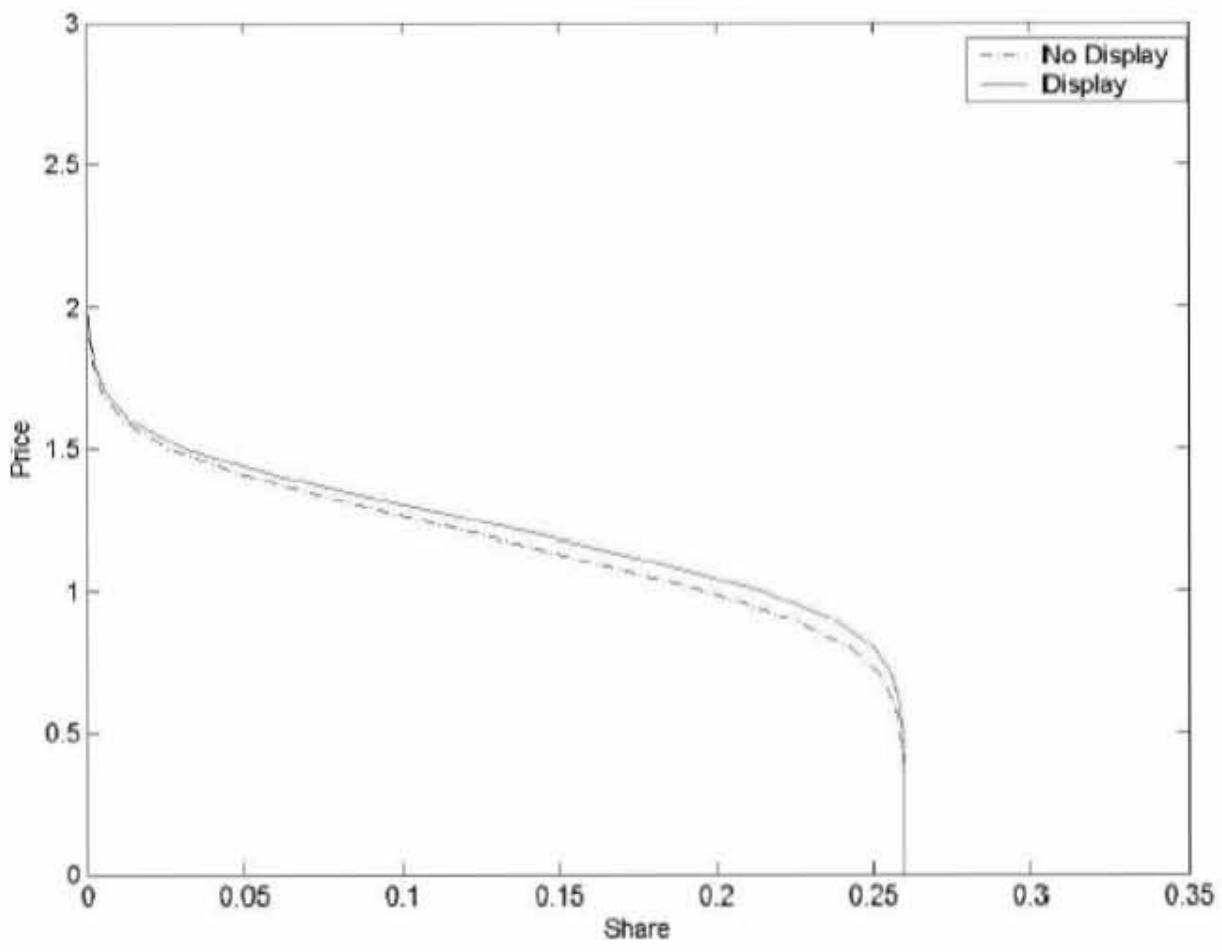


Figure C.6: Frequency Distribution of Price Coefficient

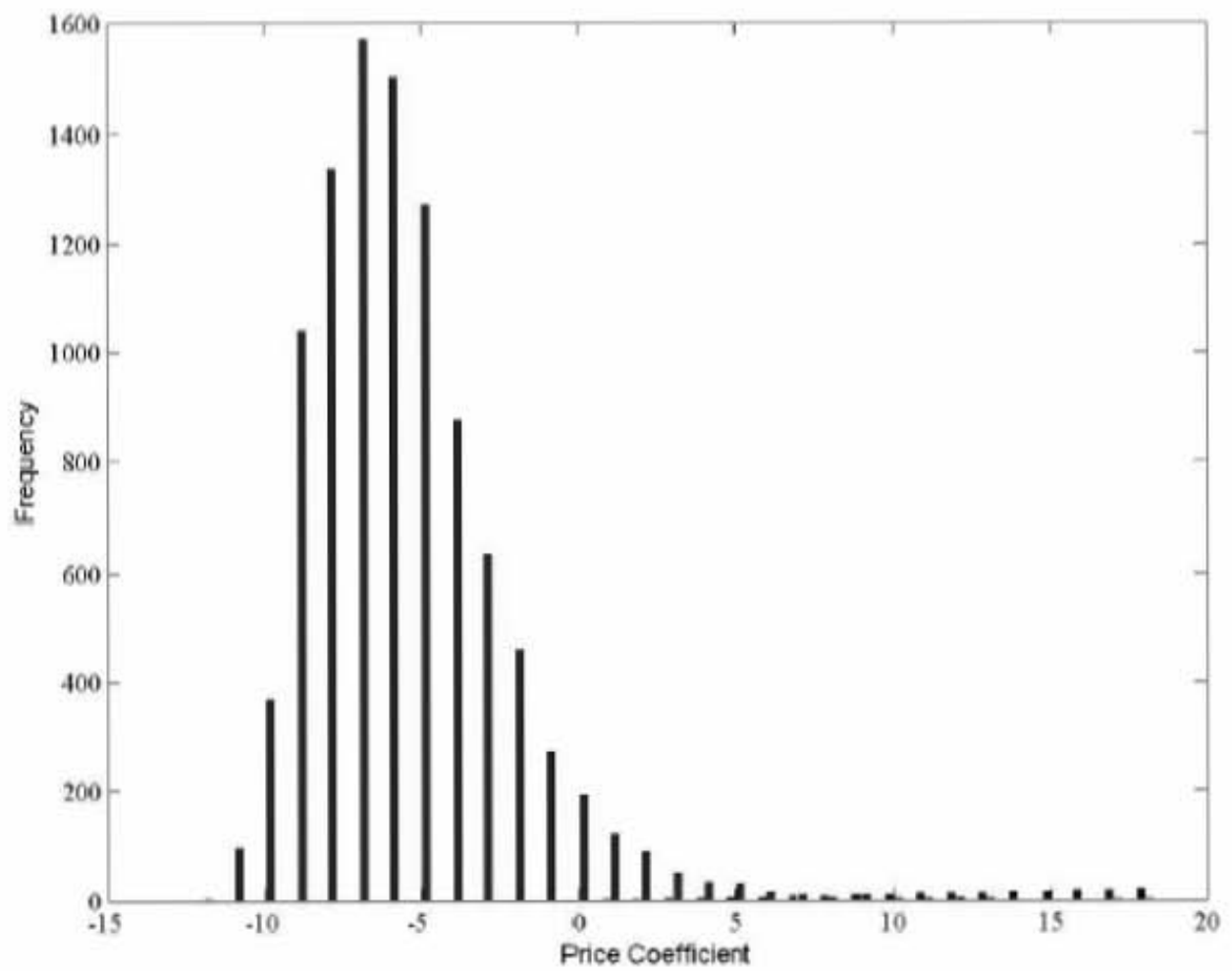


Figure C.7: Perception Map \#1

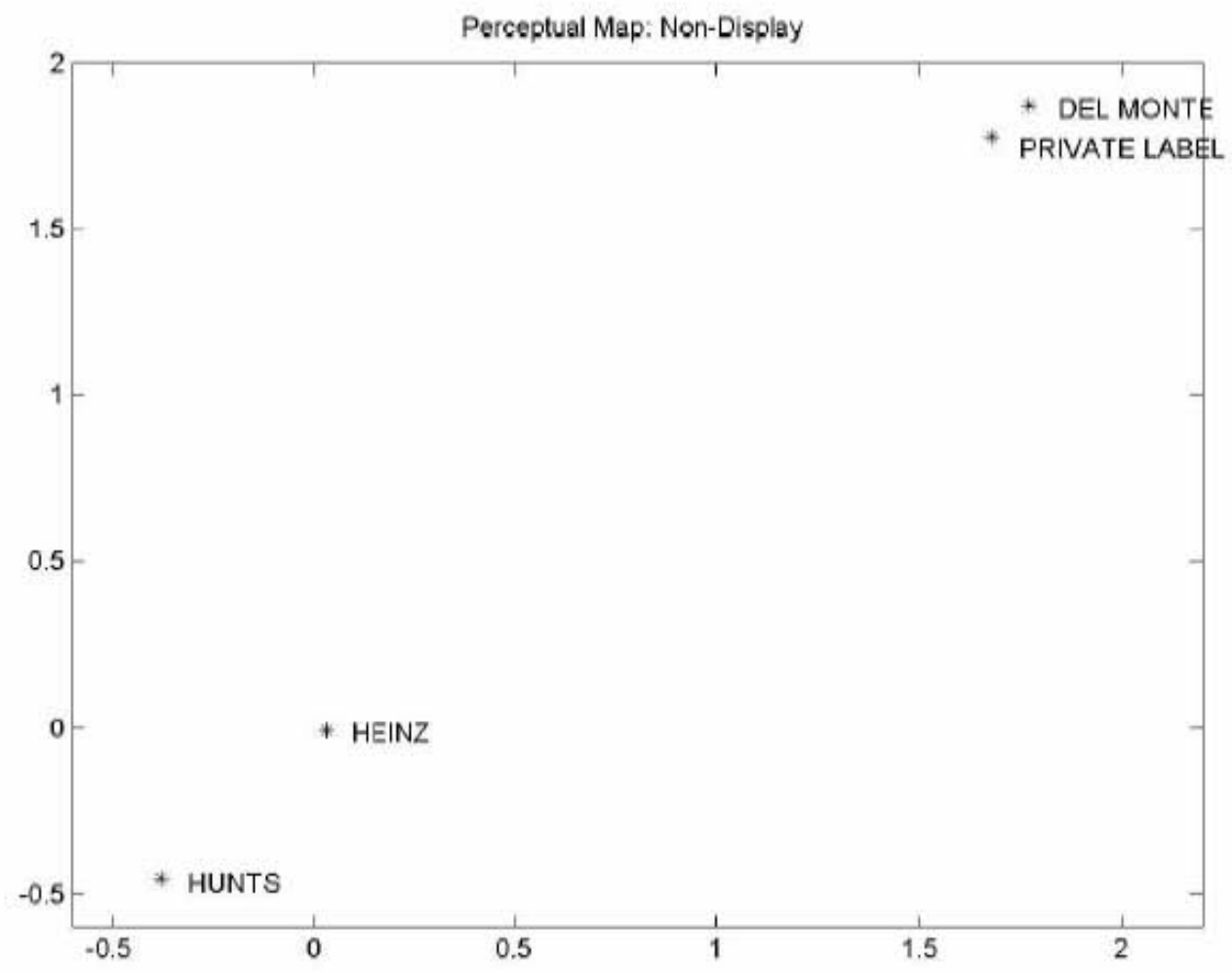


Figure C.8: Perception Map \#2

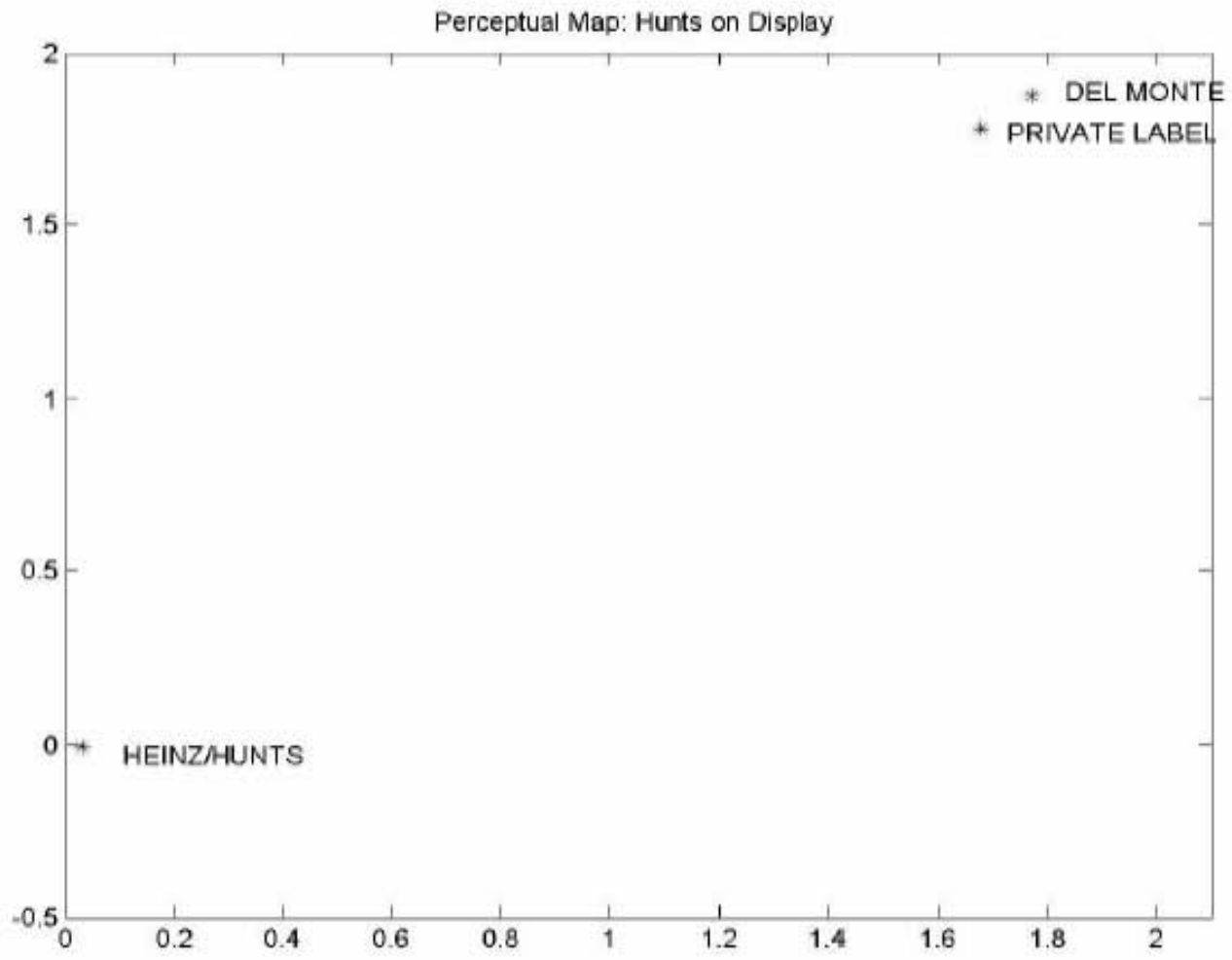


Figure C.9: Perception Map \#3

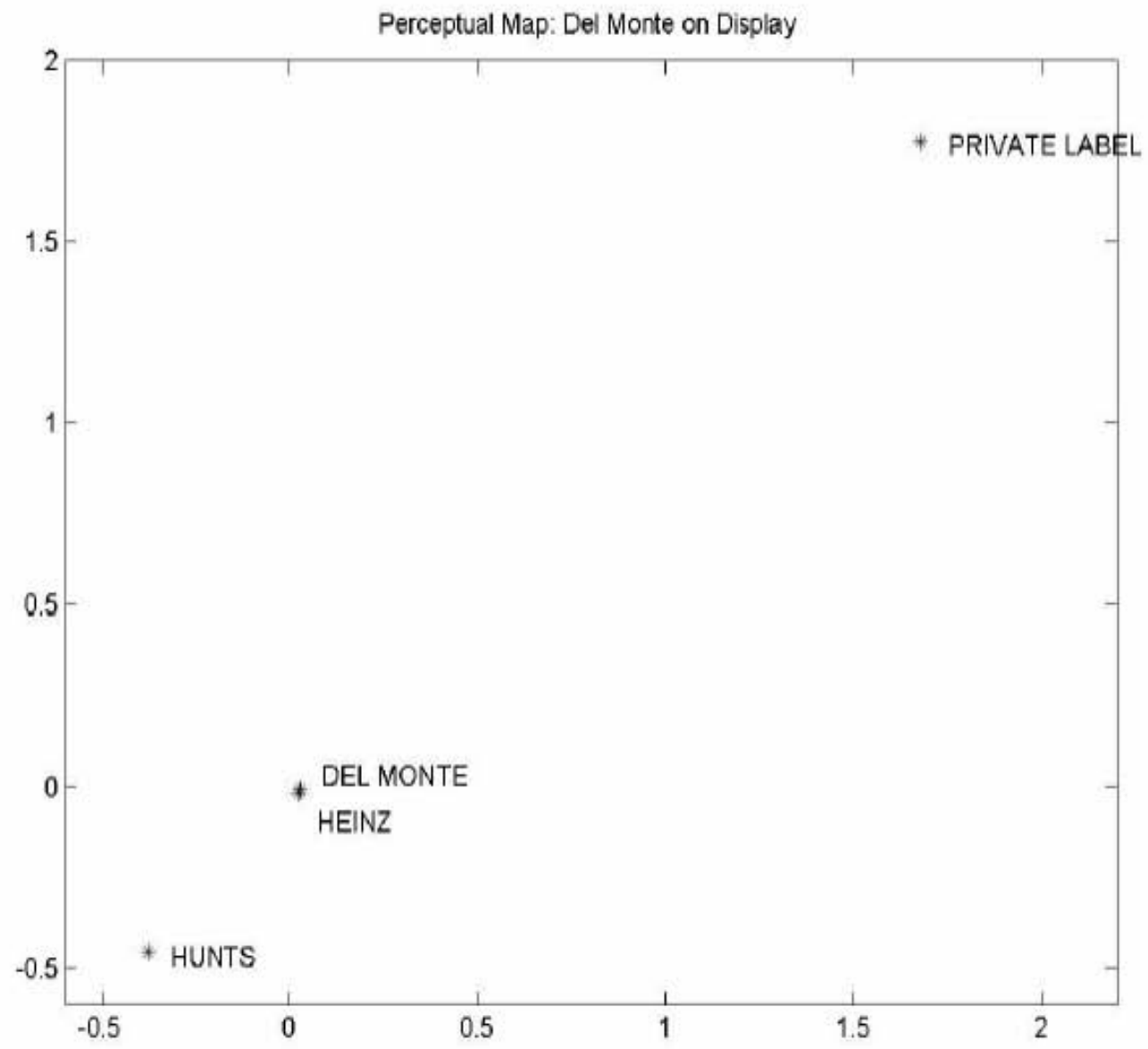




\section{C.7 Figures and Tables of Chapter 12}

Table C.18: Counterfactual Experiment \#1: Two Wholesale Prices

\begin{tabular}{ccccc}
\hline \multicolumn{5}{c}{ With Slotting Allowances } \\
\hline \multirow{2}{*}{ Average Expected Price per Unit } & 1.6916 & 1.4972 & 1.7605 & 1.0060 \\
& & & & \\
& Without Slotting Allowances \\
\hline & Heinz & Hunts & Del Monte & Pr. Label \\
$\begin{array}{c}\text { Average Expected Price per Unit } \\
\text { Price Change }\end{array}$ & 1.7034 & 1.6741 & 1.4077 & 0.8935 \\
& Higher & Higher & Lower & Lower \\
\hline $\begin{array}{c}\text { \% of Time Price is Higher with } \\
\text { Slotting }\end{array}$ & $37 \%$ & $23 \%$ & $60 \%$ & $56 \%$ \\
\hline
\end{tabular}


Table C.19: Expected Wholesale Prices

\begin{tabular}{cccc}
\hline \multicolumn{4}{c}{ With Slotting Allowances } \\
\hline & Heinz & Hunts & Del Monte \\
\cline { 2 - 4 } Average Expected Wholesale Per Unit & 1.0103 & 0.9651 & 0.8033 \\
& & & \\
Without Slotting Allowances & & \\
\hline & Heinz & Hunts & Del Monte \\
\cline { 2 - 4 } Average Expected Wholesale Per Unit & 1.0499 & 0.8802 & 0.5100 \\
Standard Deviation & 0.0168 & 0.0146 & 0.0165 \\
Price Change & Lower & Lower & Lower \\
\hline
\end{tabular}


Table C.20: Display Probabilities without Slotting Allowances

\begin{tabular}{ccccc}
\hline & Heinz & Hunts & Del Monte & Private Label \\
\cline { 2 - 5 } Mean & 0.3010 & 0.3159 & 0.2329 & 0.1502 \\
Max & 0.3181 & 0.3641 & 0.2872 & 0.1689 \\
Min & 0.2763 & 0.2735 & 0.2022 & 0.1334 \\
\hline
\end{tabular}


Table C.21: Counterfactual \#1 Welfare Analysis

\begin{tabular}{cccccc}
\hline & $\begin{array}{c}\text { Change in } \\
\text { Manu. } \\
\text { Profit }(\$)\end{array}$ & $\begin{array}{c}\text { Change in } \\
\text { Retail Profit } \\
(\$)\end{array}$ & $\begin{array}{c}\text { Change in } \\
\text { Total Profit } \\
(\$)\end{array}$ & $\begin{array}{c}\text { Change in } \\
\text { Consumer } \\
\text { Welfare } \\
(\$)\end{array}$ & $\begin{array}{c}\text { Total } \\
\text { Change in } \\
\text { Welfare }(\$)\end{array}$ \\
\cline { 2 - 6 } Individual & ---- & --- & --- & -0.0006 & --- \\
Metropolitan & $4,077.28$ & $-243,907.89$ & $-239,830.61$ & $-2,010.59$ & $-241,841.20$ \\
National & $163,091.20$ & $9,756,315.69$ & $-9,593,224.49$ & $80,423.71$ & $9,673,648.20$ \\
\hline
\end{tabular}

Note: Change is measured as (No Slotting Counterfactual - Slotting)

$\%$ of "Individuals"
worse off
because of
slotting


Table C.22: Counterfactual Experiment \#2: One Wholesale Price

\begin{tabular}{lcccc}
\cline { 2 - 4 } Average Expected Price Per Unit & Heinz & Hunts & $\begin{array}{c}\text { Del } \\
\text { Monte }\end{array}$ & $\begin{array}{c}\text { Private } \\
\text { Label }\end{array}$ \\
\cline { 2 - 5 } & 1.6916 & 1.4972 & 1.7605 & 1.0060
\end{tabular}

Without Slotting Allowances

\begin{tabular}{ccccc}
\hline & Heinz & Hunts & $\begin{array}{c}\text { Del } \\
\text { Monte }\end{array}$ & $\begin{array}{c}\text { Private } \\
\text { Label }\end{array}$ \\
\cline { 2 - 5 } Average Expected Price Per Unit & 1.4855 & 1.4939 & 1.5228 & 1.1693 \\
Price Change & Lower & Lower & Lower & Higher \\
\hline
\end{tabular}

With Slotting

$\begin{array}{ccc}\text { Heinz } & \text { Del } & \text { Private } \\ \text { Label }\end{array}$

$\%$ of Time Price is Higher

$69.50 \%$

$46 \%$

$30.50 \% \quad 30 \%$ 
Table C.23: Expected Wholesale Price

\begin{tabular}{cccc}
\hline \multicolumn{4}{c}{ With Slotting Allowances } \\
& Heinz & Hunts & Del Monte \\
\cline { 2 - 4 } Average Expected Wholesale Per Unit & 1.0103 & 0.9651 & 0.8033 \\
& & & \\
Without Slotting Allowances & & \\
\cline { 2 - 4 } & Heinz & Hunts & Del Monte \\
\cline { 2 - 4 } Average Expected Wholesale Per Unit & 0.7177 & 0.6250 & 0.5535 \\
Standard Deviation & 0.0304 & 0.0287 & 0.0449 \\
Price Change & Lower & Lower & Lower \\
\hline
\end{tabular}


Table C.24: Display Probabilities without Slotting Allowances (Counterfactual \#2)

\begin{tabular}{ccccc}
\hline & Heinz & Hunts & Del Monte & Private Label \\
\cline { 2 - 5 } Mean & 0.2657 & 0.2663 & 0.2767 & 0.1913 \\
Max & 0.3373 & 0.3122 & 0.3444 & 0.2341 \\
Min & 0.2400 & 0.1794 & 0.1956 & 0.1498 \\
\hline
\end{tabular}


Table C.25: Counterfactual \#2 Welfare Analysis

\begin{tabular}{cccccc}
\hline & $\begin{array}{c}\text { Change in } \\
\text { Manu. Profit } \\
(\$)\end{array}$ & $\begin{array}{c}\text { Change in } \\
\text { Retail Profit } \\
(\$)\end{array}$ & $\begin{array}{c}\text { Change in } \\
\text { Total Profit } \\
(\$)\end{array}$ & $\begin{array}{c}\text { Change in } \\
\text { Consumer } \\
\text { Welfare }(\$)\end{array}$ & $\begin{array}{c}\text { Total Change } \\
\text { in Welfare }(\$)\end{array}$ \\
\cline { 2 - 6 } Individual & ---- & ---- & --- & -0.0008 & --- \\
Metropolitan & $4,077.28$ & $-243,907.89$ & $-239,830.61$ & $-2,946.99$ & $1,976,053.44$ \\
National & $163,091.20$ & $9,756,315.69$ & $-9,593,224.49$ & $-117,879.75$ & $79,042,137.55$ \\
\hline $\begin{array}{c}\% \text { of } \\
\text { "Individuals" } \\
\text { worse off } \\
\text { because of } \\
\text { slotting }\end{array}$ & $32.54 \%$ & & & & \\
\end{tabular}


Figure C.10: Expected Profit (function of wholesale prices)

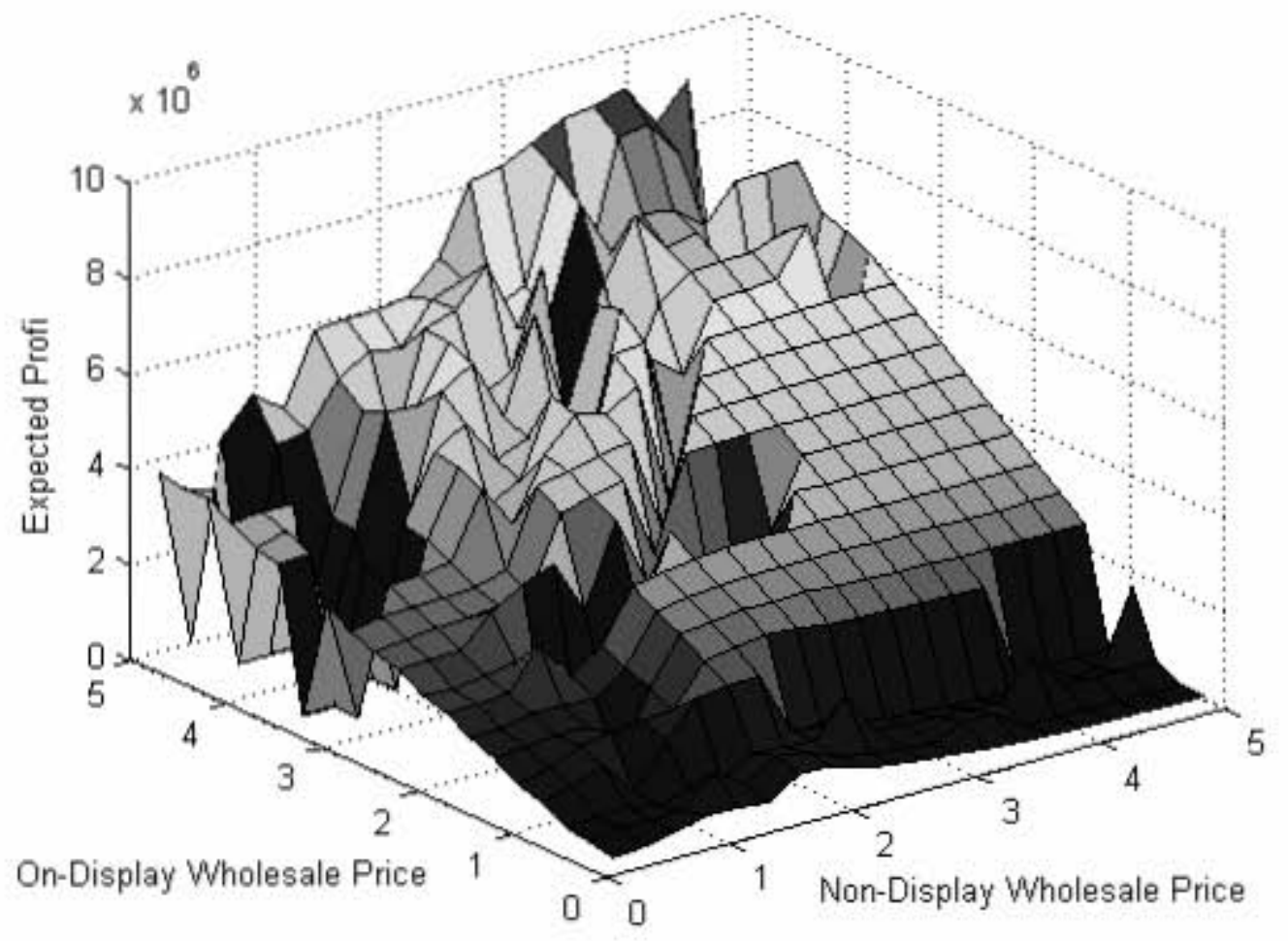




\section{Bibliography}

[1] Amemiya, T. (1981): "Qualitative Response Models: A Survey," Journal of Economic Literature, 19, 4, 483-536.

[2] Anderson, Evan E. (1979): “An Analysis of Retail Display Space: Theory and Methods," Journal of Business, 52, 103-118.

[3] Anderson, Simon P., Andre de Palma, and J.F. Thisse (1992) : Discrete Choice Theory of Product Differentiation, MIT Press, Cambridge, MA.

[4] Anderson, Simon P. and Andre de Palma (2001): "Product Diversity in Asymmetric Oligopoly: Is the Quality of Consumer Goods too Low?" The Journal of Industrial Economics, 49, 113-135.

[5] Areni, Charles S., Dale F. Duhan, and Pamela Kiecker (1999): "Point-of-Purchase Displays, Product Organization, and Brand Purchase Likelihoods," Journal of the Academy of Marketing Science, 27, 428-441.

[6] Associated Press (2003): "Nike Outbids Reebok for LeBron James," The New York Times, May 22, 2003, http://www.nytimes.com/aponline/business/AP-NikeEndorsements.html. 
[7] Azzam, Azzeddine M. (1991): "Slotting Allowances and Price-Cost Margins: A Note," Agribusiness, 17, 416-422.

[8] Baker, M. Sharon (1996): "Software markers say Egghead charging new fees," Puget Sound Business Journal, 16, 52, 5-6.

[9] Berry, Steven T. (1994): "Estimating Discrete-Choice Models of Product Differentiation," RAND Journal of Economics, 25, 242-262.

[10] _____ (1992): "Estimation of a Model of Entry in the Airline Industry," Econometrica, 60, 889-917.

[11] _____, James Levinsohn, and Ariel Pakes (1995): "Automobile Prices in Market Equilibrium," Econometrica, 63, 841-890.

[12] Besanko, David, Jean-Pierre Dubé, and Sachin Gupta (2002): "Competitive Price Discrimination Strategies in a Vertical Channel Using Aggregate Retail Data," forthcoming Management Science.

[13] _____ (2003): "Own-brand and Cross-brand Retail Pass-through," forthcoming Marketing Science.

[14] Besanko, David, Sachin Gupta, and Dipak Jain (1998): "Logit Demand Estimation Under Competitive Pricing Behavior: An Equilibrium Framework," Management Science, 44, 1533-1546.

[15] Bloom, Paul, Gregory Gundlach, and Joseph Cannon (2000): "Slotting Allowances 
and Fees: Schools of Thought and the Views of Practicing Managers," Journal of Marketing, 64, 92-108.

[16] _____, and Gregory Gundlach (1998): "Slotting Allowances and the Retail Sale of Alcohol Beverages," Journal of Public Policy E Manufacturing, 17, 173-184.

[17] Bommer, William and Rockney G. Walters (1996): "Measuring the Impact of Product and Promotion-Related Factors on Product Category Price Elasticities," Journal of Business Research, 36, 203-216.

[18] Borin, Norm, Paul W. Farris, and James R. Freeland (1994): "A Model for Determining Retail Product Category Assortment and Shelf Space Allocation," Decision Sciences, $25,359-383$.

[19] Bryan-Low, Cassell (2003): "Problems With Vendor Rebates May Be Broader Than Thought," Wall Street Journal, May 13, 2003.

[20] Carter, Mary Ellen and Luann J. Lynch (2001): “An examination of executive stock option repricing," Journal of Financial Economics, 61, 207-225.

[21] Chintagunta, Pradeep K., Jean-Pierre Dube, and Vishal Singh (2003): "Balancing Profitability and Customer Welfare in a Supermarket Chain," Quantitative Marketing and Economics, 1, 111-147.

[22] Chu, Wujin (1993): "Demand Signalling and Screening in Channels of Distribution," Marketing Science, 11, 327-341. 
[23] Cohen, Andrew (2001): "Evidence of Price Discrimination Based on Package Size in the Paper Towel Industry," working paper.

[24] Comanor, William S. and Patrick Rey (2000): "Vertical Restraints and the Market Power of Large Distributors," Review of Industrial Organization, 17, 135-153.

[25] Corstjens, Marcel and Peter Doyle (1983): "A Dynamic Model for Strategically Allocating Retail Space," Journal of the Operational Research Society, 34, 943-951.

[26] Curhan, Ronald C. (1972): "The Relationship Between Shelf Space and Unit Sales in Supermarkets," Journal of Marketing Research, 9, 406-412.

[27] Deloitte \& Touche (1990): Managing the Process of Introducing and Deleting Products in the Grocery and Drug Industry, Grocery Manufacturers of America.

[28] Desiraju, Ramarao (2001): "New product introductions, slotting allowances, and retailer discretion," Journal of Retailing, 77, 335-358.

[29] Desmet, Pierre and Valérie Renaudin (1998): "Estimation of Product Category Sales Responsiveness to Allocated Shelf Space," International Journal of Research in Marketing, 15, 443-457.

[30] DeVuyst, Cheryl Sinn (2000): Slotting Allowances, Failure Fees and Asymmetric Information in the Grocery Supply Chain, Doctoral Dissertation from the University of Illinois at Urbana-Champaign.

[31] Drèze, Xavier, Stephen J. Hoch, and Mary E. Purk (1994): "Shelf Management and Space Elasticity," Journal of Retailing, 70, 301-326. 
[32] Elrod, Terry (1988): "Choice Map: Inferring a Product Market Map from Panel Data," Marketing Science, 7, 21-40.

[33] _____, and Michael P. Keane (1995): "A Factor-Analytic Probit Model for Representing the Market Structure in Panel Data," Journal of Marketing Research, 32, $1-16$.

[34] Federal Trade Commission (2001a): Report on the Federal Trade Commission Workshop on Slotting Allowances and Other Marketing Practices in the Grocery Industry.

[35] Feighery, Ellen, Kurt Ribisl, Dale Achabal, and Tyzoon Tyebjee (1999): "Retail Trade Incentives: How Tobacco Industry Practices Compare With Those of Other Industries," American Journal of Public Health, 89, 1564-1566.

[36] Frank, Ronald E. and William F. Massy (1970): "Shelf Position and Space Effects on Sales," Journal of Marketing Research, 7, 59-66.

[37] Ghitelman, David (2002): "Industry Plays New Numbers Game; Accounting Rule Change Forces Manufacturers to Review Alllowances," Supermarket News, June 3, $2002,1$.

[38] Goeree, Michelle S. (2001): "Informative Advertising and the U.S. Personal Computer Market: A Structural Empirical Examination," working paper.

[39] Goldberg, Pinelopi K. (1995): "Product Differentiation and Oligopoly in International Markets: The Case of the U.S. Automobile Industry," Econometrica, 63, 891-951. 
[40] Grossman, Gene M. and Carl Shapiro (1984): "Informative Advertising with Differentiated Products," Review of Economic Studies, 51, 63-81.

[41] Lariviere, Martin and V. Padmanabhan (1997): "Slotting Allowances and New Product Introductions," Marketing Science, 16, 112-128.

[42] MacAvoy, Christopher J. (1997): "Antitrust Treatment of Slotting Allowances," paper presented at ABA Section of Antitrust Law, 45th Annual Spring Meeting, Washington, DC.

[43] Maddala, G. S. (1999): Limited-Dependent and Qualitative Variables in Econometrics, Econometric Society Monographs No. 3, Cambridge University Press.

[44] Manuszak, Mark D. (2001): "The Impact of Upstream Mergers on Retail Gasoline Markets," working paper.

[45] McKay, Betsy (2003): "Coke Hires Firms to Probe Allegations of Marketing and Accounting Fraud," Wall Street Journal, May 21, 2003.

[46] McManus, Brian (2001): "Nonlinear Pricing in an Oligopoly Market: the Case of Specialty Coffee," working paper.

[47] Nevo, Aviv (1997): "Demand for Ready-to-Eat Cereal and Its Implications for Price Competition, Merger Analysis, and Valuation of New Goods," Ph.D. Dissertation, Harvard University.

[48] _____ (2000): “A Practitioner's Guide to Estimation of Random-Coefficients Logit Models of Demand," Journal of Economics $\&$ Management Strategy, 9, 513-548. 
[49] ____- (2001): "Measuring Market Power in the Ready-to-Eat Cereal Industry," Econometrica, 69, 307-342.

[50] Petrin, Amil (2002): "Quantifying the Benefits of New Products: The Case of the Minivan," Journal of Political Economy, 110, 705-729.

[51] Prince, Marcelo and Donna Fuscaldo (2003): "Use of Vendor Rebates Is Common in Tech Sector," Wall Street Journal, February 23, 2003.

[52] Rey, Patrick and Jean Tirole (1986): "The Logic of Vertical Restraints," The American Economic Review, 76, 921-939.

[53] Shaffer, Greg (1991): "Capturing Strategic Rent: Full-Line Forcing, Brand Discounts, Aggregate Rebates, and Maximum Resale Price Maintenance," Journal of Industrial Economics, 39, 557-575.

[54] _____ (1994): "Rendering Alternative Offerings Less Profitable with Resale Price Maintenance," Journal of Economics \&3 Management Strategy, 3, 639-662.

[55] _____ (1991): "Slotting Allowances and Resale Price Maintenance: A Comparison of Facilitating Practices," RAND Journal of Economics, 22, 120-135.

[56] Slade, Margaret E. (1995): "Product Market Rivalry with Multiple Strategic Weapons: an analysis of price and advertising competition," Journal of Economics and Management Strategy, 4, 445-476.

[57] Sudhir, K. (2001): "Structural Analysis of Manufacturer Pricing in the Presence of a Strategic Retailer," Marketing Science, 20, 244-264. 
[58] Sullivan, Mary W. (1997): "Slotting Allowances and the Market for New Products," Journal of Law E3 Economics, 40, 461-493.

[59] Tom, Willard K. (1999): "Slotting Allowances and the Antitrust Laws," Testimony before the Committee on the Judiciary, U.S. House of Representatives, October 20, 1999.

[60] Turcsik, Richard (2000): "It's a smaller world," Progressive Grocer, 79, 22-28.

[61] Wellman, David (2002): "Trade Promos: A Big Chill?", Frozen Food Age, 50, 12, 1-2.

[62] Williams, Monci Jo (1983): "The No-Win Game of Price Promotion," Fortune, July 11, 92-102. 